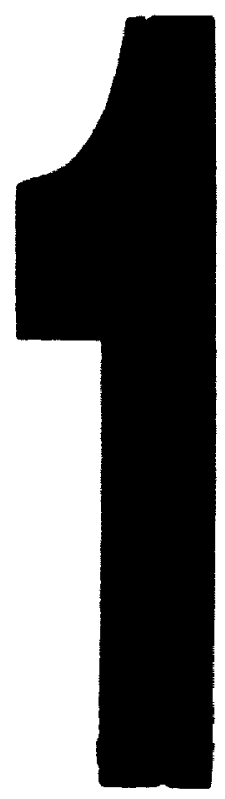

PM-1 3': "x4" PHOTOGRAPHIC MICROCOPY TARGET NES 1010a ANSI/ISO *2 EQUIVALENT

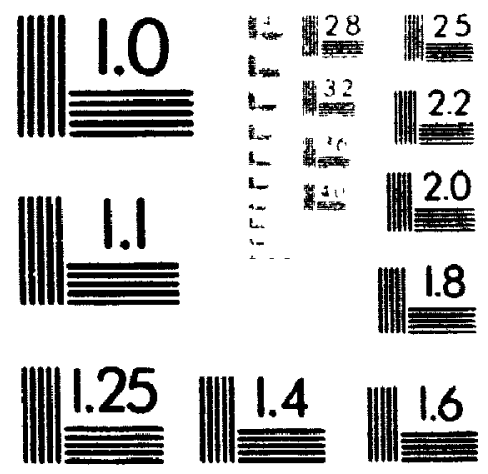

PRECISION"M RESOLUTION TARGETS 
A Study of the Velocity and Turbulence Effects on

Volatile Organic Compound Emissions

from Carpet-Adhesive Assemblies

hy

J. Michele Low: P.Fing.

B.Eng. (Mechanical), Technical Cniversty of Noral Scottal

This thesis is submitted to the

Faculty of Graduate Studies and Research

in partial fulfilment of the requirements for the degrec of

Master of Engineering

Department of Mechanical and Acrovpace Engine'trme

\title{
Ottawa-Carleton Institute
}

for Mechanical and Aerospace Engineering

\author{
Carleton Iniversity \\ Ottawa, Ontario \\ Octoher 1996 \\ (c) Copyrighı
}

1996, J. Michele Low 
The author has granted an irrevocable non-exclusive licence allowing the National Library of Canada to reproduce, loan, distribute or sell copies of his/her thesis by any means and in any form or format, making this thesis available to interested persons.
L'auteur a accordé une licence irrévocable et non exclusive permettant à la Bibliothèque nationale du Canada de reproduire, prêter, distribuer ou vendre des copies de sa thèse de quelque manière et sous quelque forme que ce soit pour mettre des exemplaires de cette thèse à la disposition des personnes intéressées.

L'auteur conserve la propriété du droit d'auteur qui protège sa thèse. Ni la thèse ni des extraits substantiels de celle-ci ne doivent être imprimés ou autrement reproduits sans son autorisation. 
Nentia

Diswatiotion Abetrocts mmmational is orranged by brood, general subject congories. Pleose select the one subject which most noorty deccibes the combent of your diswertotion. Enter the corresponding four-digit code in the spoces provided

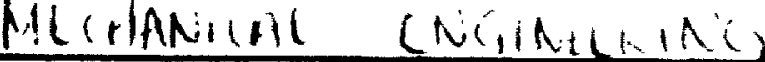

savect riam

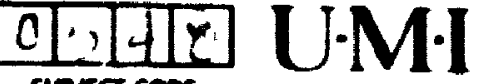

suxer coos

\section{Subinat Congories}

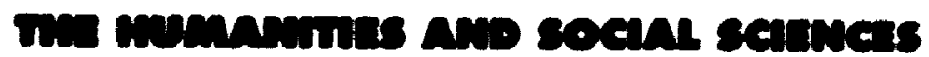

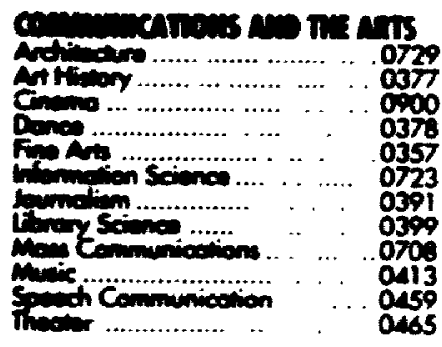

\section{Eucritam}

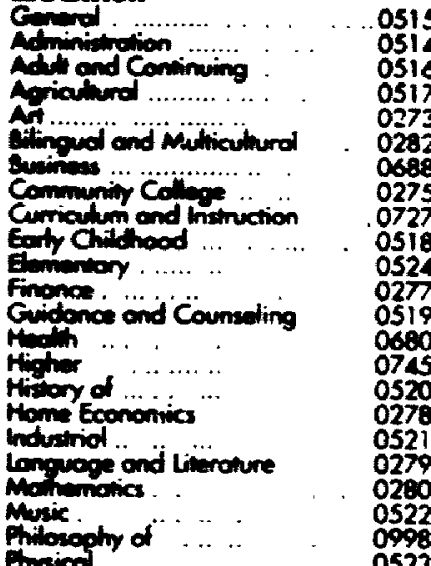

0515

0516

0517

0273

688

0275

0518

0524

0519

0600

0520

0278

0279

0280

0998

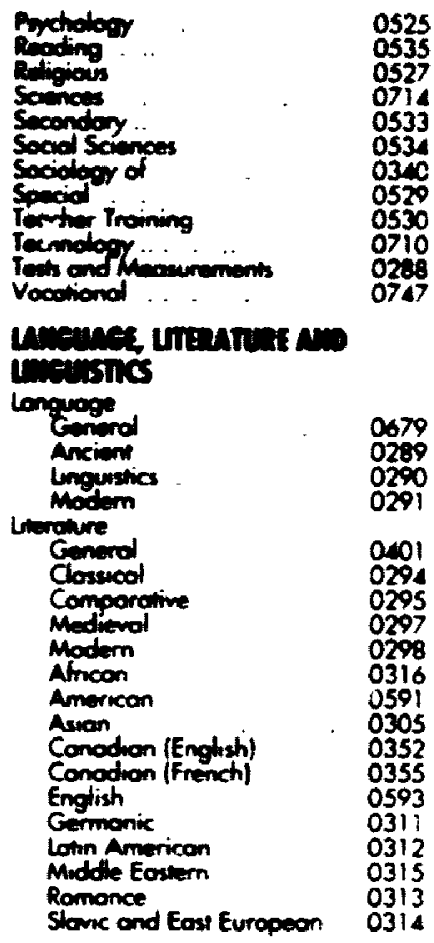

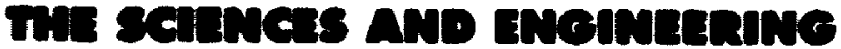

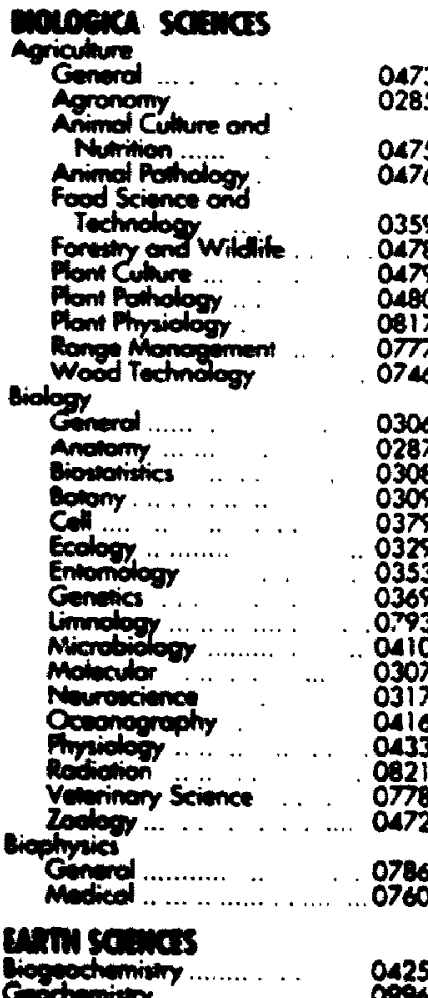

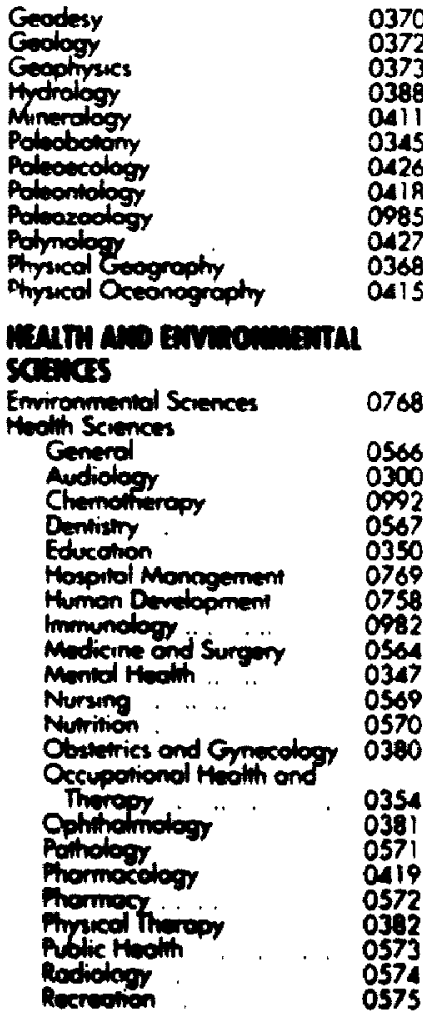

mmosonr naveron am Intater

Philowophy

Ratrom

Gevol

Eiblucol Sindies

Clorgy

Piloriphy of

Theology

\section{senul scancs}

Amencon Siudien

Antropology

Antroiology

Culured

Business Admunustrotion

Generd

Accounting

Bontung

Monogement

Morketing

Conodion Shidves

Economics

Agricuturol

Agrculurol

Commerce

Finonce

cotor

Theory

Folletere

Geogrophy

Geromology

Histony

General
0422

0318

032

0319

0322

Oas?

0323

0324

0326

0310

0272

0770

045.

0338
0385

0501

0503

0505

0508
0509

0510

0511

0358

0366

0351

0578

$\begin{array}{ll}\text { Ancient } & 0570 \\ \text { Madimol } & 050 \\ \text { Modern } & 058 \\ \text { Ahricon } & 032\end{array}$

Avetrabo and Oreanio

0332

Canadion 033

Europeon 0335

Lomn Americon $\quad 0336$

Muddil Eovern $\quad 0333$

Hestory of serence

Pow

Science

Gererd

internotionol tow and

Relotions

Putic Admonitrotion

0585

0398

Rocriol Wort

Sociology

Germol

Fthrer and Rociol Sudves $\quad 0631$

Indimounol and famity

Sindies

Industrial and labor

Retotions.

Public and Socred Wethere

criol Structure and

Development

Theory and Methods

Ironsportotion

Urton and Regronal Planning

Women s Smudies

0628

0629

0630

0700

0344

0009

0.5?

\begin{tabular}{|c|}
\hline 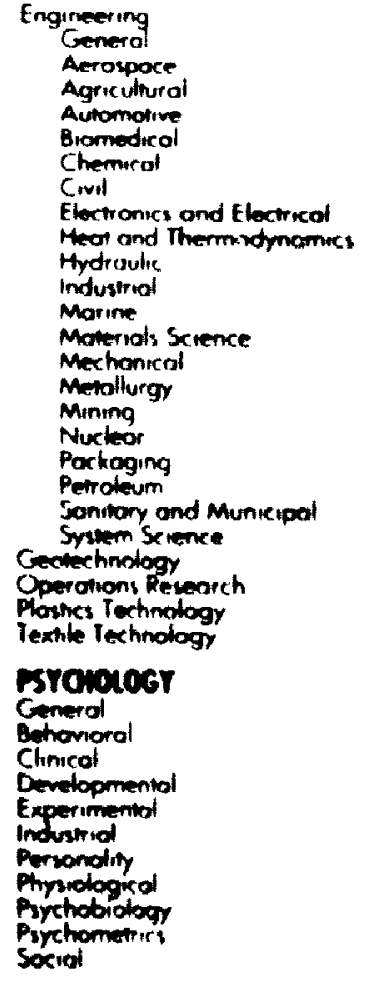 \\
\hline
\end{tabular}

os 37

0538

0579
0540

0541

$05 n$

0343

0348

0545

$05 a s$

0547

0548

074

oss

0552

0549

055

$07 \%$

0428

0796

0094

0621

O3A4

0622

0620

0623

0625

0984

0349

0632
0451 
The undersigned hereby recommend to the Faculty of Graduate Studies and Research acceptance of the thesis.

\section{A Study of the Velocity and Turbulence Effects on \\ Volatile Organic Compound Emissions \\ from Carpet-Adhesive Assemblies}

submitted by

\section{J. Michele Low, P.Eng.}

in partial fulfilment of the requirements for

the degree of Master of Engineering
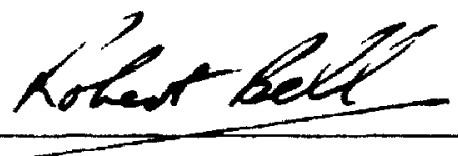

Dr. R. Bell. Chair, Department of Mechanical and Aerospace Engineering

Carleton University

October 1996 


\section{List of Tables}

Paige'

Tible 2.1: Tint Schedulc

Table 3.1: Matterial Sately Dattat Sheet Summary

Table 4.1: Data Sheer is

Table 5.1: Mam Headupace compound and Rekenton Times is

Table 5.2: Compound Information

Tahle 5.3: Classification of Some ldentitied Compound, 3)

Table 5.4: Aclual Test Parameters

Table 5.5: Temperatture and RH Data - Tein 4 - s

Table 5.6: Initial Concentrations - Catpet Syringe Sampler

Table 5.7: Total TVOC Concentraton for Specified Time Pernod

Table E.1: Velocity Protile Ditla - Mid-Height Chamber Locillon

Table E.2: TSt/Roomair Calibrattion Ditti

Table E.3: Cyclohexame Calibration Data 


\section{Acknowledgements}

I would like to thank Dr. E.G. Plett. Carleton University. along with Dr. John Shaw and Dr. Jianshun Zhang. both at National Research Council's Institute for Research in Construction, for their invaluable assistance provided throughout my research and with this thesis. The use of National Research Council's facilities is greatly appreciated.

The following people also provided assistance with analysis techniques. equipment operation and test set-ups: Bob Magee. Marcel Brouzes. Juergen Weichert. Xiandong Li, Boh MacDonald. Ewa Lusztyk, Malgosia Kanabus-Kaminska, Jocelyn Henrie. and Frank Lohmann. Thank you all for your help. 


\section{Table of Contents}

Pagco

Abstract

Acknowledgements

Table of Contents

List of Tables

List of Figures $\quad x$

Nomenclature $\quad$ xii

I Introduction |

1.1 Ohjectives

1.2 Significance

1.3 Mass Transfer Principles 3

2 Experimental Design 5

2.1 Environmental Conditions 5

2.2 Test Plan

3 Equiprnent and Test Facilities 8

3.1 Test Materials

3.2 Small Test Chamber and Test Room 9

3.2.1 Inner Chamber

3.2.2 Outer Chamber II)

3.2.3 Test Room 11

$\begin{array}{ll}3.3 \text { System Operation } & 11\end{array}$

$\begin{array}{ll}3.4 \text { Measurement Equipment } & 12\end{array}$ 
3.4.1 Environnental controller

3.4.2 Hydrocarbon Analy/er

3.4. 3 Dala Acyuisition

3.4.4 Gas Chromatography Analysis

4 Test Procedures

4.1 Set-lp Procedures

4.2 Sample Preparation

4.2.1 Adhesive Preparation

4.2.2 Carpet Preparation

4.3 Sampling Procedures

4.3.1 Headupace Samples

4.3.1.1 Carpet Headspace Samples

4.3.1.2 Adhesive Head palce Samples

4.2.1.3 Concrele Headspace Sample

S Results and Discussion

5.1 Headspace ldentification

5.1.1 Adhesive Results

5.1.2 Carpet Results

22

\$.1.3 Concrete Results 
5.3.1 TVOC Concentratuon is Time

5.4 Sperific VOC Results

5.4.1 Concentration w Time

5.4.2 Emission Rates is Time

6 Conclusions and Recommendations

References

Bibliography

Tables

Figures

Appendix A - Equipment List

Appendix B - Concrete Forming Procedures

Appendix C - Detailed Test Set-l ip Procedures

Appendix D - Sampiing Procedures

D.I Syringe Sampling Procedure

D.2 Calculation of Sample Volume

D.3 Regular Sampling Procedures

D.4 Sampling Error 
1:.3 TSI Anemometer Calibration

E.4 Flow (alibration

i: 5 Meloy HCA Calibration

E.G G C Calibration

93

Appendix F' - GC Methos for Analyzing Samples

F.1 Semi-automated Procedure for the GC:

96

F.2 GC Flow Calibration 


\section{List of Tables}

Page

Table 2.1: Test Schedule 17

Table 3.1: Material Sately Data Sheet Summary

Table 4.1: Data Sheet

Table 5.1: Main Headspace Compounds and Retention Times

Table 5.2: Compound Information 39)

Table 5.3: Classification of Sone ldentitied Compounds

Table 5.4: Actual Test Parameters

Table 5.5: Temperature and RH Dalta - Tests 4-8

Table 5.6: Initial Concentrations - Carpet Syringe Samples 4

Table 5.7: Total TVOC Concentration for Specified Time Period 41

Table E.I: Velocity Profile Data - Mid-Height Chamber Location

Table E.2: TSI/Roomair Calibration Data 42

Table E.3: Cyclohexane Calibration Data 


\section{List of Figures}

Page

Figure 3.1 a: Photograph of Thermal Desoprtion Tube

Figure 3.1 b: Schematic of a Thermal DesorptionTube (multi-layer)

Figure 3.2 a: ('hamber Schematic

Figure 3.2 b: System Schematic

Figure 3.3 a: Photograph of Chamber in Test Room

Figure 3.3 b: Pholograph of Assembled Inner Chamber in Outer Chamber

Figure 3.4 a: Inner Chamber Dimensions

Figure 3.4 h: Photograph of Sample in Inner Chamber

Figure 3.5: Photograph of Screen Attachments/End Plates

Figure 3.6: Flow Characterization Points

Figure 3.7: Photograph of Dehumidification System (Drierite Desiccant)

Figure 3.8: Photograph of Sampling Line Connection

Figure 3.9: GC Method - Temperature Ramp vs Time

Figure 3.10: GC Results Output File - Test 4. 2.38hrs

Figure 5.1 a: Headspace Results - Adhesive I

Figure 5.1 b: Headpsace Results - Adhesive 2

Figure 5.1 : : Headpsace Results - Adhesive 3

Figure 5.1 d: Headspace Results - Carpet C

Figure 5.1 e: Headspace Results - Concrete

Figure 5.2: TVOC Emission Rates - Test 1.2.\& 3 
Figure 5.3 h: Velocity and Turbulence - Test 5

Figure $5.3 \mathrm{c}$ : Velocily and Turbulence - Test 6

Figure 5.3 d: Velocity and Turbulence - Fen orl

50

Figure 5,3 : Velocity and Turbulence - Test or:

5n

Figure 5.3 t: Velocity and Turbulence - Tos 8

50

Figure 5.4: TVOC Concentration is Time

Figure 5.5: TVOC Emission Rate vs Time

Figure 5.6: Nonane Concentration is Time

Figure 5.7: Decane Concentration is Time

Figure 5.8: 4PC Concentration is Time

Figure 5.9: Concentration vs Time - Test 6

Acetone, Nonane, Decane, and 4 PC

Figure 5.10: Time vs, Boiling Point for Maximum and

Constant Concentrations

Figure 5.11: Nonane Emission Rate vs Time

Figure 5.12: Decane Emission Rate vs Time

Figure 5.13: TVOC Concentrationvs Time - Test 6, 6r1, \& 6r2.

Figure 5.14: Acetone Concentration vs. Time - Test 6, 6r1, 6r2 67

Figure 5.15: Nonane Concentration vs. Time - Test 6. Gr1, or2. ok

Figure 5.16: Decane Concentration vs. Time - Test 6. 6r1.6r2. (1)

Figure D.1: Syringe Sampling Set-up 70)

Figure E.1: TSI Calibration Curve-Fit 70)

Figure E.2: GC Calibration Curve - Cyclohexanc 71 


\section{Nomenclature}

A emission surface area, $\mathrm{m}^{2}$

ACH air change per hour

C concentration inside the chamber, $\mathrm{mg} / \mathrm{m}^{3}$

FID flame ionization detector

GC gas chromotograph

GC/MS gas chromotograph with a mass spectrometer analyzer

HCA hydrocarbon analyzer

IRC Institute for Research in Construction

LPM liters per minute

NRC National Research Council Canada

Q air flow rate into and out of chamber, $\mathrm{m}^{3} / \mathrm{hr}$

R emission rate per unit emission area, $\mathrm{mg} / \mathrm{m}^{2} \mathrm{hr}$

RH relative humidity, $\%$

RKE relative kinetic energy, $\left(\mathrm{m}^{2} / \mathrm{s}^{2}\right) /(\mathrm{m} / \mathrm{s})^{2}$

RT retention time

RT-GC retention time from GC analysis

RT-MS retention time from GCMS analysis

SBR styrene-butadiene rubber

THC total hydrocarbons

TVOC total volatile organic compound

V volume of chamber. $\mathrm{m}^{3}$ 
viii

VOC volatile organic compound

k kinetic energy of turbulence, $\left(\mathrm{m}^{2} / \mathrm{s}^{2}\right)$

t time. hours

$\bar{u} \quad$ average air velocity, $m / s$

$u_{i} \quad$ air velocity data used to calculate $\bar{u} . m / s$

APC 4 phenylcyclohexene 


\section{Chapter 1}

\section{Introduction}

\subsection{Objectives}

The emissions of volatile organic compounds (VOCs) from carpets and carpet adhesives in office buildings are of concern because of their potential influence on the wellness of building occupants. Many studies have been conducted to investigate the emissions of VOCs from carpets, adhesives and building materials. The local air temperature, relative humidity $(\mathbf{R H})$ and air change rate were usually kept constant, while the concentrations of VOCs from different carpets, adhesives and building materials were measured [1-8]. A study published by Sollinger and Levsen [9] in 1994, found that temperature and RH changes had little effect on the rate of emissions of VOCs from carpetadhesive assemblies, with the possible exception of aniline. Some studies $[4,6]$ measured the air velocity close to the carpet surface, however, full-scale velocity and turbulence studies did not seem to exist.

As such, this particular study investigates the effects that the local air velocity and turbulence have on the emission rates of VOCs from carpet-adhesive assemblies. At the time this research began, a similar study had been done for wood stains [10]. Therefore, similar procedures were followed for testing the carpet-adhesive assemblies in a small test chamber built at NRC following ASTM's small-scale chamber guidelines [11]. 
The carpets and adhesives tested were typical commercial products normally installed in office buildings. They were tested at different velocity and turbulence levels to determine the effect on the emission rates of VOCs. The emission rates of the total volatile organic compounds (TVOCs) along with nonane, decane and 4PC ( 4-phenylcyclohexene) will bs the focus of this study.

An initial set of tests using the same type of carpet, but a different adhesive, was also run to compare the emissions from carpet alone, from adhesive alone. and then from the carpet-adhesive assembly.

\subsection{Significance}

Emission tests conducted in the past are useful for comparing the relative VOC emission rates of different building materials and products. However, hecause the local velocity and turbulence were not controlled and the local environmental conditions generally vary from location to location in an office building, it is difficult to use the data obtained from these tests to predict the VOC concentrations and emission rates in actual buildings. More importantly, the installations (carpet-adhesive assemblies) may alter the emission characteristics of the individual components. Therefore, it was necessary to study the local environmental effects on the emission rates of the installations and compare this with the emission rates of individual components.

Increasing the initial emission rates when a building is unoccupicd while reducing the long-term emission rates may improve the air quality in such a building. Since the air temperature and RH have little effect on emission rates, and an increase in the air change 
rate in an sccupied building would increase energy costs, increasing the local velocity and turbulence may provide an opportunity to increase the initial emission rates and reduce the long term emission rates at minimal cost.

\subsection{Mass Transfer Principles}

Assuming the air in the small chamber is fully mixed, the mass balance of a volatile organic compound can be described by the following equation:

change in mass $=$ mass emitted - mass leaving chamber

$$
V d C=A R(t) d t-Q C(t) d t
$$

Eq. 1

or, in differential form.

$$
V d C / d t=A R(t)-Q C(t)
$$

where,
A = emission surface area, $m^{2}$;
$\mathrm{Q} \quad=$ air flow rate, $\mathrm{m}^{3} / \mathrm{hr}$;
$R=$ cmission rate per unit emission area, $\mathbf{m g} / \mathrm{m}^{2} \mathbf{h r}$;
t = time, hr;
$V \quad=$ outer chamber air volume, $\mathrm{m}^{3}$; 
C = concentration of the VOC inside the chamber. $m g / \mathrm{m}^{3}$.

The data from each test provides the concentration als a tunction of time. Thus, for a given flow rate, $Q$, and a sample size, $A$, in the small chamber volume. $V$, the cmissiun rate. $R(1)$. can be calculated by rearranging $\mathrm{Eq} .2$ as follows:

$$
R(t)=[V d C / d t+Q C(t)] / A
$$

This is the data analysis procedure followed to determine the emission rates of the total volatile organic compounds, as well as for individual compounds. The sofitware package used to curve-fit the concentration vs. time relationship, (1). Was Tablec 'urve. The $\mathrm{dC} / \mathrm{dt}$ term in Eq. 3 was then calculated by difterentiating $C(t)$ with respect (o timle. Both equations were then input into Eq. 3 to get the emission raltes for the sompounds studied. 


\section{Chapter 2}

\section{Experimental Design}

\subsection{Environmental Conditions}

The environmental conditions controlled during testing were the air temperature in the chamber, the relative humidity $(\mathrm{RH})$ in the chamber, the supply air flow rate into the chamber, the velocity (fan motor), the turbulence level and the relative pressure in the chamber.

The air temperature and relative humidity were kept constant for all tests at $23^{\circ} \mathrm{C}$ and $45 \%$, respectively. The fresh air supply flow rate was kept constant at approximately 6.67 LPM which is equivalent to I $\mathrm{ACH}$ (air change per hour) for the $400 \mathrm{~L}$ chamber. The relative pressure in the chamher was maintained at approximately $10 \pm 5 \mathrm{~Pa}$ above the almospheric pressure to ensure that no contaminants entered the chamber during testing.

The test velocity set points were $0.05,0.15$, and $0.25 \mathrm{~m} / \mathrm{s}$. These velocities were chosen because they are representative of the air flow values measured close to the floor in actual buildings $[4,6]$. The two turbulence levels used were High and Low, and they were achieved using different inlet screens. The relative kinetic energy, RKE. is a measure of the turbulence level and is calculated as follows:

$$
\mathrm{RKE}=\frac{\mathrm{k}}{\bar{u}^{2}}
$$


where.

$k=$ kinetic energy of turbulence, $\left(\mathrm{n}^{2} \% \mathrm{~s}^{2}\right)$.

$\overline{\mathrm{u}}=$ average air velocity. $\mathrm{m} / \mathrm{s}$

$u_{1}=$ air $v$ slocity data used to calculate $\bar{u}, \mathrm{~m} / \mathrm{s}$

and

$$
k=\Sigma_{1=1 \ldots n}\left(u_{i}-\bar{u}\right)^{2}
$$

İy. 5

The relative kinetic energies tor the low and high turbulence seltings. al a velexity of approximately $0.25 \mathrm{~m} / \mathrm{s}$, were approximately 0.003 and 0.06 , respectively.

\subsection{Test Plan}

A full factorial experimental design for the three velocity and two lurbulence lest points required six tests. The test schedule followed can be found in Table 2.1. The repeall tests shown in the schedule were decided upon after tests 1-8 had heen completed. This ensured that only a successful test was repeated and a successful test meint that all the predefined test variables had been met, most importantly, the air velicity.

Tests 1, 2, and 3 were the tests designed to compare the effect that carpet had on the emission rates of adhesive VOCs. Tests 4-9 were the regular tests designed to determine if there was a velocity and/or turbulence effect on the cmission of $V O C:$ from carpet-adhesive assemblies.

Prior to beginning the tests, headspace samples were taken from the carpets, adhe:sives, and concrete substrate. The headspace samples were analyzed, as described in more 
detail in Section 4.3, 10 identify the compounds present in each test material.

To determine the kngth of time each test should be run. Test 4 was run for 20 days. It was found that after 6 days, the TVOC concentration was approximately $2.8 \%$ of the peak concentration and after 20 days it was approximately $0.8 \%$. This roughly translated (1) a decrease in TVOC concentrations of $0.14 \%$ per day after 6 days, compared to $16.2 \%$ per day from day 1 to day 6 . As such, the tests were each run for a minimum of 6 days. 


\section{Chapter 3}

\section{Equipment and Test Facilities}

All testing was done at tie Nattional Research Council Canadal s (NRC) Institute for Research in Construction. The actual test materials and lest equipment used are described in the following sections.

\subsection{Test Materials}

The primary test materials, which are the carpet and adhesives, were donaled by their respective manufacturers. To simplify their representation, they will be referred 1 o as Carpet A, B, C \& D, and Adhesive 1, 2.\& 3.

Carpets A, B, C, \& D were all 28oz level-loop nylon carpel supplied from one

manufacturer. The Action Bac ${ }^{(\bar{B})}$ (polypropylene) carpet wass a graphic construction, made using 100\% nylon Dupont Fiber and a synthetic Jute textured back. The fiber was upace dyed, which means that the dye process was done after the fiber was made.

Adhesives $1 \& 2$ were both synthetic latex based adhesives made by the sane manufacturer with approximately $3 \%$ and $5-10 \%$ mineral spirit content, respectively. Adhesive 3 was a solvent-free adhesive made by a different manufacturer. A summary of the material safety dat 1 shet information for the adhesives is provided in Table 3.1. Although adhesive 3 was the "environmentally-friendly" adhesive, it was also more 
expenstve and not widely used by carpet installers. Thus, adheste I was chosen for full velocity-turbulence tests, since it !s most commonly used in carpet installations for the carpets used, and it also had a lower mineral spirit content compared to adhesive 2.

Concrete substrates were made following the concrete procedures in Appendix B. As ykecilied in the Residential Carpet Installation Standard |12]. the relative humidity of the concrete had to be helow $65 \%$ to ensure preper adhesion. The humidity was tested by sealing the concretc in a bag with a humidity sensor and taking readings for several days.

Oher matcrials required for testing were the thermal desorption tubes shown in Figure 3.1 a \& b. the adhesive trowels, a carpet knife, a weigh scale, and a suction pump for taking samples.

\subsection{Small Test Chamber and Test Room}

A $1.0 \mathrm{~m} \times(0.8 \mathrm{~m} \times 0.5 \mathrm{~m}$ stainless steel chamber built at NRC following ASTM's Simall-scale Chamber Guidelines [11] was used to test the carpet-adhesive assemblies. A whematic of the chamber is included in Figure 3.2 a, with the system schematic shown in Figure 3.2 b. Photographs are shown in Figure 3.3 a \& b.

The chamber consisted of an inner and outer chamber. The outer chamber, which housed the inner chamber, was located in the test room. The inner chamber housed the Test assembly. 


\subsubsection{Inner Chamber}

The inner chamber was $0.55 \mathrm{~m} \times 0.6 \mathrm{~m} \times 0.08 \mathrm{~m}$ (Figure 3.4 is $\mathrm{A}$ b) without the screened attachments. The screened attachments (ligure 3.5) all the anr inlet and outlet increase the length from $0.55 \mathrm{~m} 10(0.69) \mathrm{m}$. These allachments are used to provide uniform air flow and to create different levels of turbulence. Two types of screencd inlet attachments were used, one for low turbulence and one for higher turbulence. Two parallel tine mesh screens spaced $20 \mathrm{~mm}$ apart were used for the low turbulence llow. The higher nur bulence flow used one sheet metal plate perforated with $1.3 \mathrm{~mm}$ holes spated $22 \mathrm{~mm}$ center to center.

A Maxon Servo-motor rated for $25 \mathrm{~V}$ was used to control the fian speed and thus the air speed across the carpet. As shown by the arrow in Figure 3.2 a, the fan pulls the air across the carpet surface. The fan housing was attached to the inner chamber's outlet attachment.

The TSI hot-wire anemometer (see Appendix A) was allached to the middle locallion of the inner chamber, as shown by the small hole in the top plate of the inner chamber in Figure $3.3 \mathrm{~b}$ and which corresponds to location $\mathrm{E}$ in Figure 3.6. It was also lecalled 4 $\mathrm{cm}$ above the carpet surface.

\subsubsection{Outer Chamber}

The outer chamber has a top plate which was screwed down to seal the chamber. This plate has attachments for the air supply, the air exhaust, the pressure line and the anemometer cable. 
The aur inlet line was attached to the lop plate of the chamber just above the fan lacatlon. The exhaus lane was altached to the oppostice end of the chamber, alse on the fop plalc.

The anemometer eable was connected to the middle of the plate, which was connected to the hot-wire anememeter inside the outer chamber.

The pressure line was attached to the lop plate between the anemometer cable and the exhaust line.

\subsubsection{Text Koom}

The chamber was set up in at small test room where the temperature was kept conVant +2 "'C for each lesting period. This is because the chamber temperature. due to the chamber's size, was the same as the room temperature. The relative humidity in the test rowm could not be controlled any better than $\pm 1.5 \%$ RH. although this was nol a critical patrameter, since the chamber's environmental controller (see Appendix A) controlled the RH inside the chamber.

\subsection{System Operation}

The three main parts of the system operation are the air supply, the exhaust and the datta alcquisition system (see Figure 3.2 b).

Fresh air, supplied directly trom outside. was pumped through an oil-free compressor, through a dehumidifier (two containers filled with Drierite desiccant to remove moisIIIC. see Figure 3.7), through a catalytic oxidizer at $300^{\prime \prime} \mathrm{C}$ (to remove hydrocarbons), and 
then into the envirormental controlker. The env ironmental controbler then humblitied the air using a filtered water sourc. The humidified air was then supplied to the chamber at the required flow ralte.

The exhaust air was pumped out of the chamter at a slightly lower llow ratc tham the supply rate in order to maintain a positive pressure difference in the chatuber (relative to the atmospheric pressure). Approximately $250 \mathrm{ml} / \mathrm{min}$ of the exhatus atr we'tu to the hydrocarbon analyzer for continuous measurement during testing. A sampling line. located upstream of the pump (see Figure 3.8 ). Was where the desorption tutues were inserted for sampling. The remainder of the air was exhausted wa a fume houl.

The data acquisition system receives and displays datat from the hydrocathon ana. lyzer, the environmental controller, the room lemperatture and RH senbro, llac manometer. and the hot-wire anemometer, and will be discussed further in the next sectiun.

\subsection{Measurement Equipment}

\subsubsection{Environmental Controller}

A Miller-Nelson HCS-30) environmental controller was teed to cumtrol the air flow and relative humidity into the chamber. The temperature was also sel to the tert temperature desired, but the room temperature, as mentuoned in secton 3.2.3. controlled the chamber temperature.

The calibration procedures for the temperature. RH and llow are included in Appendix E. 


\subsubsection{Hydrocarbon Analyzer}

A Meloy Hydrocarbon analyzer, model HCS00-2C was used to measure the hydrocarbon concentration from the chamber. It used a flame ionization detector (FID) which was calibrated using cyclohexane gas as its reference substance (see Appendix $E$ for details).

\subsubsection{Data Acquisition}

A Keithley 500A Measurement and Control System was the interface used with

NRC's ViewDac software to record and monitor the following parameters:

Room Temperature,

Room Relative Humidity,

Chamber Temperature,

Chamber Relative Humidity,

Air Flow, Q.

Relative Pressure,

Total Hydrocarbon level,

and Velocity voltage.

Roomair software, developed at NRC, was used simultaneously with ViewDac to record and plot the velocity data voltages. This voltage data was the data used in the Roomvent software, also developed at NRC, to calculate the velocity and turbulence intensity. The actual voltage value represents the voltage required to maintain the hotwire anemometer at a constant operating resistance of 8.844 ohms. 


\subsubsection{Gas Chromatography Analysis}

A Varian Star $3400 C X$ gas chromatograph was used to analyze the samples taken from the chamber's exhaust air. Compounds from the exhaust air samples, which were adsorbed onto the thermal desorption tubes, were desorbed using an Envirochem Multitube Desorber, model 8916, and concentrated using Envirochem's Unacon 810X. The concentrated sample then flowed into Varian's Star $3400 \mathrm{CX}$ gas chromatograph (GC) column. A heating cycle developed for the column for carpet-adhesive assemblies begins (see Fig. 3.9 for the temperature ramp), and different compounds come through the column to the flame-ionized detector (FID) at different retention times, producing characteristic peaks which are the results of the GC analysis (see Figure 3.10). These peaks are then compared with the GC/MS results to determine which peaks from the Star $3400 \mathrm{CX}$ GC results correspond to the GC/MS peaks.

The retention time is primarily a function of a compound's molecular weight and boiling point. The relationship can generally be simplified as the following: the larger the molecular weight, the higher the retention time, and vice versa. This also means that compounds with larger molecular weights remain in the environment longer than compounds with low molecular weights. This will become evident in Section 5 when the results of specific compounds are examined.

The GC was calibrated using cyclohexane as the reference compound. Cyclohexane was chosen because of its almost 1:1 output ratio with respect to other hydrocarbons, i.e., $1 \mathrm{mg}$ of cyclohexane will give approximately the same output on the GC as $\mathbf{I} \mathbf{m g}$ of another hydrocarbon. The calibration details for the GC are provided in Appendix E. 


\section{Chapter 4}

\section{Test Procedures}

\subsection{Set-Up Procedures}

The main set-up procedures performed the day before the test began were: 1) getting the measurement equipment and room ambient conditions ready for test; 2) cleaning and pre-conditioning the small chamber overnight; 3) cleaning the inner sample holder and leaving it outside of the small chamber; and 4) placing sample materials in test room. Step-by-step procedures can be found in Appendix C.

The procedures which were done immediately before the testing began were: 1) taking a background air sample in the test room; 2) turning on any equipment not already running; 3) preparing the test samples; and 4) beginning the test.

\subsection{Sample Preparation}

Approximately 18 hours prior to testing, the carpet sample (in a sealed mylar bag), the adhesive sample (in a sealed plastic bag) and the concrete substrate were all placed in the test room. This was done to allow the materials to reach the test room temperature, and to allow the carpet to flatten out.

Before the sample preparation began, a $300 \mathrm{ml}$ vapour sample was take: from the 
mylar bag (containing the carpet) to determine the initial VOC concentration of the carpet sample. After the carpet vapour sample was taken. the adhesive and carpet samples were weighed and prepared for testing.

\subsubsection{Adhesive Preparation}

The adhesive was spread onto the substrate and allowed to get "tacky" for no more than 20 minutes. This time limit, which was specified by the adhesive manufacturer, was the time window where the carpet could be placed on the adhesive and still be adjusted. The remaining adhesive materials were then put back in the adhesive sample bag to be reweighed after the test began.

\subsubsection{Carpet Preparation}

Once the adhesive was spread onto the substrate, the carpet was removed from its mylar bag and cut to size $(250 \mathrm{~mm} \times 500 \mathrm{~mm})$. It was then placed onto the adhesive. The carpet remnants were then put back into the mylar bag for re-weighing after the test was started.

At this stage, the complete sample was placed in the inner sample holder and adjusted until the carpet was flush with the inner surface of the sample holder (as shown in Figure 3.4 b). The inner sample holder was then placed inside the small chamber, where final assembly of the sample holder was done. The anemometer was put in place and the small chamber was sealed. The exhaust pump was immediately adjusted to maintain a 
positive pressure difference in the chamber of approximately $10 \pm 5 \mathrm{~Pa}$. Sampling began immediately, as described in Section 4.3.2.

\subsection{Sampling Procedures}

\subsubsection{Headspace Samples}

A headspace sample is usually a vapour sample taken from a vial that is partially filled with a liquid. The sample is taken after the vapour and liquid in the vial have reached equilibrium. It is called a headspace sample because it is taken from the space above the saturated liquid. Similar vapour samples can be taken for non-liquid materials such as carpets, however, larger containers must be used to store the samples and it may lake much longer to reach equilibrium.

Headspace samples were taken for each test material prior to testing to determine the main VOCs present in each test material. The vapour samples were trapped onto thermal desorption tubes (set-up shown in Figure 3.8) and then desorbed using a GC/MS process, which uses a mass spectrometer to identify the main VOCs. The vapour samples were obtained in different manners for different materials, as described in the following sections.

\subsubsection{Carpet Headspace Samples}

Various sampling methods were used and various volumes were sampled to deter- 
mine the headspace volume required for carpet. Initially, a test size sample of carpet was placed in a static chamber $(50 \mathrm{~L}$ volume) and sealed for 24 hours. The sample volumes taken for the first carpet sample were $60 \mathrm{ml}$. 1.15 L. $5 \mathrm{~L}$ and $15 \mathrm{~L}$. The $60 \mathrm{ml}$ sample was too small and the $1.15 \mathrm{~L}$ sample was too large, therefore, subsequent carpet vapour sumples of approximately $0.8 \mathrm{~L}$ needed to be taken from the $50 \mathrm{~L}$ static chanther. Subsequently, $100 \mathrm{ml}$ syringe samples were taken directly from the mylar bags containing the carpet and they were used for the final headspace analyses.

Immediately prior to testing, vapour samples were taken from the carpet using the syringe sampling procedure. Altho'sh these $300 \mathrm{ml}$ samples weren't used for true headspace analysis, they were used to determine the initial concentrations of carpet compounds.

\subsubsection{Adhesive Headspace Samples}

Small amounts of adhesive were placed in small glass vials and scaled for at least 72 hours. A syringe sample of the vapour in the vial was taken and injecled onto a thermal desorption tube, which was then analyzed using the GC/MS process. The vapour volumes taken from the adhesives were $0.5 \mathrm{ml}$.

\subsubsection{Concrete Headspace Sample}

One concrete substrate was placed in the $50 \mathrm{~L}$ static chamber and sealed for 24 hours. A $2 \mathrm{~L}$ sample of the chamber's vapour was sampled directly onto a thermal desorp- 
tion tube using a suction flow of $250 \mathrm{ml} / \mathrm{min}$. The sample was then analyzed using the CiC/MS process.

\subsubsection{Test Samples}

The daily procedures for each test included re Jrding the barometric pressure, taking vapour samples from the chamber, gathering the velocity data, and running the vapour samples on the GC.

The vapour samples were taken on thermal desorption tubes for subsequent analysis on the GC. The volume of the sample was calculated such that the total weight of the compounds on the thermal desorption tube remained less than $12 \mathrm{ng}$. This limit was reduced to $10 \mathrm{ng}$ as the testing continued to improve the GC analysis. The total hydrocarbon level, $\mathbf{x}(\mathrm{ppm})$, monitored by the Meloy hydrocarbon analyzer was used to calculate this volume, according to Eq. 6

$$
\text { Volume }(\mathrm{ml})=\frac{-12 \mathrm{ng} * 24450 \mathrm{~m}^{3} / \mathrm{mol} * 1000000 \mathrm{ml} / \mathrm{m}^{3}}{84000000 \mathrm{ng} / \mathrm{mol} * \mathrm{x} \mathrm{ppm}} \quad \text { Eq.6 }
$$

Once the sample volume was calculated, the sampling flow rate and length of time for sampling had to be calculated. A maximum limit of $250 \mathrm{ml} / \mathrm{min}$ was used for the flow rate through the thermal desorption tubes and the minimum sampling time was 3 minutes (see Appendix D - Calculation of sample volume).

Once the volume, flow rate and sampling time were known, the exhaust pump flow was decreased so that the positive pressure difference in the chamber would increase to 
approximately 15 Pa. The sample was taken and the information was recorded onto the test Data Sheet (Table 4.1). After the sampling was finished. the exhaust pump was readjusted to get positive pressure difference of $10 \pm 5 \mathrm{~Pa}$.

\subsubsection{Sampling Intervals}

The samples were taken as follows:

Day One:

The samples were taken every 15 min for the Ist hour. every 20 -30 min for the next 4 hours, then every 1-2 hours until the total concentration began to decrease.

Day Two and Three:

Two samples were taken: one at approximately 9:00) am, then another at approximately 5:00 pm.

Day Four and later:

One sample was taken each day, usually before 12 nown. The timing of this sample was not as critical as the samples for Days 1-3, since the concentrations were decreasing very slowly and the levels had decreased substantially compared to the maximum concentration. 


\section{Chapter 5}

\section{Results and Discussion}

\subsection{Headspace Identification}

The headspace results obtained from adhesive 1,2 , and 3, carpet $C$, and concrete are shown in Figures 5.1 a-e, respectively. Refer to Table 5.1 for the identification of the main headspace compounds.

\subsubsection{Adhesive Results}

The $0.5 \mathrm{ml}$ adhesive headspace samples shown in Figures 5.1 a-c show the different peaks/compounds present in each adhesive. Adhesive 1 (Ad1) has many compounds in the GC/MS retention time (RT-MS) range of $27-36 \mathrm{~min}$. with large concentrations, whereas Adhesive 2 (Ad2) has much lower concentrations in the same RT-MS range. Adhesive 3 (Ad3) had some large peaks within the 27-35 min range, but there were very fiw peaks compared to Ad1 and Ad2. The TVOC concentrations for the adhesives were 1661. 2018, and $664 \mathrm{mg} / \mathrm{m}^{3}$ for $\mathrm{Ad} 1, \mathrm{Ad} 2$, and Ad3, respectively. The relative TVOC concentrations of Ad1:Ad2:Ad3, using Ad3 as the reference. was $2.5: 3.0: 1$. Thus, the statement made in Section 3.1 that Ad3 was "environmentally friendly" was proven by the 
lower TVOC concentrations.

The main compounds identitied were acetone. noname and decane from Adhesive 1: acetone. br-decane. br-undecane, and tridecanc from Adhesive2: and acetone, 1 butanol, benzene,1-ethyl-2-methyl-, and 1,2,3-trimethylbenzene from Adhesive 3. Their retention times are shown in Table 5.1.

\subsubsection{Carpet Results}

A $100 \mathrm{ml}$ vapour sample was taken from a mylar bag for the headspace sample of each carpet. The headspace results were the same for each sample, since they were the same type of carpet, thus only Carpet B headspace results are provided (Figure $5.1 \mathrm{~d}$ ). At a first glance, the carpet concentrations seem larger than the adhesive concentrations, however, there was only $0.5 \mathrm{ml}$ of adhesive vapour sampled. while there was $f(x) \mathrm{ml}$ of carpet vapour sampled. The $100 \mathrm{ml}$ carpet sample TVOC concentration was $4.45 \mathrm{mg} / \mathrm{m}^{3}$. To get a better idea of the concentration ratio, the TVOC concentration of the carpet is compared with the adhesive TVOC concentrations. The result is a ratio of $\mathrm{Ad} 1: \mathrm{Ad} 2$ : Ad3 $:$ Carpet $=2.5: 3.0: 1: 0.007$, which clearly shows that the cirpet $T V(X)$ concentrations are much smaller than the adhesive concentrations. This is also evident from the results of tests 1 - carpet \& Ad2, 2 - carpet only, and 3 - Ad2 only, where the TVOC cmission rates are plotted vs, time (Figure 5.2). These emission rates were obtained following the procedures explained in Section 1.3.

The main compounds identified in the carpet were acetone, toluene, and styrene. The compound 4PC (4-phenylcyclohexene), which is assoxiated with the new carpet 
smell, was also identified, but at much lower concentrations than the main compounds. The retention time information is provided in Table 5.1

As a result of the headspace analyses, the specific compounds selected for study in tests 4, 5, 6, 7, and 8 were nonane, decane, and 4 PC. Acetone data was also obtained for lest 6. A summary of the compound information is in Table 5.2. and the classifications for identified compounds is provided in Table 5.3.

\subsubsection{Concrete Results}

The concrete headspace analysis results in Figure 5. le were obtained from a $1.97 \mathrm{~L}$ volume from the $50 \mathrm{~L}$ static chamber. The TVOC concentration for this volume was only $0.43 \mathrm{mg} / \mathrm{m}^{3}$. This leads to a concrete : carpet : Ad3 ratio of $0.00065: 0.007: 1$. This ratio shows that the concrete TVOC concentration was negligible compared to the adhesives analyzed and the compounds identified were most likely from the air in the chamber, rather than the concrete itself.

\subsection{Test Results}

Each test was run and the data recorded. The actual test parameters are provided in Table 5.4. As mentioned in Section 2.2, each test was run for a minimum of 6 days. The average time trom adhesive application to the time the inner chamber was placed inside the chamber was 23.4 minutes, with a variation of \pm 6.5 minutes. The temperature and RH varied slightly from test to test (Table 5.5), however, as mentioned in Section 1 , 
the temperature and relative humidity variations do not atfect the emission rates of VOCs from carpet-adhesive assemblies.

\subsubsection{Velocity and Turbulence Results}

The velocity and turbulence data are shown in Figures 5.3 a-t. The drop in velocity that occurs at approximately 50 hours for test 4 was the result of problems with the fan motor. The motor was replaced before test 5 began and no further problems were encountered. The results for test 7 are not plotted, since the velocity was less than $0.025 \mathrm{~m} / \mathrm{s}$ (the lower range value for calibration of the hot-wire anemometer (see Appendix F..3)).

The average velocities during the first 30 hours of tests $4,5,6,6 r 1,6 r 2$. and 8 were $0.045,0.09,0.23,0.26,0.265$, and $0.24 \mathrm{~m} / \mathrm{s}$, respectively.

The low turbulence screens used for tests 4, 5, 6, 6r1. and 6r2, resulted in relative kinetic energy values of approximately $0.003,0.004,0.003,0.0025$, and 0.0025 , respectively. Test 8 , which used the high turbulence perforated plate, had a relative kinetic energy of approximately 0.06 , which is an order of magnitude higher than the low lurbulence tests.

\subsection{TVOC Results}

The two sources of TVOC concentration data for each test were: I) the hydrocarbon analyzer providing continuous TVOC concentrations, and 2) the GC which analyzed desorption tube samples taken at different time intervals. The hydrocarbon analyzer results were used only to determine the sample size required, as discussed in Section 4.3.2. 
However, the GC: results were used primarily to identify and quantify the concentrations of individual comprounds. The initial concentration results for the carpet are provided in Table 5.6, for tests 6.6 , 2 , and 8.

\subsubsection{TVOC Concentration vs. Time}

A comparison of the TVOC concentrations vs. time for tests $4,5,6,7$, and 8 is shown in Figure 5.4. As can be seen from the inset, test $6(0.22 \mathrm{~m} / \mathrm{s}$, LOW $)$ and test 8 $\left(0.26 \mathrm{~m} / \mathrm{s}\right.$. HIGH) have peak concentrations of approximately $160 \mathrm{mg} / \mathrm{m}^{3}$ compared to tests 4,5 , and 7 which have peak concentrations of approximately $125 \mathrm{mg} / \mathrm{m}^{3}$. Thus it appears that increasing the velocity increases the emission concentrations during the first 30 hours of a test. The results also show that atter approximately 30 hours, there is very little difference in the concentrations from test to test. Investigating the total TVOCs emitted during different time periods also provided a method of comparison (see Table 5.7). During the first 30 hours of testing, the higher velocity tests $(6,6 \mathrm{rl}, 6 \mathrm{r} 2, \& 8)$ emitted approximately $250-550 \mathrm{mg} / \mathrm{m}^{3}$ more TVOCs than the lower velocity tests and the adhesive mass had little effect. A comparison of the total TVOCs emitted from $30-100$ hours revealed that the tests with larger adinesive masses, rather than higher velocities, had larger total TVOC concentrations.

The reduced velocity effect after 30 hours is not surprising when boundary layer Iransport mechanisms are considered. The concentrations will increase with increased velocities at the beginning of a test, since the film at the adhesive-carpet interface is just beginning to form. As the adhesive film gets thicker, the velocity effects are reduced and 
the intemal diffusion process begins to control the emissions. This results in the similar concentrations from test to test after 30 hours.

The TVOC concentration equations, obtained using 'TableC urve to get the best wit. are included in Appendix $G$. These equations were used to calculate the emission rates which are discussed in the next section.

\subsubsection{TVOC Emission Rate vs. Time}

The emission rate, Eq. 3 from Section 1.3. is a function of the concentration vs. time, the change in concentration vs. time, the chamber volume, the air change rilte, and the carpet surface area.

$$
R(t)=|V d C / d t+Q C(t)| / A
$$

The concentration equations in Appendix G give the best-fit curve of the concentration vs. time relationship, $(C(t))$. These equations were differentiated to get the change in concentration vs. time $(\mathrm{dC} / \mathrm{dt})$. The emission rates, $R(t)$, were then calculated $(\Lambda p p e n$ dix $\mathrm{G}$ ) and ple tted to compare the emission rates for the different tests (ligure 5.5 )

As expec: ?d, the peak emission rates of test 6 and 8 were greater than the peak emission rates for tests 4,5 , and 7 (by approximately 1.3 times). There was also little: difference in the emission rates from test to test after $\mathbf{3 0}$ hours. It appears that increased turbulence had little effect in the emission rates or concentrations of TVOC s, although the emissions rate was slightly higher for the higher turbulence test 8 , than for the lower turbulence test 6 . 


\subsection{Specific VOC Results}

\subsubsection{Concentration vs. Time}

The concentrations of nonane, decane and 4PC are plotted vs. time in Figures 5.6, 5.7, and 5.8, respectively. The concentration of acetone is compared to nonane, decane and $4 \mathrm{PC}$ for test 6 and is provided in Figure 5.9. Table 5.2 provides a summary of the molecular weights and boiling points of the specific compounds studied.

An increase in velocity does not seem to affect the concentrations of nonane as it did for the TVOC concentrations. Further investigation into the amount of adhesive present for each test seems to clarify the results. When comparing tests 4,7 , and 8 , which had adhesive masses of $59.1 \mathrm{~g}, 59 \mathrm{~g}$, and $58 \mathrm{~g}$, respectively, it appears that an increase in velocity from $<0.025 \mathrm{~m} / \mathrm{s}$ (test 7) to $0.05 \mathrm{~m} / \mathrm{s}$ (test 4) and $0.26 \mathrm{~m} / \mathrm{s}$ (test 8 ), increased the peak concentration of nonane. Test $8(58 \mathrm{~g}, 0.26 \mathrm{~m} / \mathrm{s}$, High turb.) also had a higher peak concentration than test $6(51 \mathrm{~g}, 0.22 \mathrm{~m} / \mathrm{s}$, Low turb. $)$, while test $6(51 \mathrm{~g}, 0.22 \mathrm{~m} / \mathrm{s})$ had a higher peak concentration than Test $5(55 \mathrm{~g}, 0.10 \mathrm{~m} / \mathrm{s})$. Unlike the TVOC concentrations, the concentrations of nonane were affected by both the adhesive mass and the velocity across the carpet surface during the first $\mathbf{3 0}$ hours, and relatively unaffected after $\mathbf{3 0}$ hours. An increase in the velocity for a given mass of adhesive increased the peak concentrations of nonane and a larger adhesive mass for a given velocity also increased the peak concentrations of nonane.

The concentration of decane vs. time behaved similarly to the TVOC concentration vs. time. Increased velocities increased the concentrations emitted during the first 30 
hours, while having little effect after 30 hours. With the lower velocities, tests $4(59 \mathrm{~g})$ and $7(59 \mathrm{~g})$ had slightly higher concentrations than test $5(55 \mathrm{~g})$ during the tirst .30 hours. The 4PC concentrations only became detectable after approximately 50 hours (sec Figure 5.8), due to the high concentrations of adhesive compounds, and tests $6.7 \& 8$ seem to have had slightly higher concentrations of 4PC emitted than tests $4 \& 5$.

To investigate the effect that the molecular weight and boiling point have on the emissions of compounds, the time of the peak concentration was compared for nonane and decane. Decane, which has a higher molecular weight, a higher boiling point, and a higher retention time than nonane, has a peak concentration time at approximately 10 hours for test $7 \& 8$, whereas, nonane's peak concentration occurs at approximately 4 hours. The acetone concentration peaked at approximately 1.2 hours, and it leveled off much earlier than nonane and decane at approximately 25 hours. This shows that the higher molecular weight compounds reach their peak concentrations at a later time than lighter molecular weight compounds. The decane concentration took approximately 100 hours to level off, whereas the nonane concentration leveled off at approximately 50 hours for all tests. As with decane, the 4PC concentration did not level off until approximately 100 hours.

The time at which the maximum peak concentration occurred and the time the concentration leveled off are plotted vs. the boiling point for acetone, nonane, and decane in Figure 5.10. The time at which the concentrations leveled off appear to be a function of the boiling point, whereas the peak concentration time was less affected by the compound's boiling point. 


\subsubsection{Emission Rates vs. Time}

The emission rates for nonane and decane were calculated in the same manner as the TVOC emission rates. The concentration equations are included in Appendix G. The emission rates vs. time for nonane and decane are shown in Figures 5.11 and 5.12, respectively.

Nonane's emission rates follow the same trends as its concentration vs. time, discussed in Section 5.4.1. The higher velocities increased the emission rates during the first 30 hours of testing for a given adhesive mass, while the emission rate was higher for a larger adhesive mass when the velocity was essentially kept constant (test $6 \& 8$ ).

Decane's emission rates increased with an increase in velocity, as its concentration did, within the first 30 hours. With the exception of test 7. the emission rates follow the same trend as decane's concentration vs. time results. It appears as though the turbulence may have had a slight effect on the emission rate for test 7 , causing an increase in decane's emission rate, although, overall, the turbulence seemed to have very little effect on the emissions of VOCs from the carpet-adhesive assemblies.

\subsection{Test Repeatability and Accuracy of Data}

To ensure that the tests were repeatable, and that the higher velocity was indeed the cause of the increased peak concentration for the TVOC results, test 6 was repeated twice with the concentration results shown in Figure 5.13. As can be seen, similar results were obtained for each repeat test, thus allowing the conclusion that the increased velocity did 
in fact increase the peak concentration and emission rate for the TVOC results. A difference of $10 \mathrm{mg} / \mathrm{m}^{3}$ in the peak concentrations is reasonable considering the potential sampling error associated with a small sample volume of approximately $120 \mathrm{ml}$ taken in approximately 3 minutes at peak concentrations of $150 \mathrm{mg} / \mathrm{m}^{3}$. This sampling error is described in Appendix D.4.

The repeated results for acetone, nonane and decane are also provided in Figures $5.14-5.16$. The scatter of the acetone data in the first 10 hours is most likely a result of the small sample volume required for a large TVOC concentration sample, as described in Appendix D.4. Thus the repeatability of acetone cannot be confirmed. However, the concentration results for nonane and decane appear to be repeatable, with deviations less than $1.2 \mathrm{mg} / \mathrm{m}^{3}$ for peak concentrations of $11 \mathrm{mg} / \mathrm{m}^{3}$ for nonane, and $14.5 \mathrm{mg} / \mathrm{m}^{3}$ for decane. 


\section{Chapter 6}

\section{Conclusions and Recommendations}

The primary focus of this research was to determine whether the local air velocity and turbulence levels had an effect on the emissions of volatile organic compounds from carpet-adhesive assemblies.

The higher velocity tests $(6 \& 8)$, with velocities of approximately $0.25 \mathrm{~m} / \mathrm{s}$, had increased TVOC concentrations and emission rates during the first $\mathbf{3 0}$ hours. However, after the first $\mathbf{3 0}$ hours, the velocity had no effect on the concentrations or emission rates. Since a building can generally be vacated for a period of $24-48$ hours, increasing the emission rate during this period while affecting a reduced emission rate after the building is re-occupied is the desired effect. The fact that this was not the case limits the value of inducing higher local velocities above a carpet surface, while at the same time, it supports the theory of a two-stage curing process for the adhesive, as expected with a wet material.

The results of nonane and decane revealed that the velocity, along with the adhesive mass influenced the concentrations and emission rates vs. time for these specific compounds. For nonane, an increase in velocity for a given mass of adhesive increased the emissions, while a larger adhesive mass also resulted in higher emissions. Decane's emissions also increased with an increase in velocity, but they were less affected by the mass of adhesive applied to the substrate.

As expected, the emissions of compounds with lower molecular weights and lower 
boiling points reached peak concentrations earlier and leveled off carlier than compounds with higher molecular weights and boiling points. This explains why 4PC, which has a high molecular weight and boiling point and a fairly low odor threshold, estimated at less than $0.5 \mathrm{ppb}$ [14], can be detected long after the carpet has been installed.

The main compounds identified in the headspace analysis were classified by compound type and whether or not they were carcinogens in Table 5.3. The only compounds identified as a possible human carcinogens were benzene, styrene and toluenc.

While full scale tests were not run for the "environmentally friendly" adhesive (Ad3), the lower TVOC concentration from the headspace analysis should be indicative of lower emissions vs. time. Further tests would be needed to prove this theory.

There are many areas within this thesis that could be investigated as individual topics. Some possibilities are: 1) detailed studies on the emissions from "environmentally friendly" adhesives, 2) higher velocity tests, if feasible, 3) more detailed lesting to investigate the mass transfer mechanisms involved, and 4) more detailed chemical analysis identify more compounds and their emission rates. 


\section{References}

1) Black, M.S., et al., “A Methodology for Determining VOC Emissions from New SBR Latex-Backed Carpet, Adhesives, Cushions, and Installed Systems and Predicting their Impact on Indoor Quality”, IAQ “9/, Healthy Buildings, Sept. 4-8, 1991, Washington, D.C., pp. 267-272.

2) Black. M., "Environmental Chamber Technology for the study of volatile organic compound emissions from manufactured products", IAQ '90, Jul29 - Aug. 3, 1990, Toronto, Vol. 3, pp. 713-718.

3) Colombo, A., et al., "Chamber Testing of Organic Emission from Building and Furnishing materials", The Science of the Total Environment, 91(1990), pp. 237-249.

4) Black, M.S., et al., "Effects of Selected Process Parameters on Emission Rates of Volatile Organic Chemical from Carpet", American Industrial Hygiene Association Journal, 53(5), 1992, pp. 275-282.

5) Wallace, L., et al., "Emissions of Volatile Organic Compounds from Building Materials and Consumer Products", Atmospheric Environment, v21, no. 2, 1993, pp. 183-192.

6) Little, J.C., et al., "Modeling Emissions of VOCs from New Carpets", Atmospheric Environment, v28, no. 2, Jan. 1994, pp. 227-234.

7) Nielsen, P.A., "The Influence of Ageing and Air Change on the Emission Rate of Gases and Vapours from Some Building Materials", CLIMA 2000, Vol. 4, Indoor Climate, Copenhagen, 1985, pp. 207-213.

8) Bayer, C.C., and Black, M.S., "Formaldehyde and Other VOC Exposures from Consumer Products”, IAQ '86. Managing Indoor Air for Health and Energy Conservation, pp. 4.54-468.

9) Sollinger, S., and Levsen, K., "Indoor Air Pollution by Organic Emissions from Textile Floor Coverings: Climate Test Chamber Studies under Static Conditions", Atmospheric Einvironment. v28, no. 14, 1994, pp. 2369-2378.

10) Zhang, J., "Selection of Material Samples and Experimental Design: Polyurethane and Wood Stain", Progress Update, NRC, May, 1994.

11) ASTM (American Society of Testing Materials) - Standard Guide for Small Scale Environmental Chamber Determination of Organics Emissions from Indoor Materials/ Products. Draft \#6 (12/89).

12) CRI 105-1995. Residential Carpet Installation Standard, The Carpet and Rug Institutc. Standard Industry Reference Guide for Installation of Residential Textile Floorcov- 
ering Materials.

13) Contract Carpet Manual. issued by the Canadian Carpet Institule.

14) Van Ert. M.D., et al., "Identification of 4-Phenylcyclohexenc - an Emission Proxduct from New Carpeting", U.S. EPA-OTS report, January 1987. 


\section{Bibliography}

Zhang, J.S., et al., "Characterizing Organic Compound Emissions from building Materials/Furnishings Using a New Small Test Chamber", ASTM Symposium on: Methods for Characterizing Indoor Sources and Sinks, Sept. 25-28, 1994, Washington, D.C.

Solinger, S. and Levsen, K., "Indoor Air Pollution by Organic Emissions from Textile Floor Coverings: Climate Chamber Studies under Dynamic Conditions", Atmospheric Enviromment, v27B, no. 2, 1993, pp 183-192.

McNair, H.M. and Bonelli, E.J., Basic Gas Chromatography, 5th Edition, Mar. 1969, Consolidated Printers, Berkeley, California.

National Research Council Canada, "Characterizing Emissions of Volatile Organic Compounds from Building Materials/Products for Indoor Air Quality Control", Preliminary proposal, Jan. 1994.

Molhave, L.. "Indoor Air Pollution Due to Organic Gases and Vapours of Solvent in Building Materials", Environment International, Vol. 8, 1982, pp 177-182.

Rothweiler, H., et al., "Long Term Emissions from Two Glued Carpets with Different Backings Measured in Indoor Air", Environmental Technology, v13, pp 891-896.

Healthy Materials, Spring 1994, No. 1.

Levin, H.. "The Evaluation of Building Materials and Furnishings for a New Office Building", IAQ '87. Practical Control of Indoor Air Problems, pp 88-103.

Davidson, J.L, et al., "Carpet Installation during Building Renovation and Its Impact on Indoor VOC Concentrations”, IAQ '91, Healthy Buildings, Sept. 4-8, 1991, Washington D.C., pp 299-303.

"Industry Bioassay Studies Find No Adverse Reactions from Carpets". Practical Research Briefs, Indoor Air Quality Update, Feb. 1995.

Monteith, D.K., "Sources and Characterization of Organic Air Contaminants Inside Manufactured Housing", Indoor Air, Vol. 4, Chemical Characterization and Personal Exposure, Stockholm, Sweden, 1984, pp 285-290

Girman, J.R., "Volatile Organic Emissions from Adhesives with Indoor Applications", Indoor Air, Vol. 4. Chemical Characterization and Personal Exposure, Stockholm, Sweden, 1984. pp 271-276.

Singghvi, R., et al., "4-Phenylcyclohexene from Carpets and Indoor Air Quality", Indoor Air. Vol. 4. Int. Conference Indoor Air Quality and Climate, July 29 - Aug. 3, 1990, 
pp 671-676.

Hodgson. A.T., et al., "Emissions of Volatile Organic Compounds from New Carpets Measured in a Large-Scale Environmental Chamber". Jenurmal of Air and Waste Manage" ment Association, 43. 1992, pp 316-324.

Lydersen, Mass Transfer in Enginecring Praclice. 198.3.

Bayer, C., "Carpet Policy Dialogue", Progressive Architecture, 72(3), 199)1, pp 127-128

Silverstein, Bassler and Morrill, Spectrometric Identification of Oryanic Compounds, 4th Edition, John Wiley \& Sons, 1981

Operator’s Manual, 3300 \& Star 3400CX Gas Chromatographs.

Operating Manual, Envirochem Concentrating/Capillary Inletting System for GC or GC/ MS. Model $810 \mathrm{X}$

Operating Manual, Envirochem Auto Tube Desorber, Model 8916

Instruction Manual, TSI IFA 100 System Intelligent Flow Analyzer.

Operation. Maintenance, and Parts Manual, FID Hydrocarbon Analyzer, Model HC5(X)2C

Handbook of Chemistry and Physics, CRC, 52nd Edition. 


\section{Tables}




\begin{tabular}{|c|c|c|c|c|c|}
\hline Test & Carpet & Adhesive & Velixcily & Turbt & ulence \\
\hline & A BCD & 123 & 123 & 1 & 2 \\
\hline 1 & C & 2 & 2 & 1 & \\
\hline 2 & C & $\ldots . .$. & 2 & 1 & \\
\hline 3 & $-\cdots-\cdot-$ & 2 & 2 & 1 & \\
\hline 4 & A & 1 & 1 & 1 & \\
\hline 5 & A & 1 & 3 & 1 & \\
\hline 6 & A & 1 & 2 & 1 & \\
\hline 7 & A & 1 & I & & 2 \\
\hline 8 & A & 1 & 3 & & 2 \\
\hline 9 & A & 1 & 2 & & 2 \\
\hline $6 \mathrm{rl}$ & A & 1 & 2 & 1 & \\
\hline $6 r^{2}$ & A & 1 & 2 & 1 & \\
\hline
\end{tabular}

Table 2.1: Test Schedule

Table 2.1 Legend:

Velocity $1,2,3: 0.05,0.15,0.25 \mathrm{~m} / \mathrm{s}$, respectively. Turbulence 1, 2: low, high turbulence, respectively

All Tests were run at $23+/-0.5{ }^{\circ} \mathrm{C}, 45+/-1 \%$ RH. and 6.67 +/- 0.05 I.PM

\begin{tabular}{|c|c|c|c|c|}
\hline Adhesive & Description & $\begin{array}{c}\text { Mineral } \\
\text { Spirits, } \%\end{array}$ & Appearance & Basc \\
\hline \hline 1 & Low VOC & 3 & Beige paste & Synthetic Lattex \\
\hline 2 & Best Holding Power & $5-10$ & Beige pastc & Synthetic I.allex \\
\hline 3 & Solvent-free & 0 & Beige paste & \\
\hline
\end{tabular}

Table 3.1: Material Safely Data Sheet Summary 
Table 4.1: Data Sheet (see Appendix $C$ for $t_{a}, t_{c}, t_{b}$ and $t_{1}$ descriptions.).

\begin{tabular}{|c|c|c|c|}
\hline Number & Compound & RT-MS. min & RT-GC, min \\
\hline 1 & Acetone & $21.21-21.47$ & $12.5-12.8$ \\
\hline 2 & 1-Butanol & 25.24 & Ad3 not run \\
\hline 3 & Toluene & $27.65-27.95$ & 23.6 \\
\hline 4 & Octane & 28.44 & Concrete not run \\
\hline 5 & Nonane & $31.46-31.51$ & $26.2-26.4$ \\
\hline 6 & Styrene & 31.69 & 26.6 \\
\hline 7 & br-Decane & 32.07 & 26.8 \\
\hline 8 & Benzene, 1-ethyl-2-methyl & 34.03 & Ad3 not run \\
\hline 9 & Decane & $35.53-35.61$ & 31.3 \\
\hline 10 & $1.2 .4-$ Trimethylbenzene & 35.55 & Ad3 not run \\
\hline 11 & br-Undecane & 36.18 & 31.8 \\
\hline 12 & Undecane & 40.78 & 36.8 \\
\hline 13 & Tridecane & 46.41 & 44.1 \\
\hline
\end{tabular}

Table 5.1: Main Headspace Compounds and Retention Times 


\begin{tabular}{|c|c|c|c|c|c|}
\hline Compound Name & $\begin{array}{l}\text { Basic Fommula } \\
\text { Composition }\end{array}$ & $\begin{array}{l}\text { Mol. } \\
\text { W1.. } \\
\text { ! }\end{array}$ & $\begin{array}{l}\text { Boviling } \\
\text { Povint. } \\
\text { "C" }\end{array}$ & $\begin{array}{l}\text { RI: } \\
\text { MS. } \\
\text { min. }\end{array}$ & $\begin{array}{l}\text { RT- } \\
\text { (id: } \\
\text { niin. }\end{array}$ \\
\hline $\begin{array}{l}\text { Acctone } \\
\text { (2-Propanol) }\end{array}$ & $\mathrm{CH}_{3} \mathrm{CH}(\mathrm{OH}) \mathrm{CH}_{3}$ & 60.11 & 82.4 & 21.2 & 12.7 \\
\hline Nonane & $\mathrm{CH}_{3}\left(\mathrm{CH}_{2}\right)_{7} \mathrm{CH}_{3}$ & 128.26 & 150.8 & 31.5 & $26 . .3$ \\
\hline Decane & $\mathrm{CH}_{3}\left(\mathrm{CH}_{2}\right)_{8} \mathrm{CH}_{3}$ & $1+2.34$ & 174.1 & 35.5 & .31 .3 \\
\hline $\begin{array}{l}\text { 4-PC. } \\
\text { (Benzene, 3-cyclo- } \\
\text { hexen-|y|-) }\end{array}$ & $\mathrm{C}_{12} \mathrm{H}_{14}$ & 158 & 252 & $50,6.5$ & 47.2 \\
\hline
\end{tabular}

Table 5.2.: Compound Information

\begin{tabular}{|c|c|c|c|c|}
\hline Hydrociarbon & $\begin{array}{l}\text { Aldehyde } \\
\text { \& Kelones }\end{array}$ & Aromatic & Alcoliol & $\begin{array}{l}\text { (arcino } \\
\text { ?'en }\end{array}$ \\
\hline Decanes & & & & Noi \\
\hline Nonanes & & & & No \\
\hline \multirow{8}{*}{$\begin{array}{l}\text { Undecianes } \\
\& \text { br-Undecanes }\end{array}$} & & & & No \\
\hline & Acetone & & & No \\
\hline & & Toluene & & pousibly \\
\hline & & 4-PC & & $N_{11}$ \\
\hline & & $\begin{array}{l}\text { Benaene, I-cthyl- } \\
\text { 2-methyl }\end{array}$ & & ponsibly \\
\hline & & $\begin{array}{l}\text { 1,2,3-Trimethyl- } \\
\text { benzene }\end{array}$ & & No \\
\hline & & Styrene & & powsibly \\
\hline & & & Methyl Alcohol & No \\
\hline
\end{tabular}

Table 5.3: Classification of Some Identified Compounds 


\begin{tabular}{|c|c|c|c|c|c|c|c|}
\hline Test & $\begin{array}{c}\text { Carpet } \\
\text { Area }\end{array}$ & $\begin{array}{c}\text { Carpet } \\
\text { Mass }\end{array}$ & $\begin{array}{c}\text { Adhesive } \\
\text { Mass }\end{array}$ & $\begin{array}{c}\text { Air } \\
\text { Flow }\end{array}$ & $t_{a}$ & $t_{c}$ & $t_{0}$ \\
\hline $\mathrm{m}^{2}$ & $\mathrm{~g}$ & $\mathrm{~g}$ & LPM & hr:min & hr:min & hr:min \\
\hline 2 & 0.123 & 305.8 & 43.6 & 6.67 & $10: 42$ & $10: 46$ & $11: 01$ \\
\hline 3 & 0.123 & 305.75 & N/A & 6.67 & N/A & $12: 43$ & $12: 50$ \\
\hline 4 & N/A & N/A & 51.9 & 6.67 & $10: 34$ & N/A & $10: 50$ \\
\hline 5 & 0.124 & 297.7 & 59.1 & 6.67 & $10: 10$ & $10: 15$ & $10: 37$ \\
\hline 6 & 0.123 & 301.5 & 55.2 & 6.67 & $10: 02$ & $10: 15$ & $10: 30$ \\
\hline $6 r 1$ & 0.124 & 328.3 & 50.6 & 6.65 & $10: 35$ & $10: 40$ & $11: 05$ \\
\hline $6 r 2$ & 0.123 & 300.8 & 55 & 6.65 & $10: 22$ & $10: 24$ & $10: 45$ \\
\hline 7 & 0.124 & 299.5 & 59 & 6.65 & $9: 44$ & $9: 52$ & $10: 02$ \\
\hline 8 & 0.122 & 299.2 & 58 & 6.67 & $10: 08$ & $10: 13$ & $10: 25$ \\
\hline
\end{tabular}

Table 5.4: Actual Test Parameters

\begin{tabular}{|c|c|c|c|c|}
\hline Test & Temp. & $\begin{array}{c}\text { Temp. } \\
\text { Deviation }\end{array}$ & RH & $\begin{array}{c}\text { RH } \\
\text { Deviation }\end{array}$ \\
\hline & ${ }^{\circ} \mathrm{C}$ & $\pm^{\circ} \mathrm{C}$ & $\%$ & $\pm \%$ \\
\hline 4 & 21.6 & 1.48 & 44.6 & 2.78 \\
\hline 5 & 23.7 & 1.3 & 50.1 & 4.47 \\
\hline 6 & 23.6 & 0.6 & 49 & 3.75 \\
\hline $6 \mathrm{r} 1$ & 24 & 1.3 & 42.9 & 2.5 \\
\hline $6 \mathrm{r} 2$ & 23 & 1.25 & 42.8 & 2.4 \\
\hline 7 & 22.9 & 1.1 & 46.4 & 6.2 \\
\hline 8 & 22.8 & 2.3 & 42.9 & 3.3 \\
\hline
\end{tabular}

Table 5.5: Temperature and RH Data - Tests 4 - 8 


\begin{tabular}{|c|c|c|c|c|}
\hline Test & Volume & TVOC & Acetone & 4PC \\
\hline & $\mathrm{ml}$ & $\mathrm{mg} / \mathrm{m}^{3}$ & $\mathrm{mg}^{3} \mathrm{~m}^{3}$ & $\mathrm{mg} / \mathrm{m}^{3}$ \\
\hline \hline 6 & 300 & 10.6 & 0.58 & 0.084 \\
\hline $6 \mathrm{r} 2$ & 300 & 5.62 & 0.108 & 0.08 \\
\hline 8 & 300 & 8.75 & 0.16 & 0.09 \\
\hline
\end{tabular}

Table 5.6: Initial Concentrations - Carpet Syringe Samples

\begin{tabular}{|c|c|c|c|c|}
\hline Test & $\begin{array}{c}\text { Adhesive } \\
\text { Mass }\end{array}$ & $\begin{array}{c}\text { TVOCs } \\
0-30 \mathrm{hrs}\end{array}$ & $\begin{array}{c}\text { TVOC } \\
30-100 \mathrm{hrs}\end{array}$ & $\begin{array}{c}\text { TVOC } \\
\text { 100 - 150 hrs }\end{array}$ \\
\hline \hline & $\mathrm{g}$ & $\mathrm{mg} / \mathrm{m}^{3}$ & $\mathrm{mg}^{3} \mathrm{~m}^{3}$ & $\mathrm{mg}^{3} \mathrm{~m}^{3}$ \\
\hline 4 & 59.1 & 2644 & 894 & 92 \\
\hline 5 & 55.2 & 2516 & 699 & 243 \\
\hline 6 & 51.35 & 2886 & 391 & 167 \\
\hline $6 \mathrm{r} 1$ & 50.6 & 3204 & 489 & 74 \\
\hline or 2 & 55 & 3020 & 648 & 86 \\
\hline 7 & 59 & 2682 & 643 & 279 \\
\hline 8 & 58 & 3084 & 860 & 293 \\
\hline
\end{tabular}

Table 5.7: Total TVOC Concentration for Specified Time Period 
LOW TURBULENCE LCVLL Hith Valoxily level

Mif Vetaxily leved

$\begin{array}{lccc}\text { Mean vatudity } u_{y}(\mathrm{~m} / \mathrm{s}): & \\ y_{i} & 1 & 2 & 3 \\ 1 & 0214 & 0241 & 0210 \\ 2 & 0228 & 025 & 0.212 \\ 3 & 0246 & 0256 & 0213\end{array}$

$u_{m}=0230 \mathrm{~m} / \mathrm{s}$

Kelative Kinetic Energy $=k_{4} /\left(u_{4}{ }^{2}\right)$ :

$\begin{array}{cccc}v_{1} & 1 & 2 & 3 \\ 1 & 0007 & 0.004 & 0.007 \\ 2 & 0007 & 0.003 & 0.010 \\ 3 & 0010 & 0.004 & 0.021\end{array}$

IIGH TURBULUNCE LEVEI.

Itiw Velacity Levet

Mesu velociiy u, (m/s) (carpet).

$\begin{array}{lccc}v_{1} & 1 & 2 & 3 \\ 1 & 017 & 0.264 & 0.116 \\ 2 & 0198 & 0249 & 0106\end{array}$

$0223 \quad 0254 \quad 0103$

$U_{m y}=0187 \mathrm{nV} / \mathrm{s}$

Relative Kinetu: lisergy $=k_{1} /\left(u_{4}{ }^{2}\right)$

$\begin{array}{cccc}1 / 3 & 1 & 2 & 3 \\ 1 & 0290 & 0167 & 0.380 \\ 2 & 0147 & 0100 & 0.380 \\ 3 & 0081 & 0058 & 0305\end{array}$

$\begin{array}{ccc}1 & 2 & 3 \\ 0120 & 0.139 & 0.122 \\ 0.136 & 0.143 & 0.121 \\ 0146 & 0.146 & 0124\end{array}$

$\mathrm{umg}_{\mathrm{m}}=0.133 \mathrm{~m} / \mathrm{s}$

$\begin{array}{ccc}1 & 2 & 3 \\ 0.003 & 0002 & 0.003 \\ 0003 & 0.003 & 0.006 \\ 0005 & 0.002 & 0012\end{array}$

Mid Vetarifvi levet

$\begin{array}{ccc}1 & 2 & 3 \\ 0134 & 0150 & 0095 \\ 0132 & 0.145 & 0095 \\ 0139 & 0160 & 0.074\end{array}$

$u_{m-2}=0125 \mathrm{~m} / \mathrm{s}$

$\begin{array}{ccc}1 & 2 & 3 \\ 0286 & 0225 & 0328 \\ 0.146 & 0.126 & 0342 \\ 0097 & 0063 & 0256\end{array}$

Low Veluxitr Ievel

$\begin{array}{ccc}1 & 2 & 3 \\ 0.053 & 0.054 & 0.048 \\ 0.057 & 0.054 & 0.052 \\ 0.060 & 0.052 & 0.046\end{array}$

$u_{\cos }=0,053 \mathrm{~m} / \mathrm{s}$

$\begin{array}{ccc}1 & 2 & 3 \\ 0.002 & 0.003 & 0.002 \\ 0.002 & 0.004 & 0.004 \\ 0.002 & 0003 & 0.005\end{array}$

Low Velocily Level

$\begin{array}{ccc}1 & 2 & 3 \\ 0.042 & 0047 & 0046 \\ 0039 & 0038 & 0.041 \\ 0053 & 0041 & 0038\end{array}$

$u_{m}=0043 \mathrm{nIs}$

$\begin{array}{ccc}1 & 2 & 3 \\ 0107 & 0087 & 0104 \\ 0065 & 0084 & 0097 \\ 0051 & 0039 & 0058\end{array}$

Table E.1: Velocity Profile Data - Mid-Height Chamber Location

\begin{tabular}{|l|l|}
\hline \multicolumn{1}{|c|}{ Std. Velocity } & \multicolumn{1}{c|}{ Roomair Output } \\
\hline \multicolumn{1}{|c|}{$(\mathrm{m} / \mathrm{s})$} & \multicolumn{1}{|c|}{ (Volts) } \\
\hline \hline 0.3 & 4.9443 \\
\hline 0.25 & 4.8862 \\
\hline 0.2 & 4.8229 \\
\hline 0.15 & 4.7500 \\
\hline 0.10 & 4.6731 \\
\hline 0.05 & 4.5904 \\
\hline 0.025 & 4.5493 \\
\hline
\end{tabular}

Table E.2: TSI/Roomair Calibration Data 


\begin{tabular}{|c|c|c|c|c|}
\hline Area & $\begin{array}{c}\text { Actual } \\
\text { Amount, } \mathrm{mg}\end{array}$ & $\begin{array}{c}\text { Predicted } \\
\text { Amount, } \mathrm{mg}\end{array}$ & Difference & $\begin{array}{c}\% \\
\text { Difference }\end{array}$ \\
\hline \hline 60580 & 0.000337 & 0.00029 & 0.000047 & 13.9 \\
\hline 60756 & 0.000337 & 0.00029 & 0.000047 & 13.9 \\
\hline 108728 & 0.000674 & 0.00051 & 0.000164 & 24.3 \\
\hline 114429 & 0.000674 & 0.00054 & 0.000134 & 19.9 \\
\hline 185061 & 0.001197 & 0.00086 & 0.000337 & 28.2 \\
\hline 257645 & 0.001197 & 0.00119 & 0.000007 & 0.6 \\
\hline 212888 & 0.001197 & 0.00099 & 0.00021 & 17.5 \\
\hline 398856 & 0.00199 & 0.00184 & 0.00015 & 7.5 \\
\hline 456493 & 0.00199 & 0.0021 & -0.00011 & -5.5 \\
\hline
\end{tabular}

Table E.3: Cyclohexane Calibration Data 
Figures 


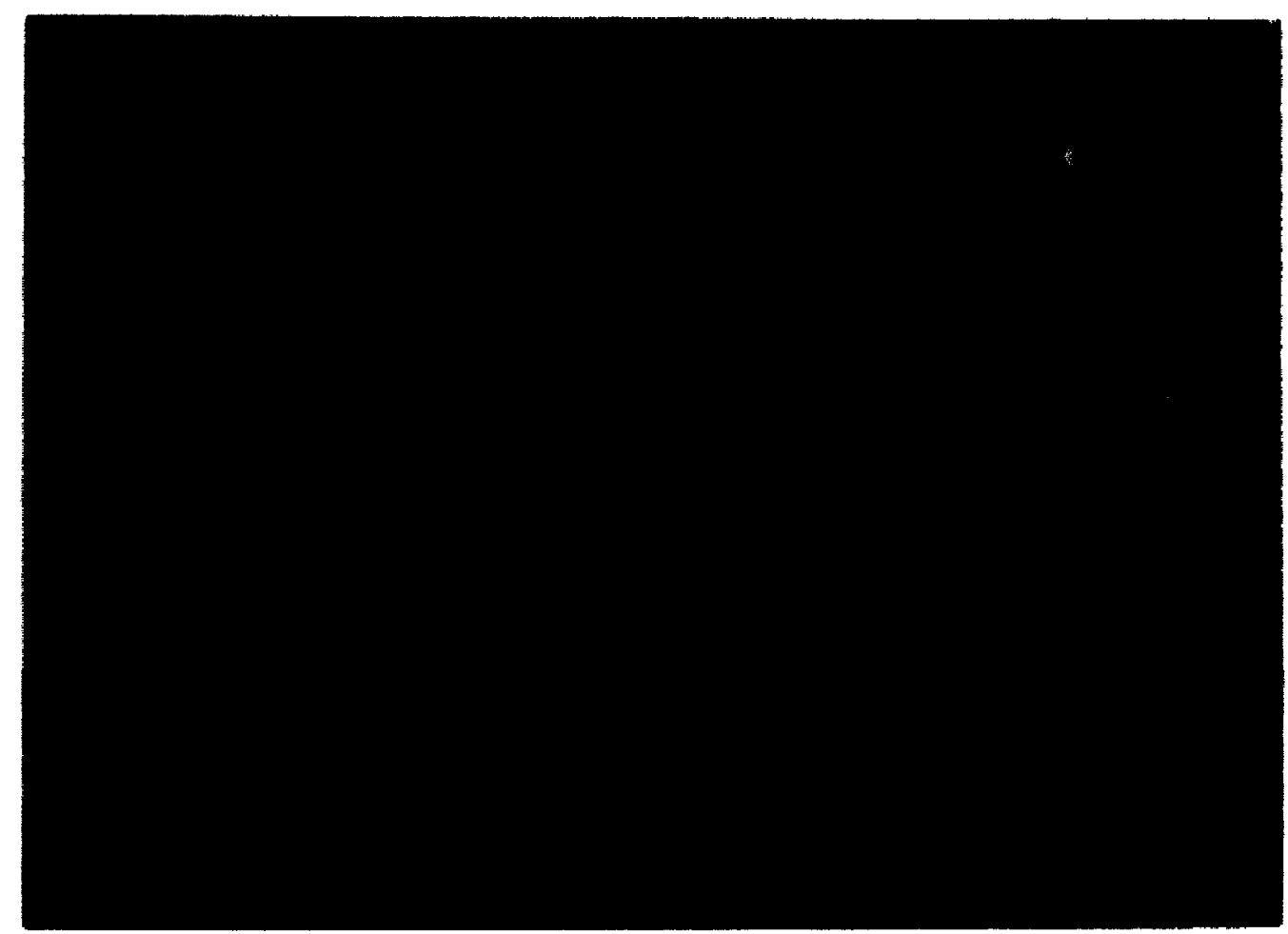

Figure 3.1 a: Photograph of Thermal Desorption Tube.

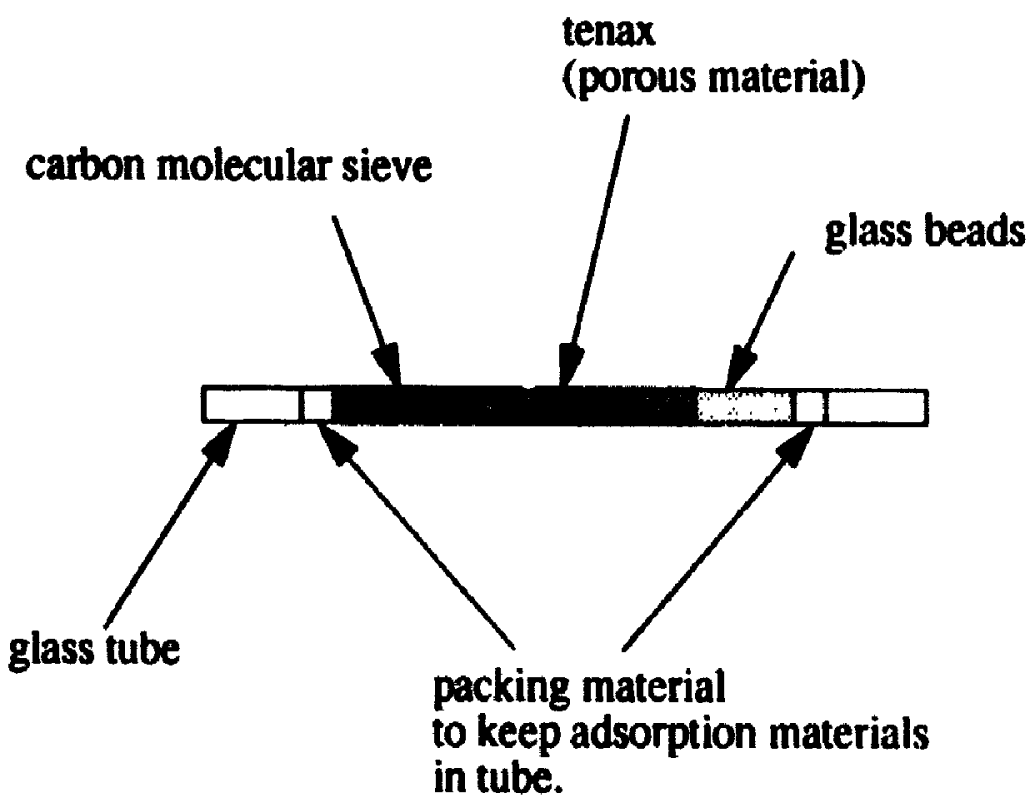

Figure 3.1 b: Schematic of a Thermal Desorption Tube (multi-layer) 


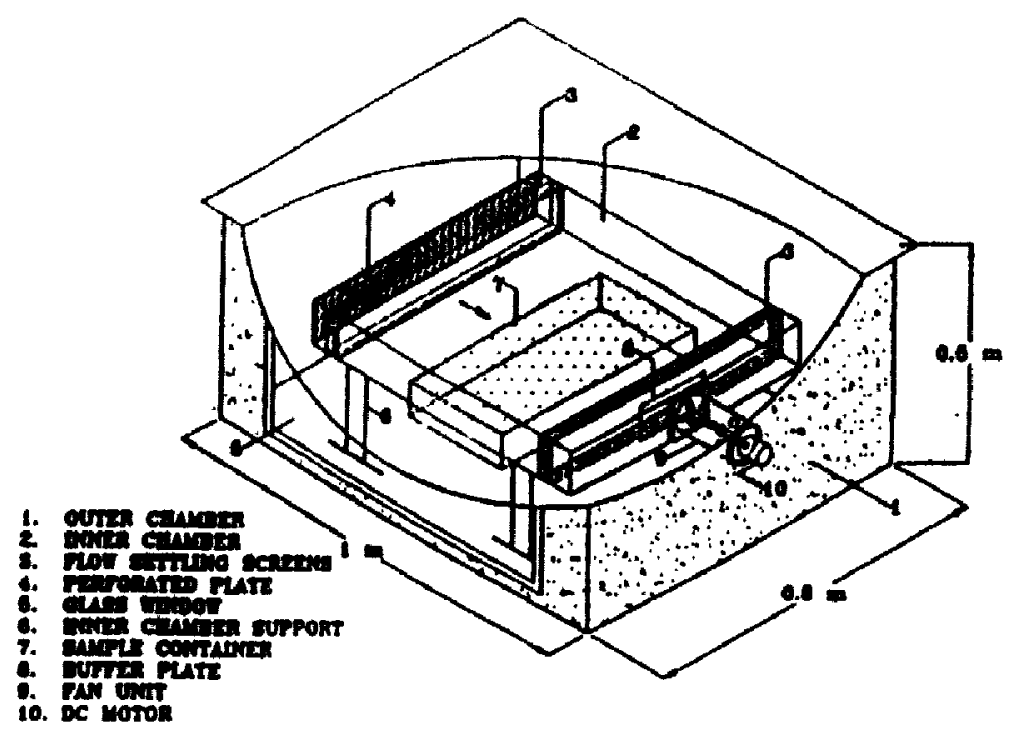

Figure 3.2 a: Chamber Schematic

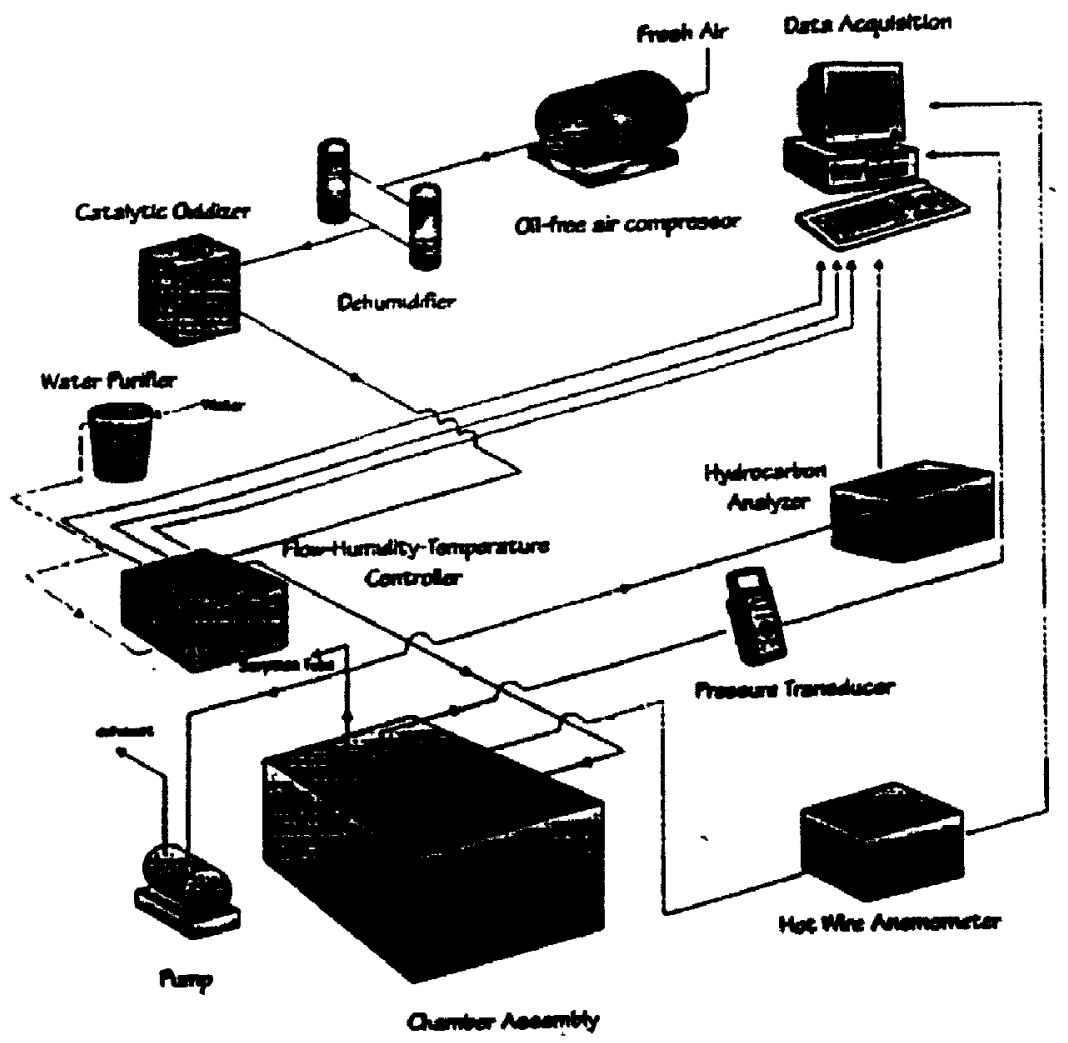

Figure 3.2 b: System Schematic 
Figure 3.3 a: Photograph of Chamber in Test Room

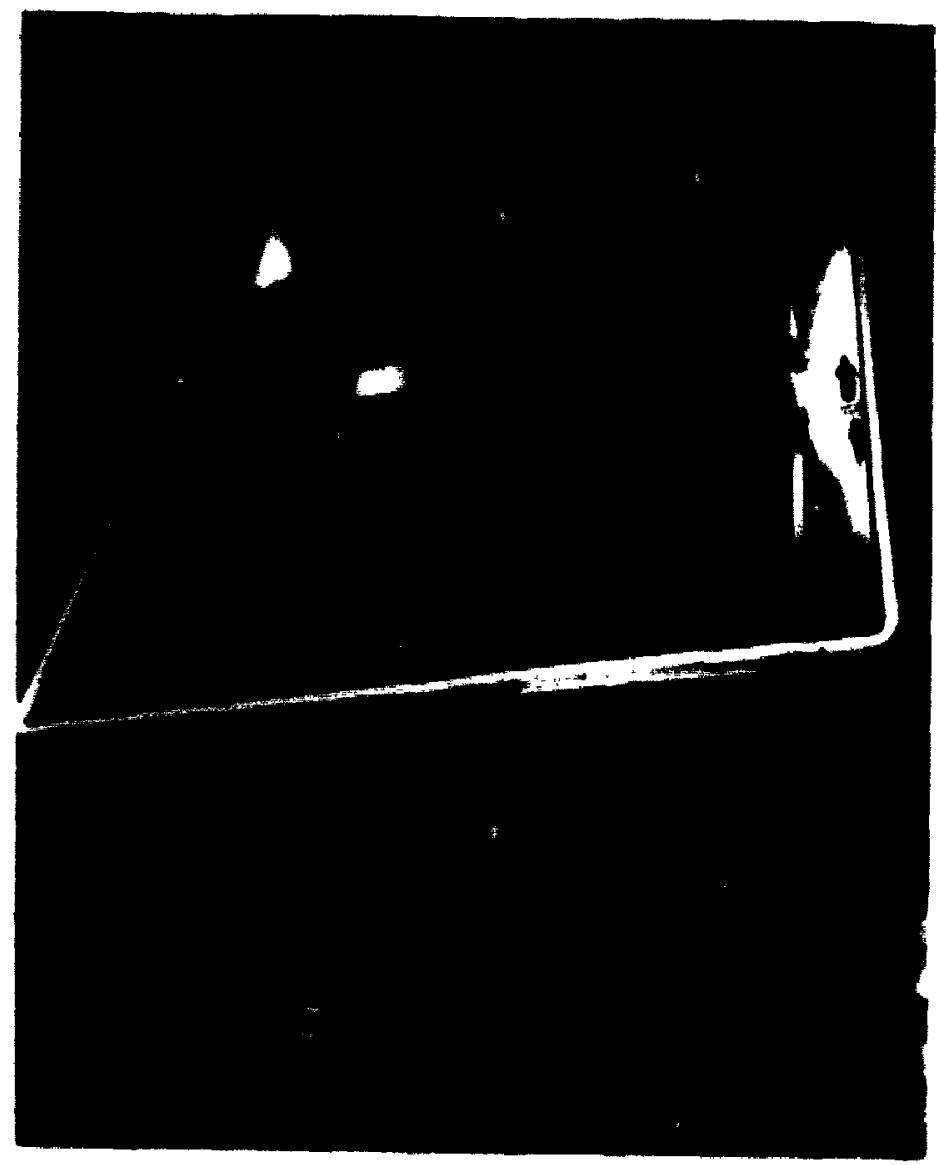

Figure $3.3 \mathrm{~b}$ : Photograph of Assembled Inner Chamber in Outer Chamber 


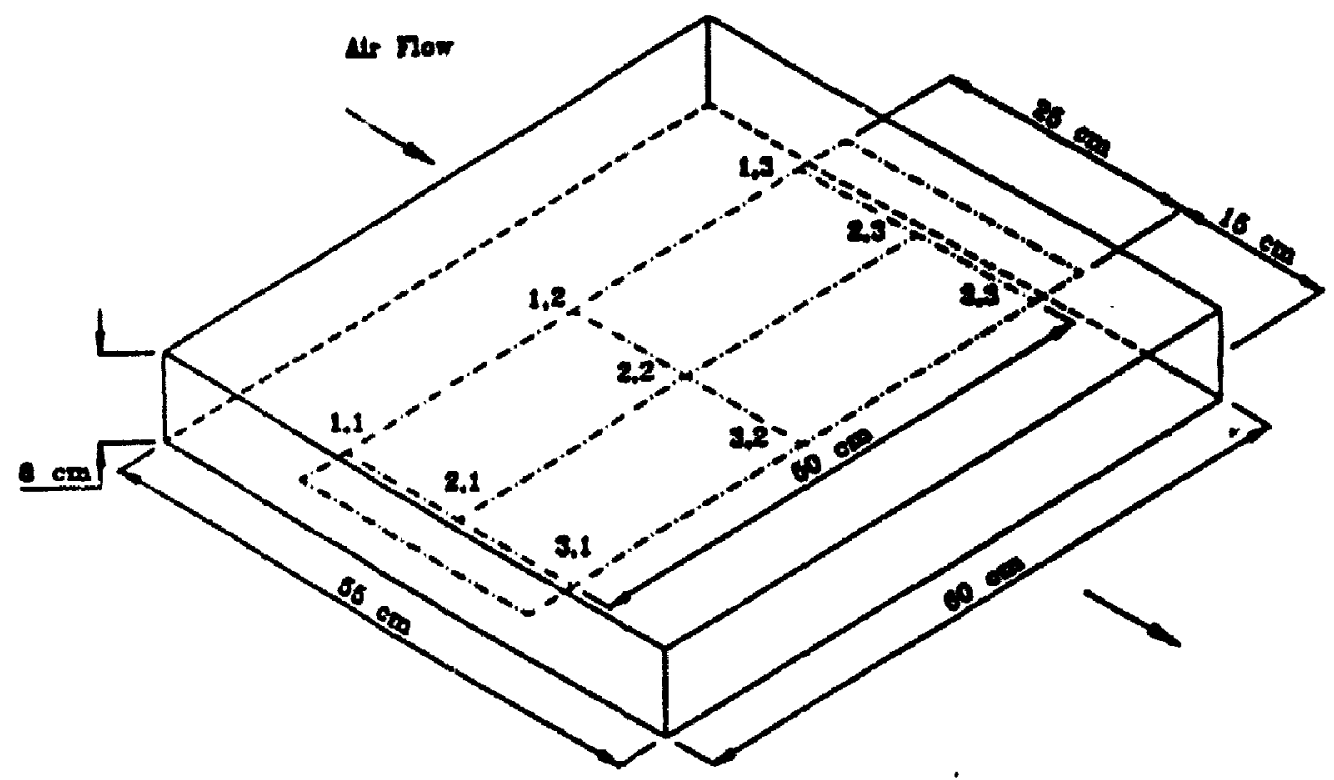

Figure 3.4 a: Inner Chamber Dimensions

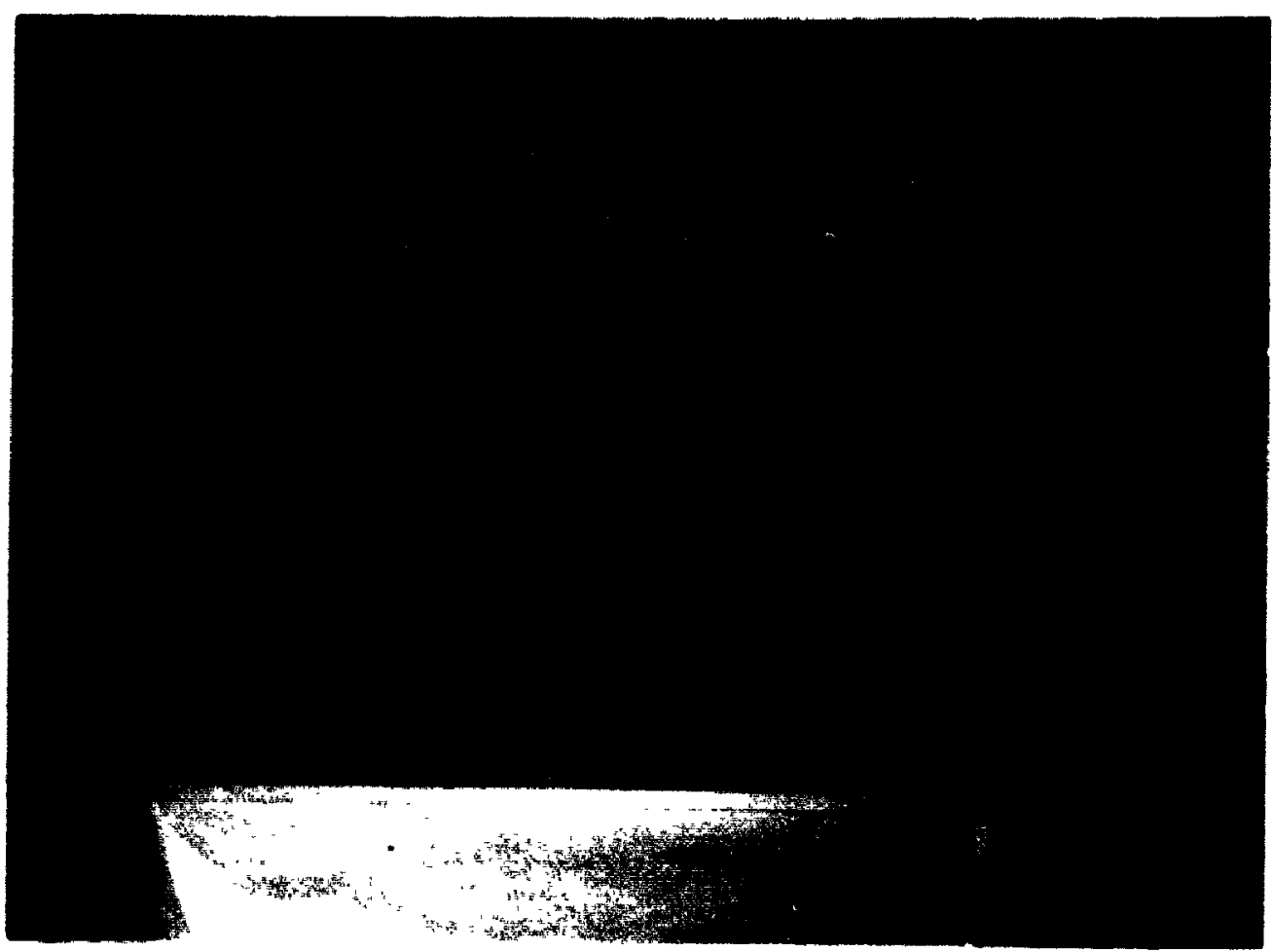

Figure 3.4 b: Photograph of Sample in Inner Chamber 


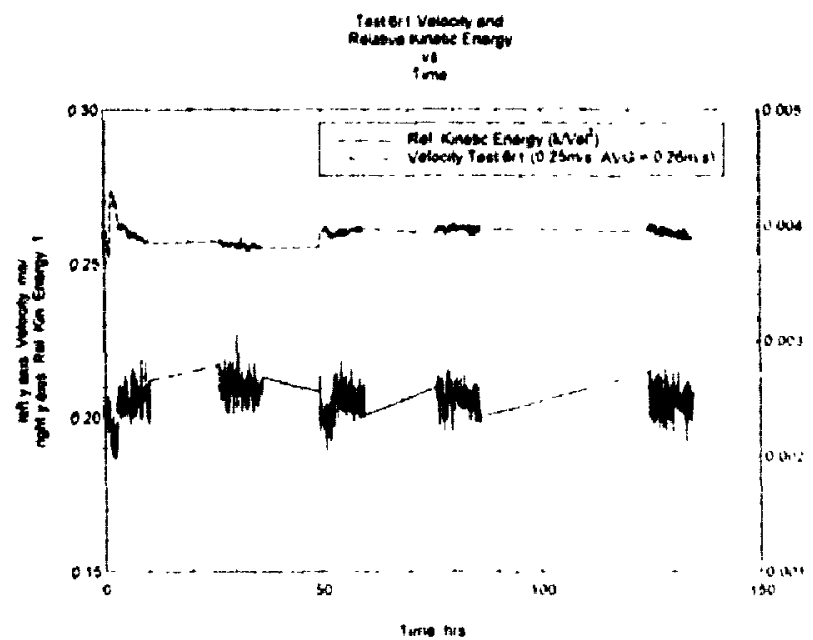

Figure $5.3 \mathrm{~d}$ : Velocity and Turbulence - Test $6 \mathrm{rl}$

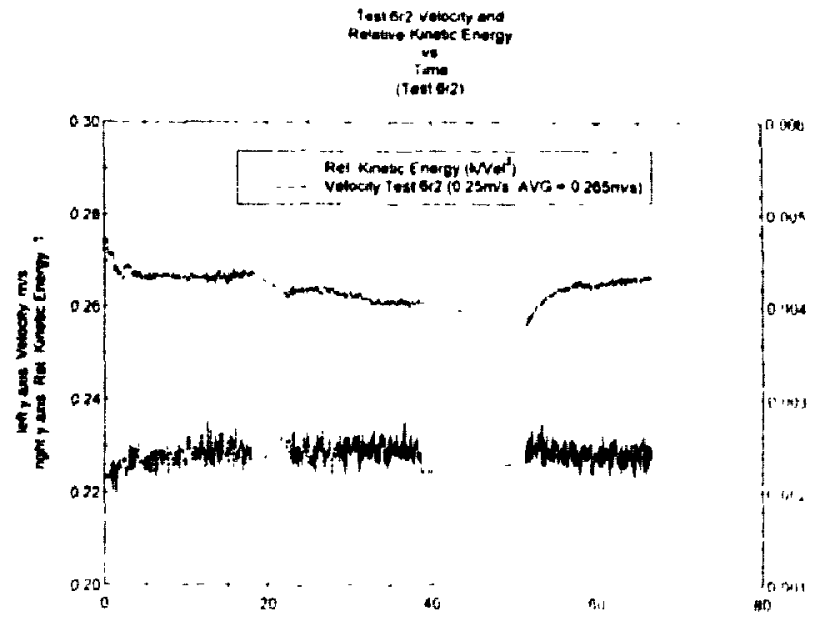

Figure 5.3 e: Velocity and Turbulence - Test $6 \mathrm{r} 2$

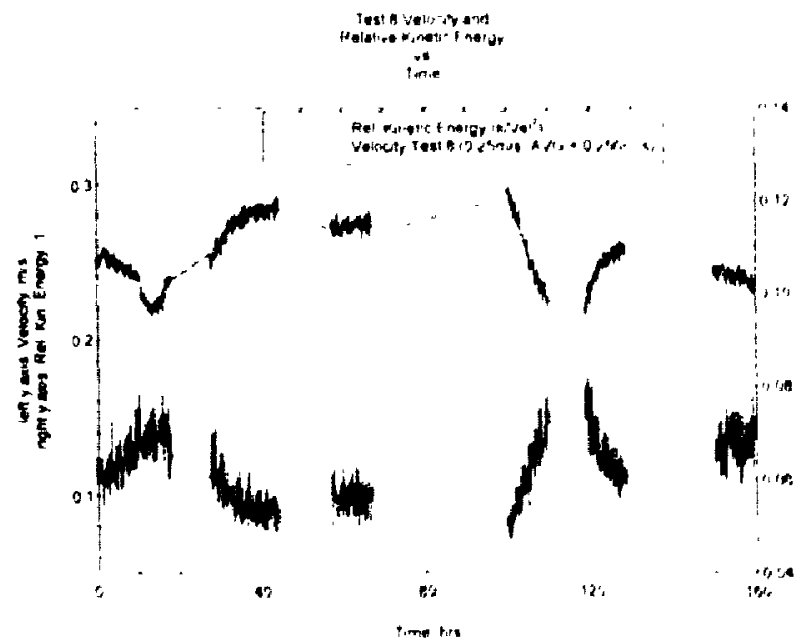

Figure $5.3 \mathrm{f}:$ Velocity and Turbulence - Test 8 


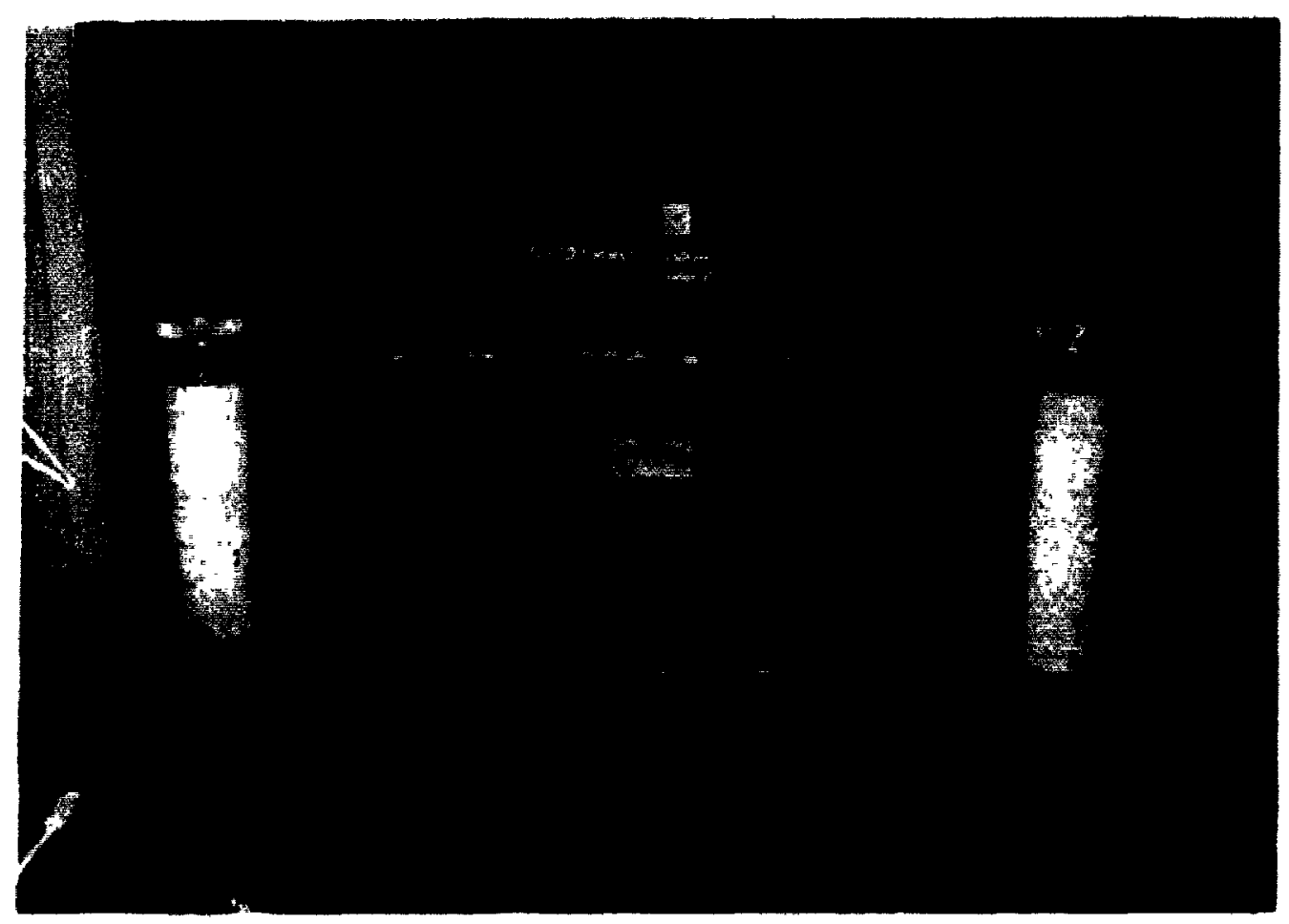

Figure 3.7: Photograph of Dehumidification System (Drierite Desiccant)

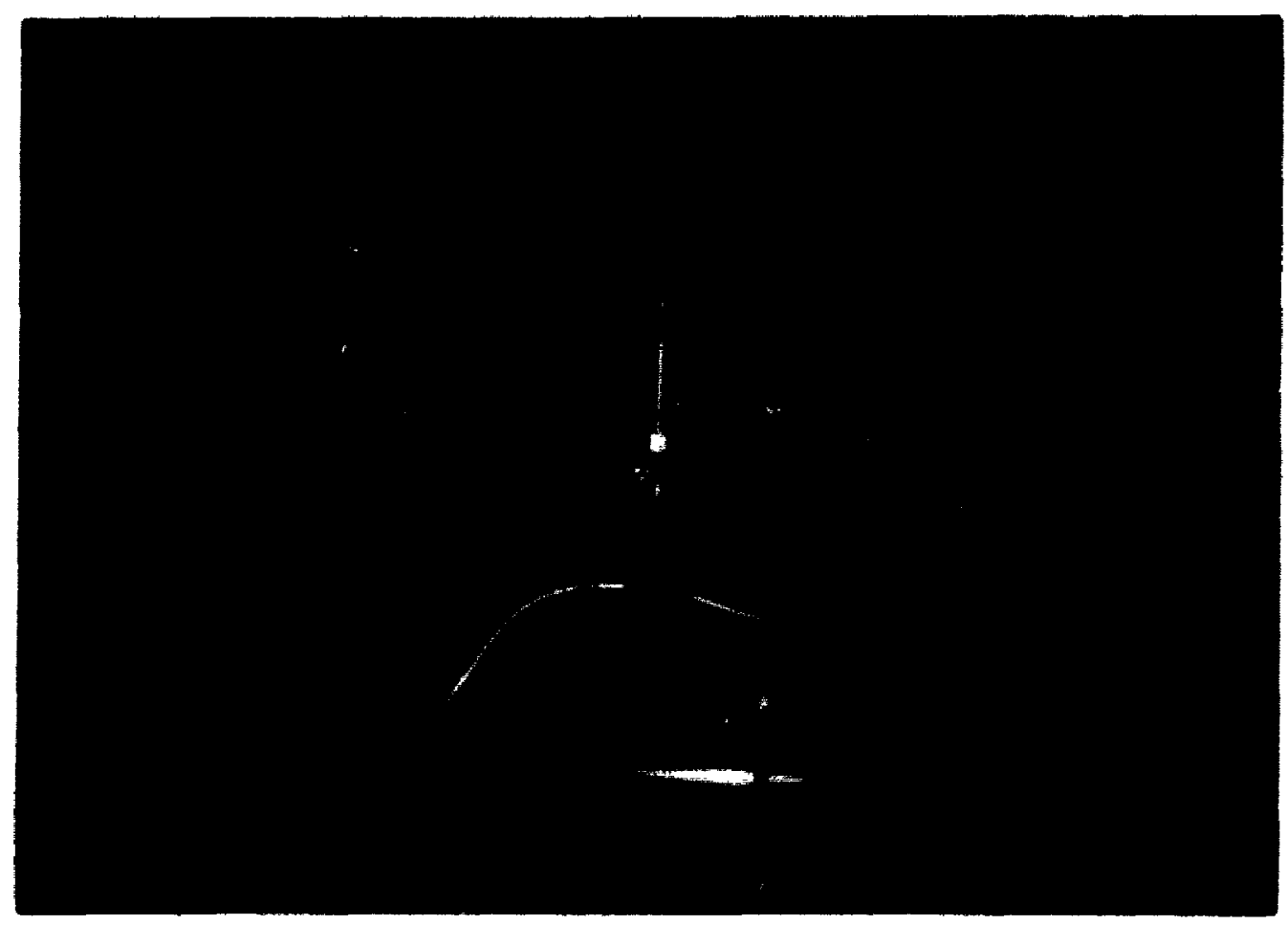

Figure 3.8: Photograph of Sampling Line Connection 


\section{GC Mothod Temp vs Time Ramp}

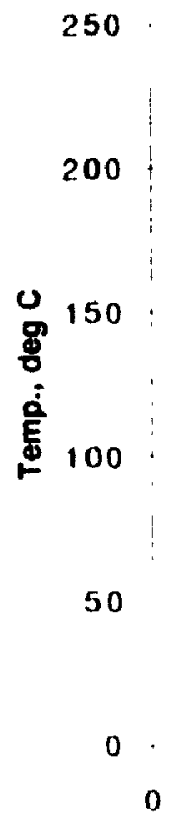

12

19

39

a!

34

Figure 3.9: GC Method - Temperature Ramp vs Time 


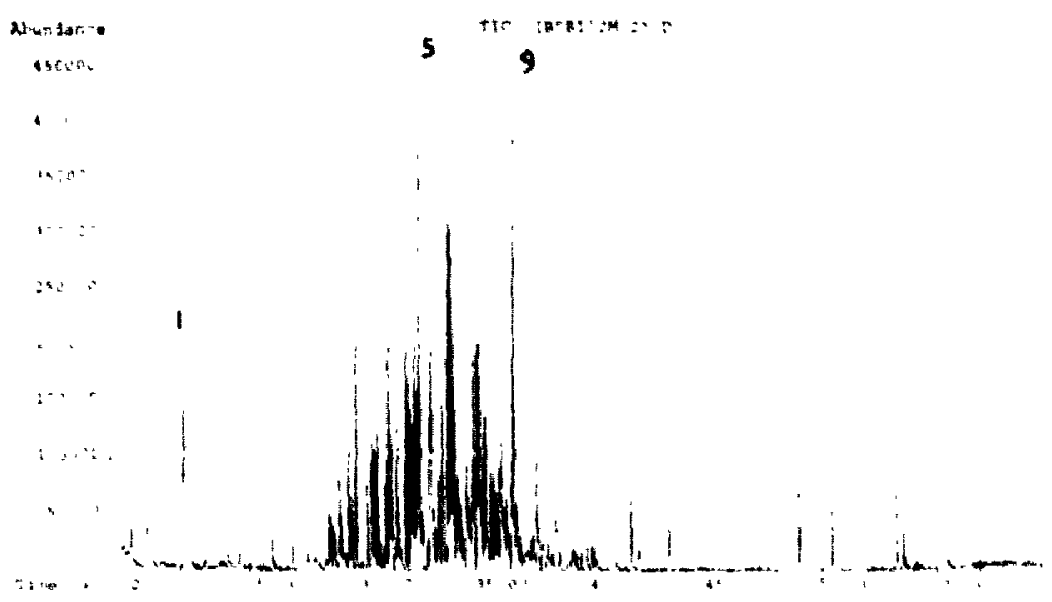

Figure 5.1 a: Headspace Results - Adhesive I (0.5 $\mathrm{ml})$

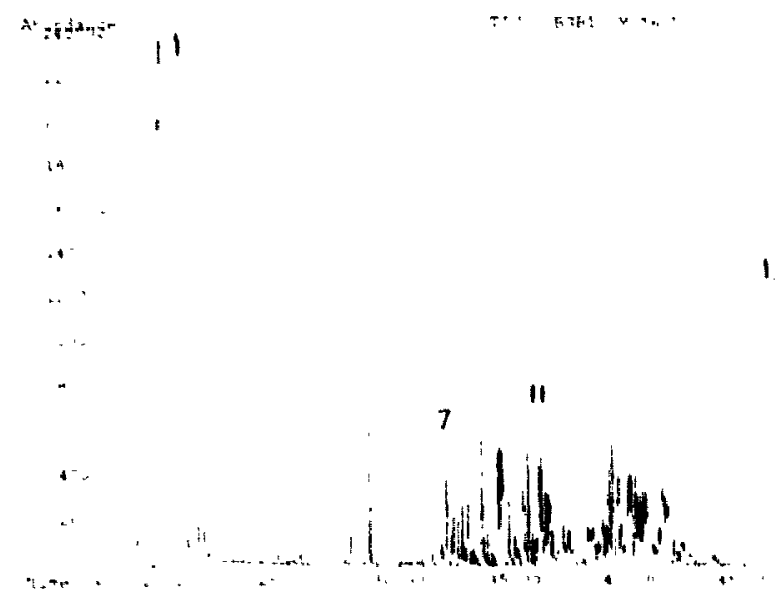

Figure $5.1 \mathrm{~b}$ : Headpsace Results - Adhesive $2(0.5 \mathrm{ml})$

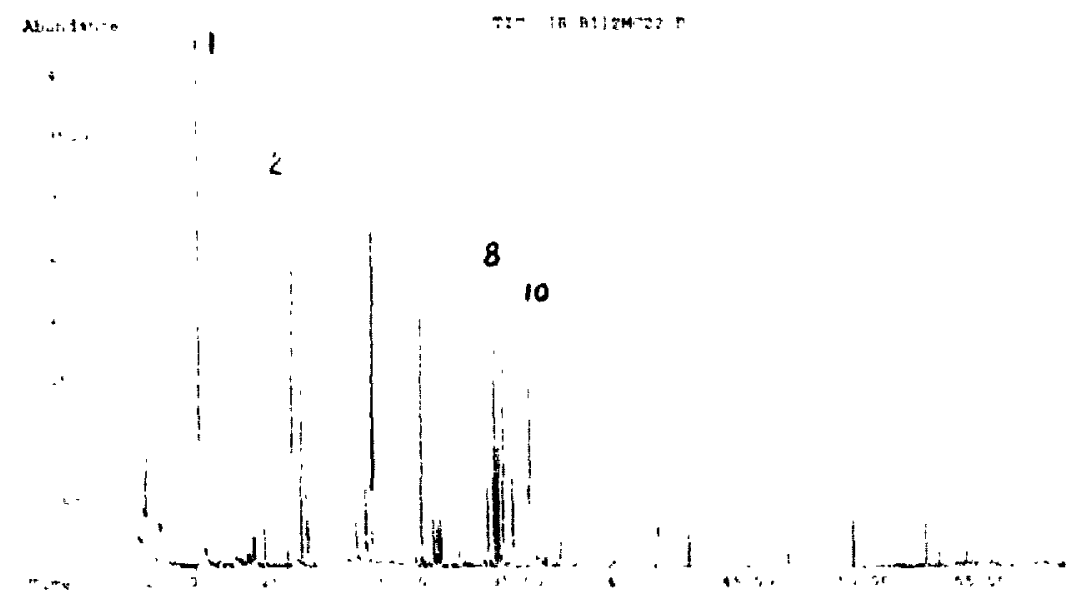

Figure 5.1 c: Headpsace Results - Adhesive $3(0.5 \mathrm{ml})$ 


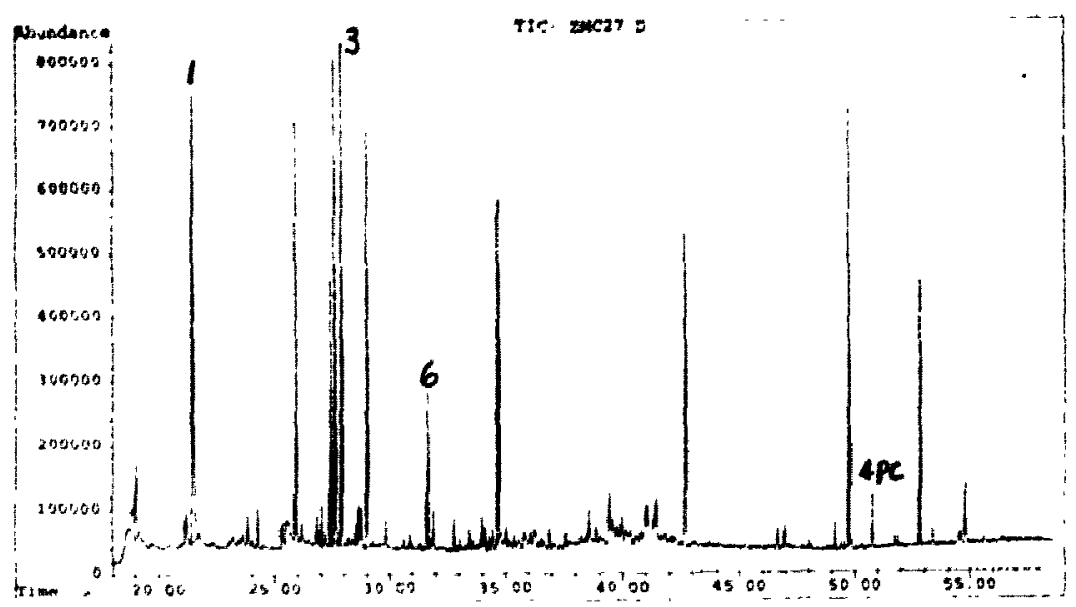

Figure 5.1 d: Headspace Results - Camei $\subseteq(100 \mathrm{ml})$

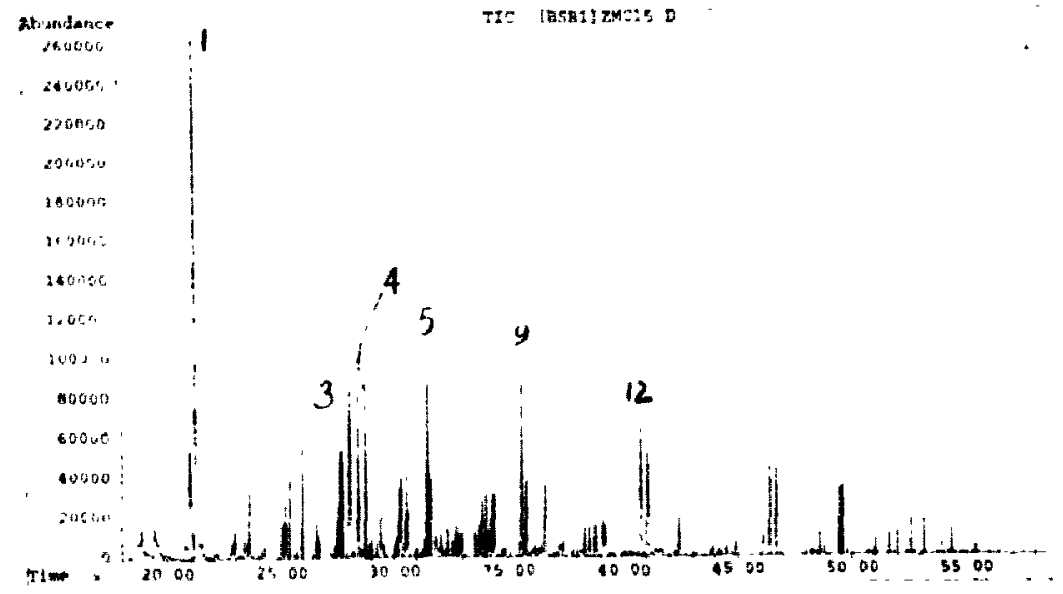

Figure 5.1 e: Headspace Results - Concrete $(1970 \mathrm{ml})$ 


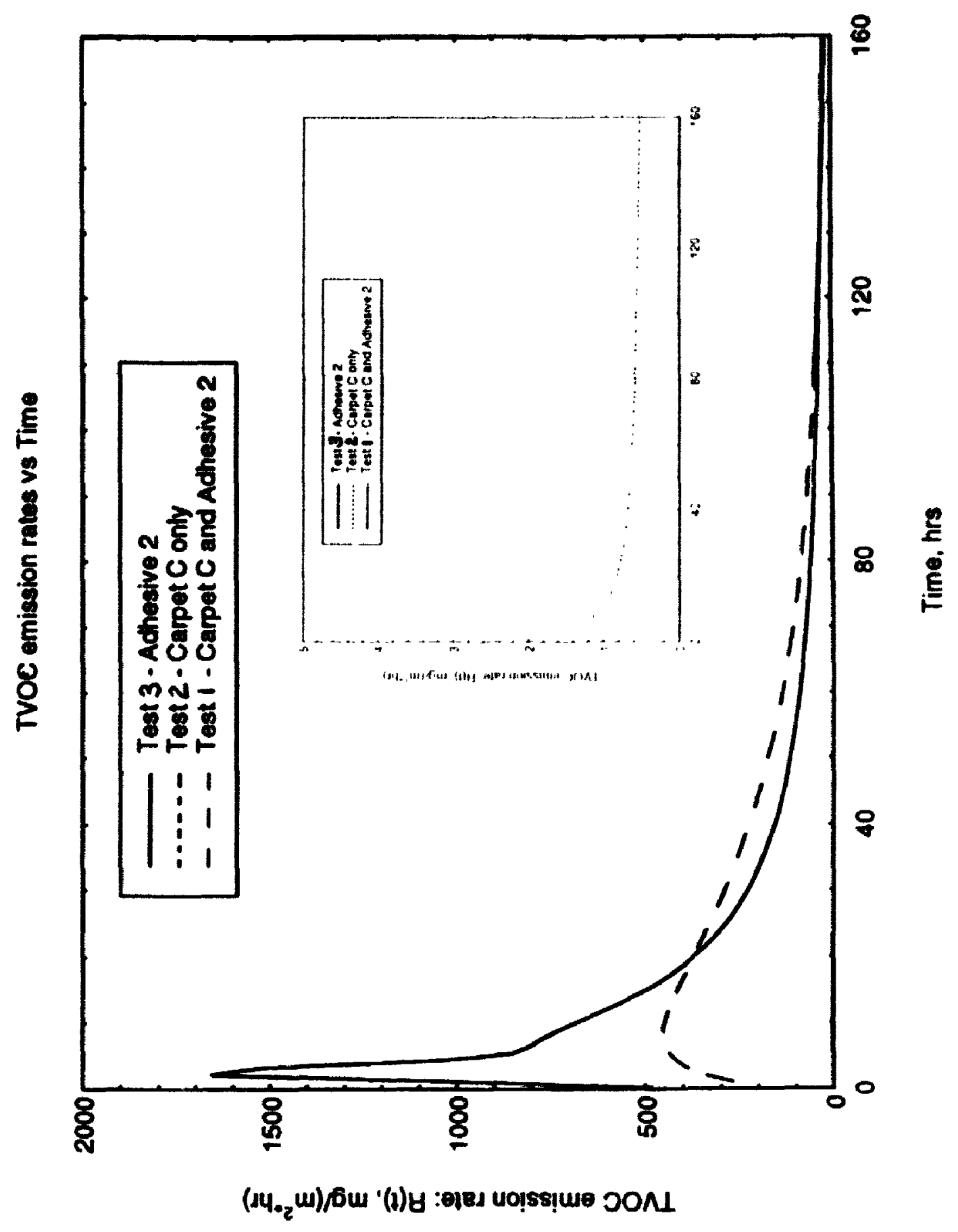

Figure 5.2: TVOC Emission Rates - Test 1, 2, \& 3 


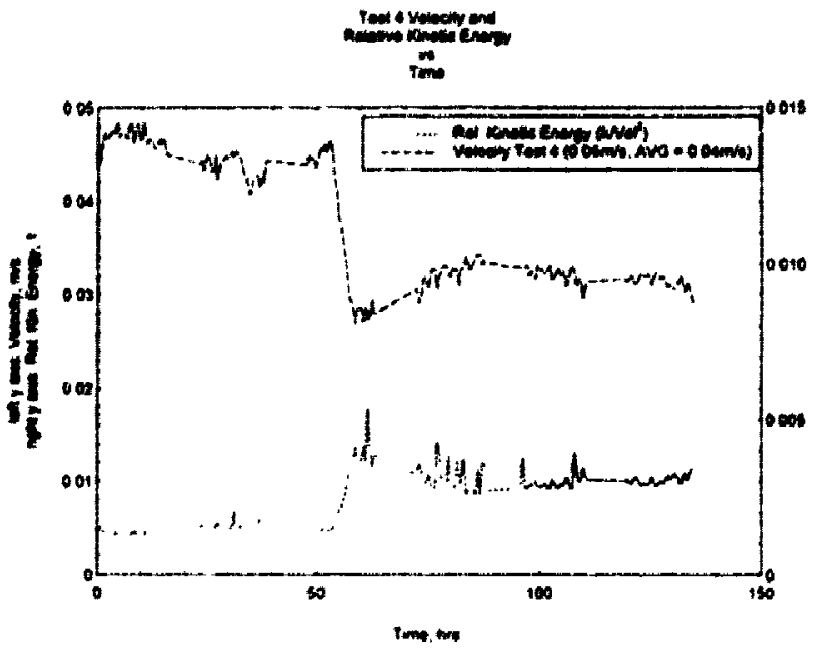

Figure 5.3 a: Velocity and Turbulence - Test 4

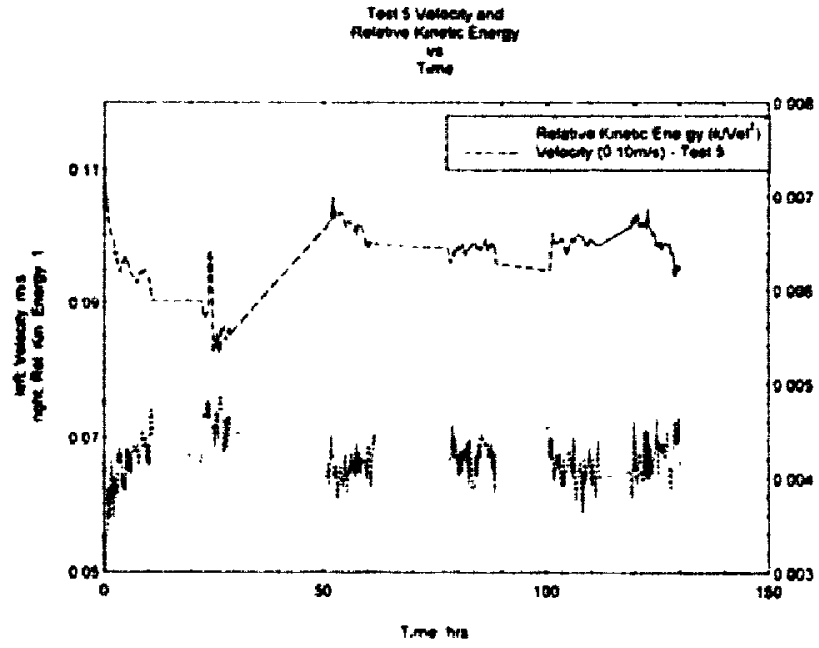

Figure 5.3 b: Velocity and Turbulence - Test 5

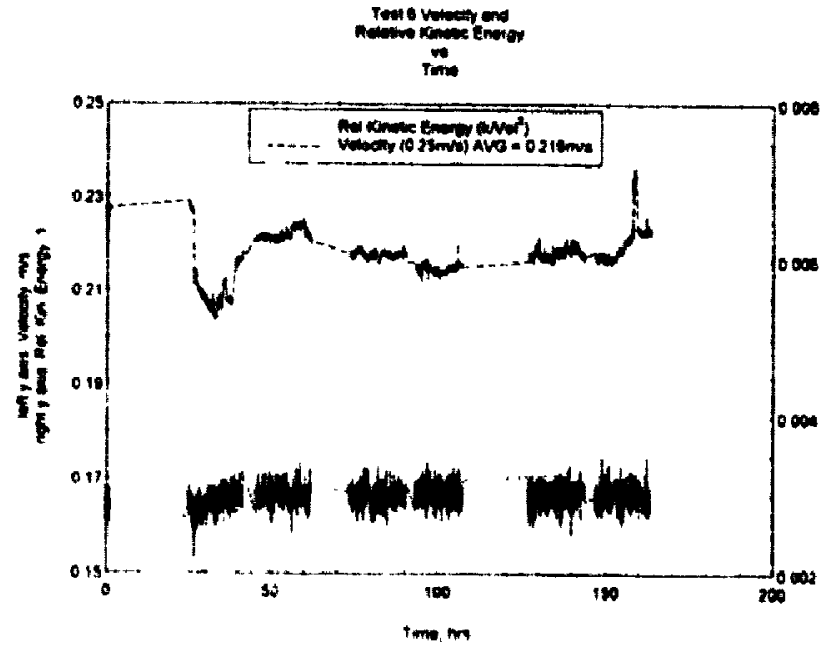

Figure 5.3 c: Velocity and Turbulence - Test 6 


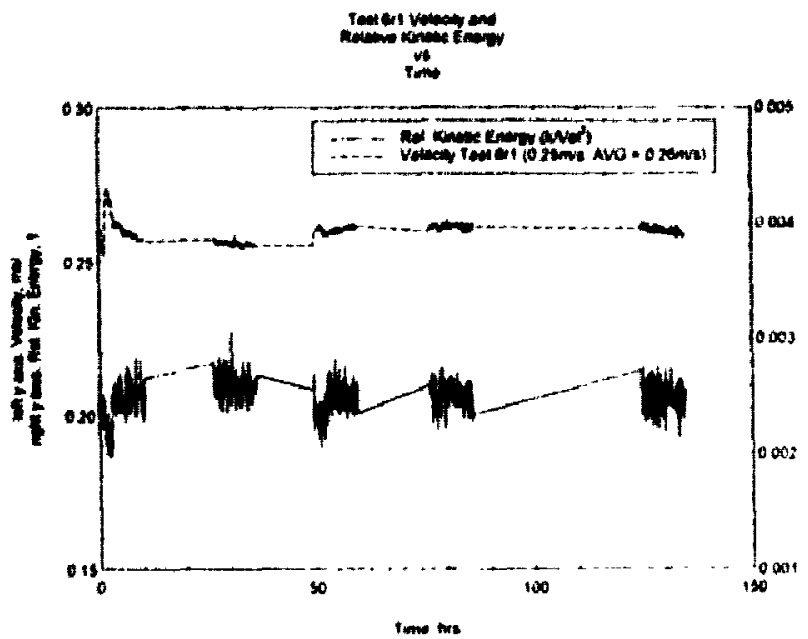

Figure $5.3 \mathrm{~d}$ : Velocity and Turbulence - Test 6rl

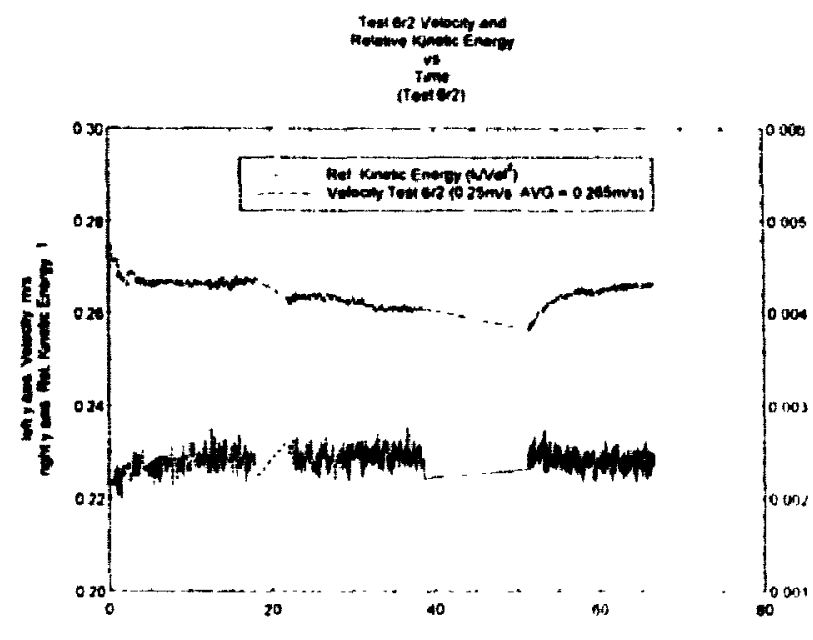

Figure 5.3 e: Velocity and Turbulence - Test $6 r 2$

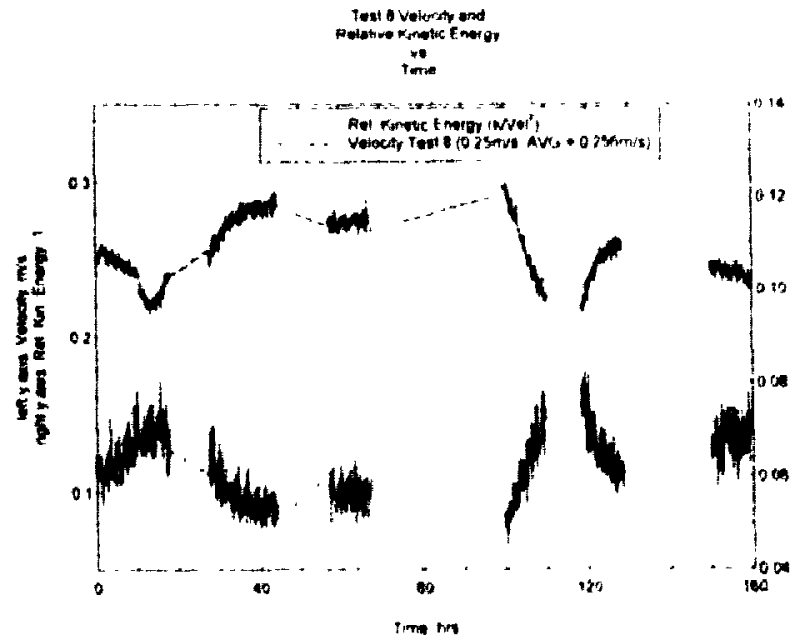

Figure $5.3 \mathrm{f}$ : Velocity and Turbulence - Test 8 


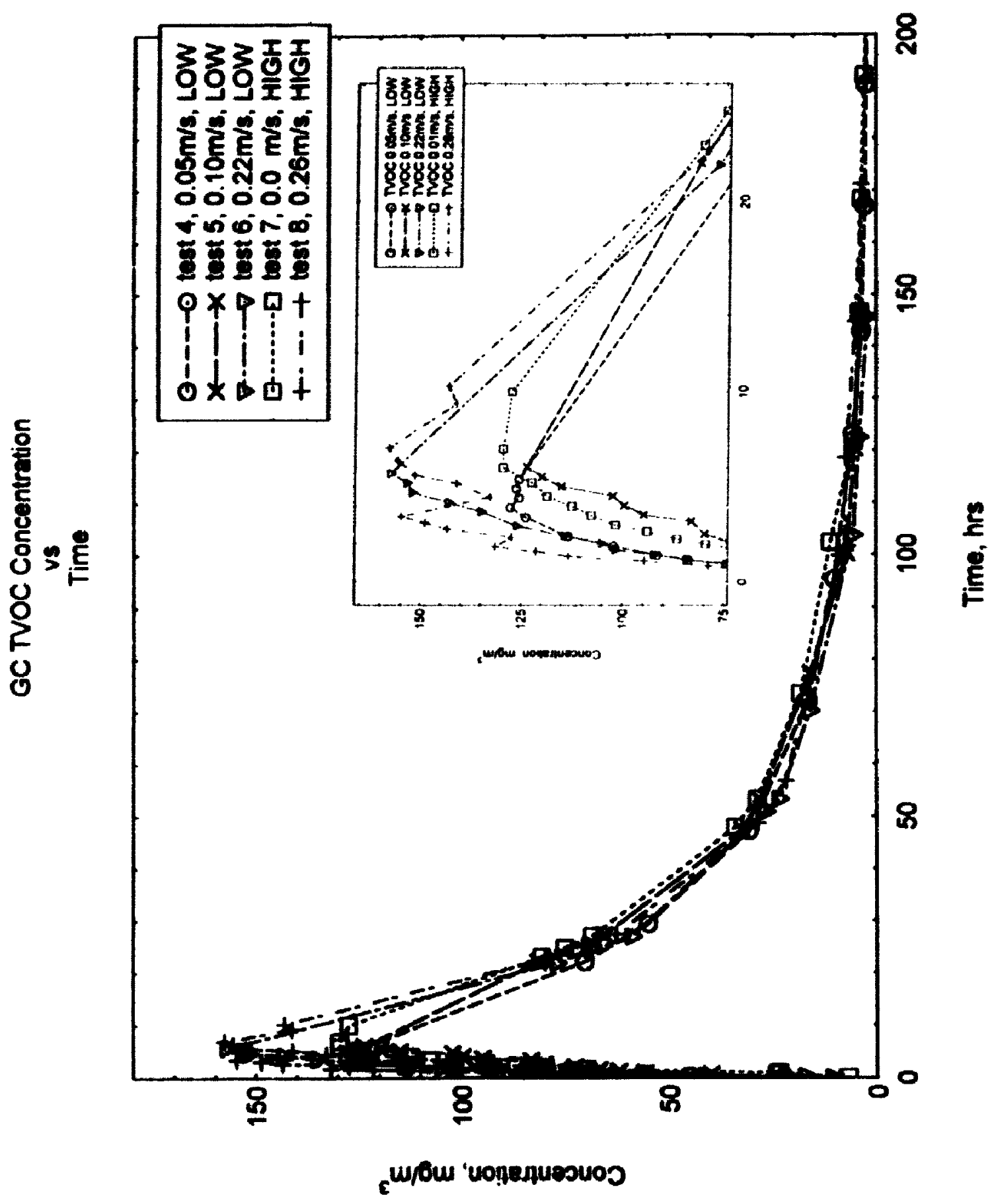

Figure 5.4: TVOC Concentration vs Time 


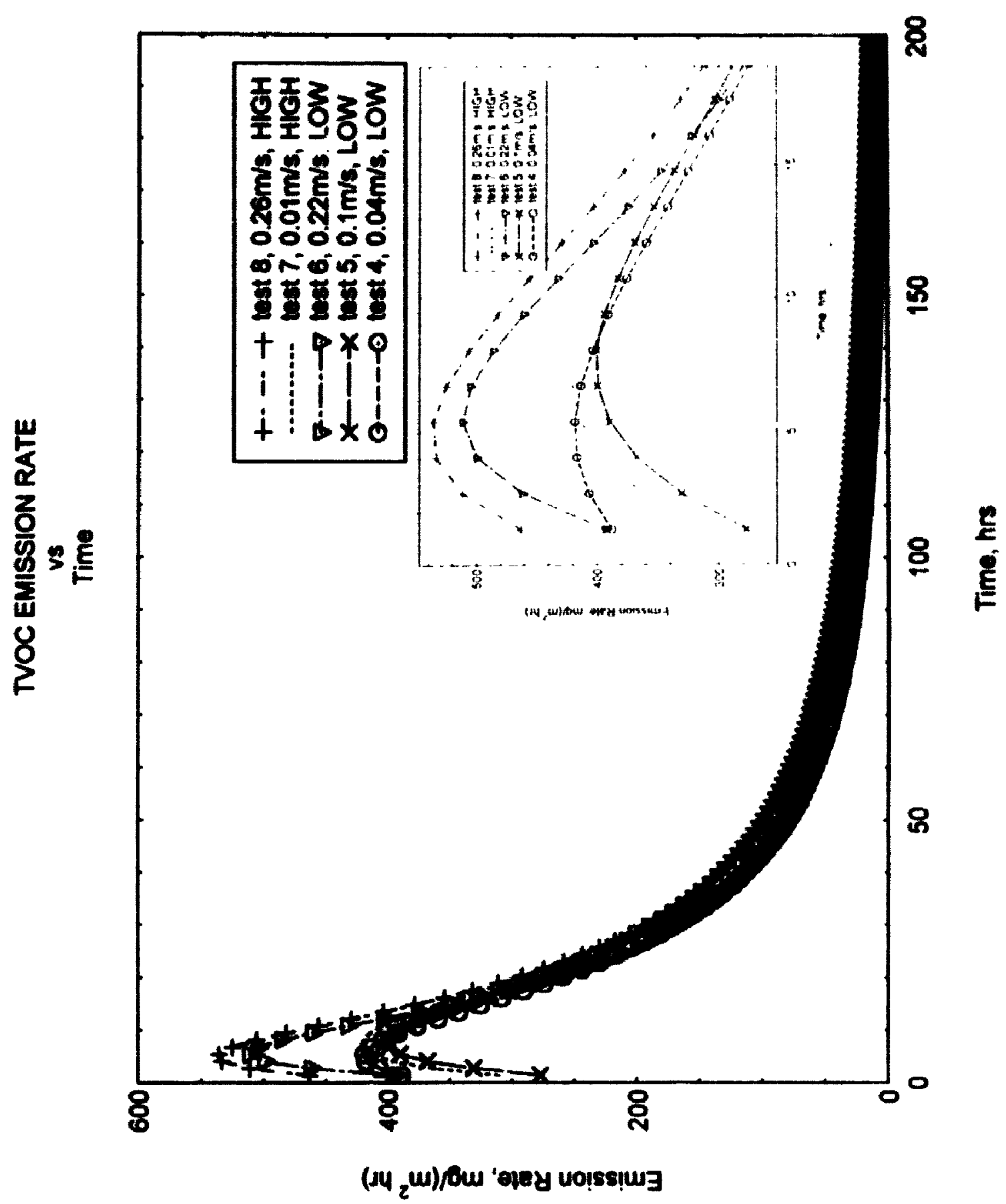

Figure 5.5: TVOC Emission Rate vs Time 


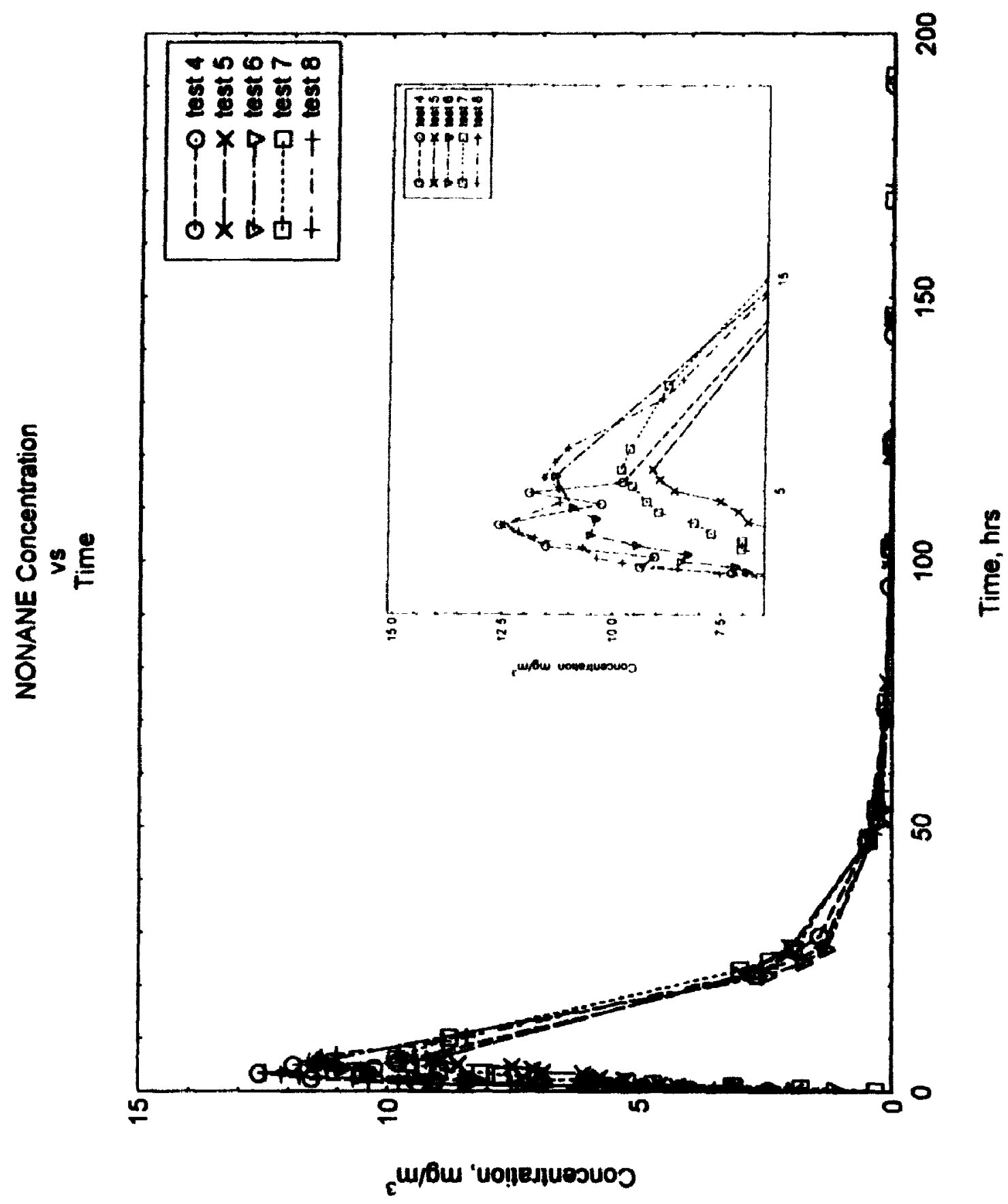

Figure 5.6: Nonane Concentration vs Time 


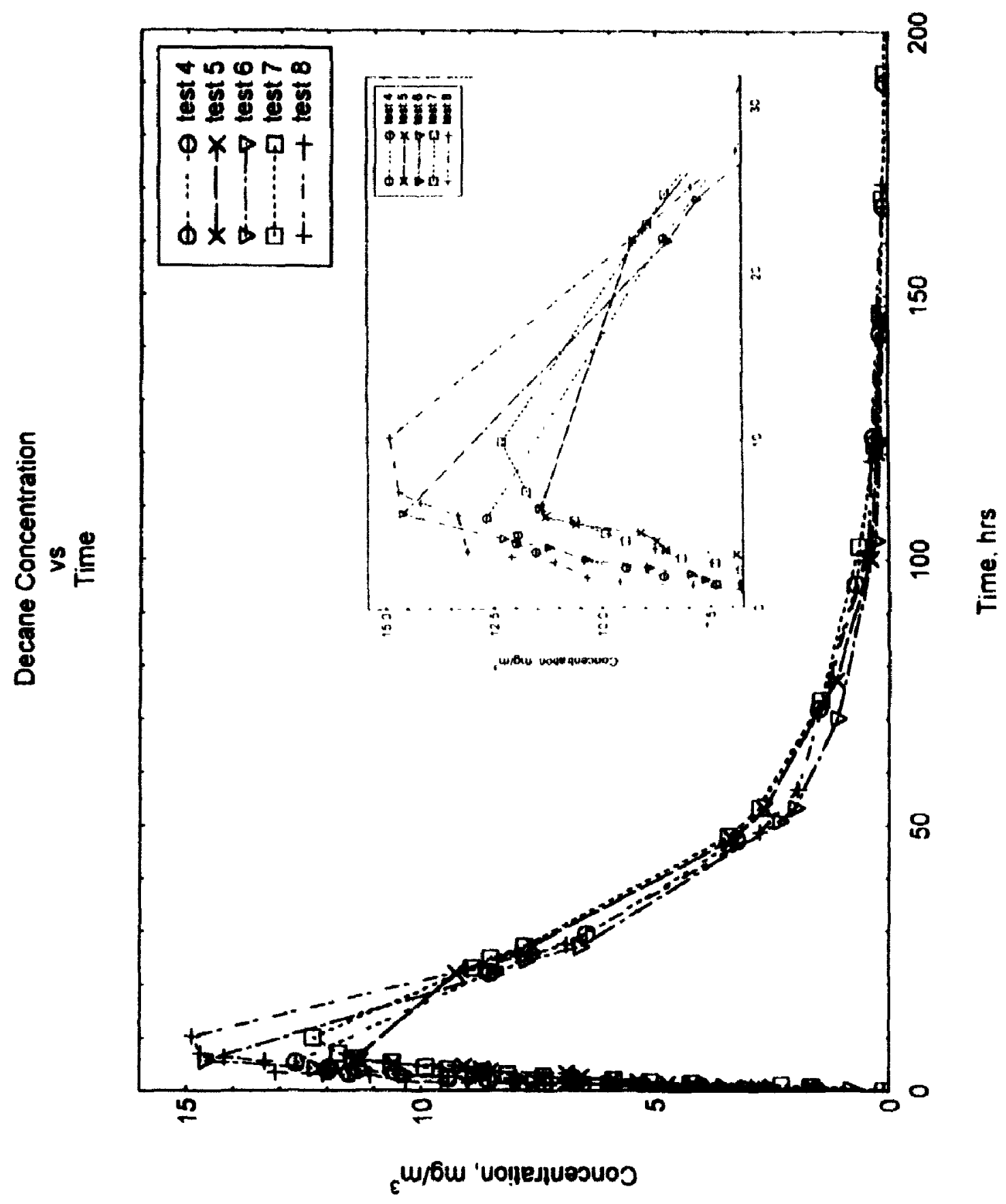

Figure 5.7: Decane Concentration vs Time 


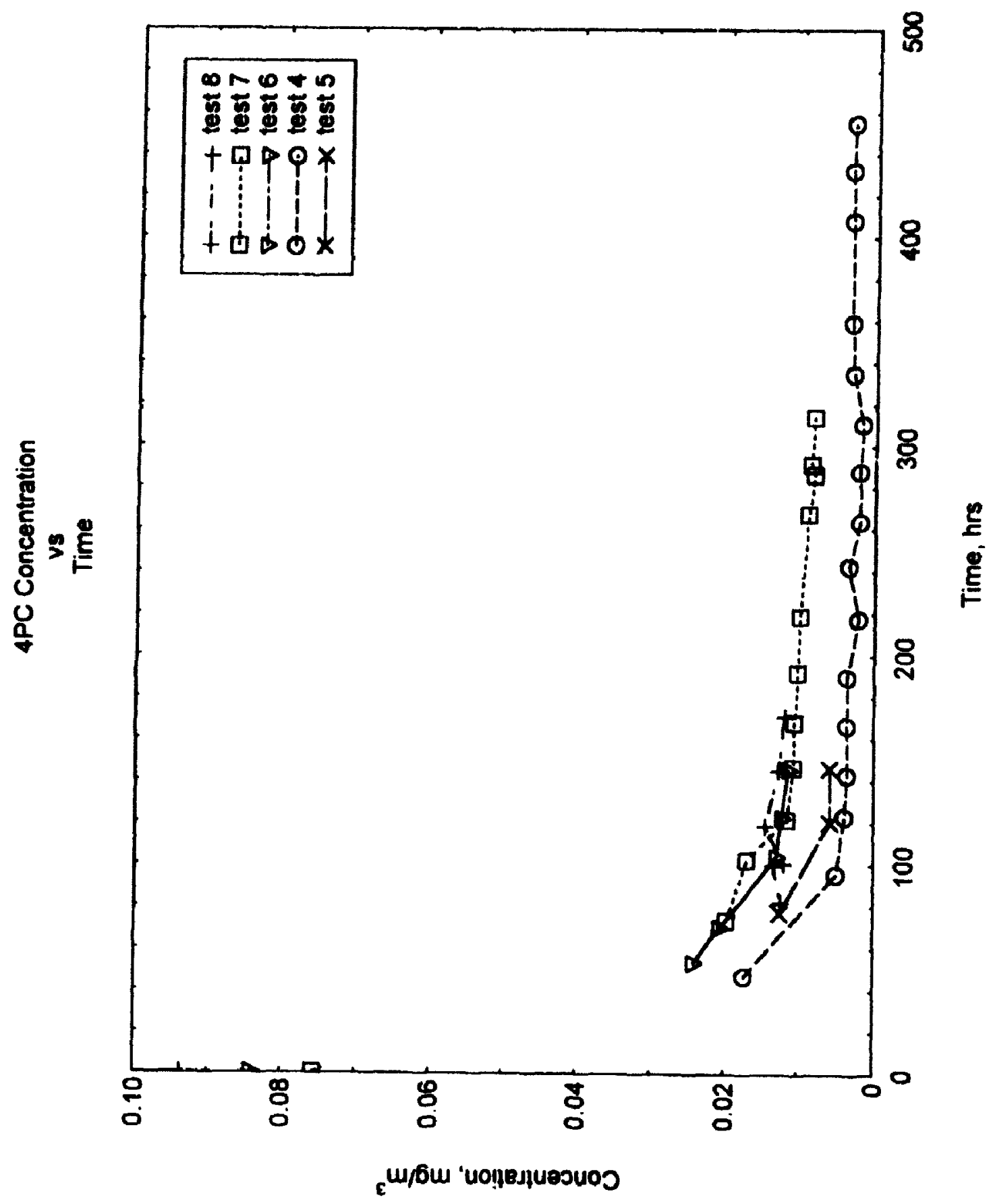

ligure 5.8: 4PC Concentration vs Time 


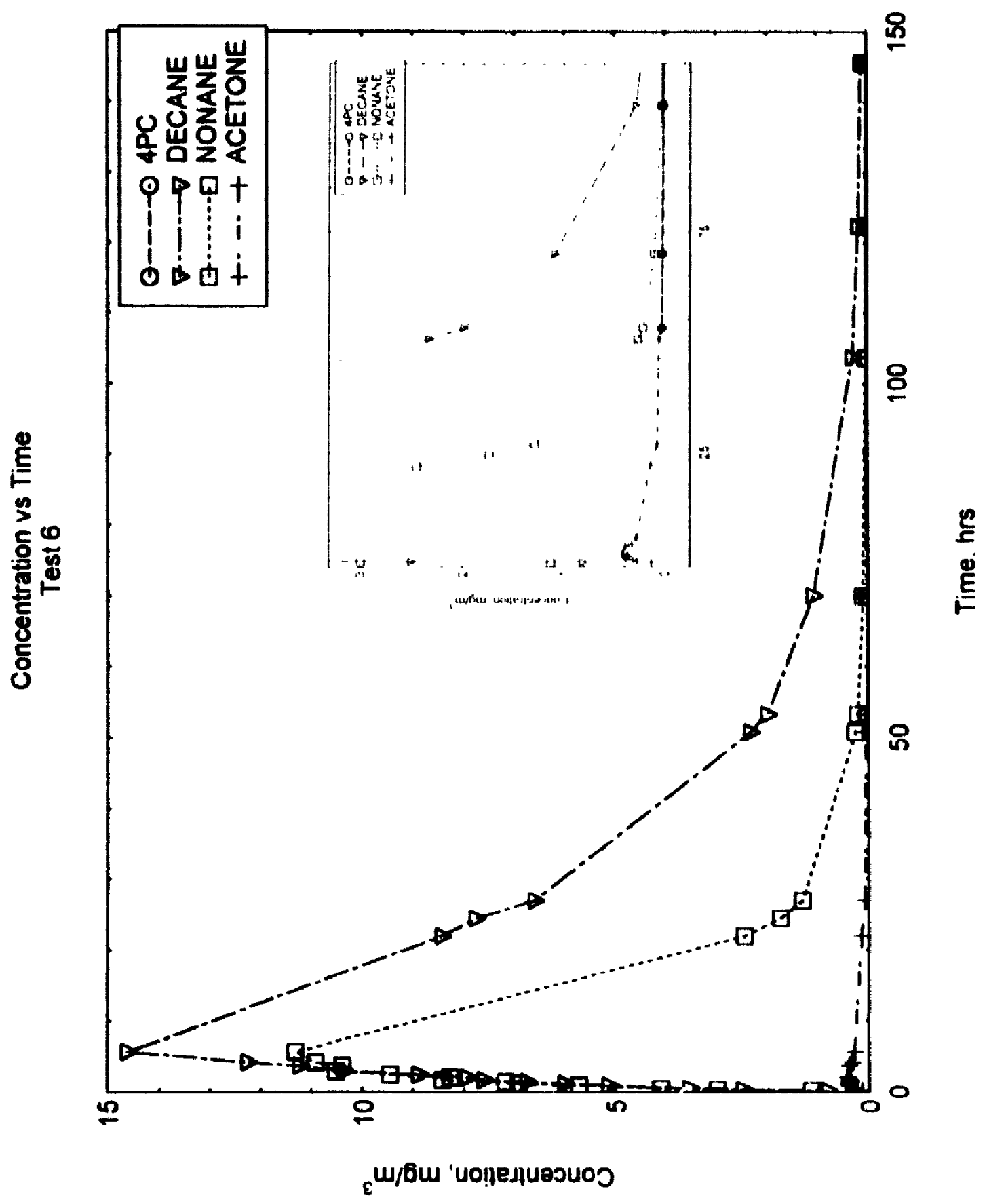

Figure 5.9: Concentration vs Time - Test 6 - Acetone, Nonane, Decanc, and 4 PC: 


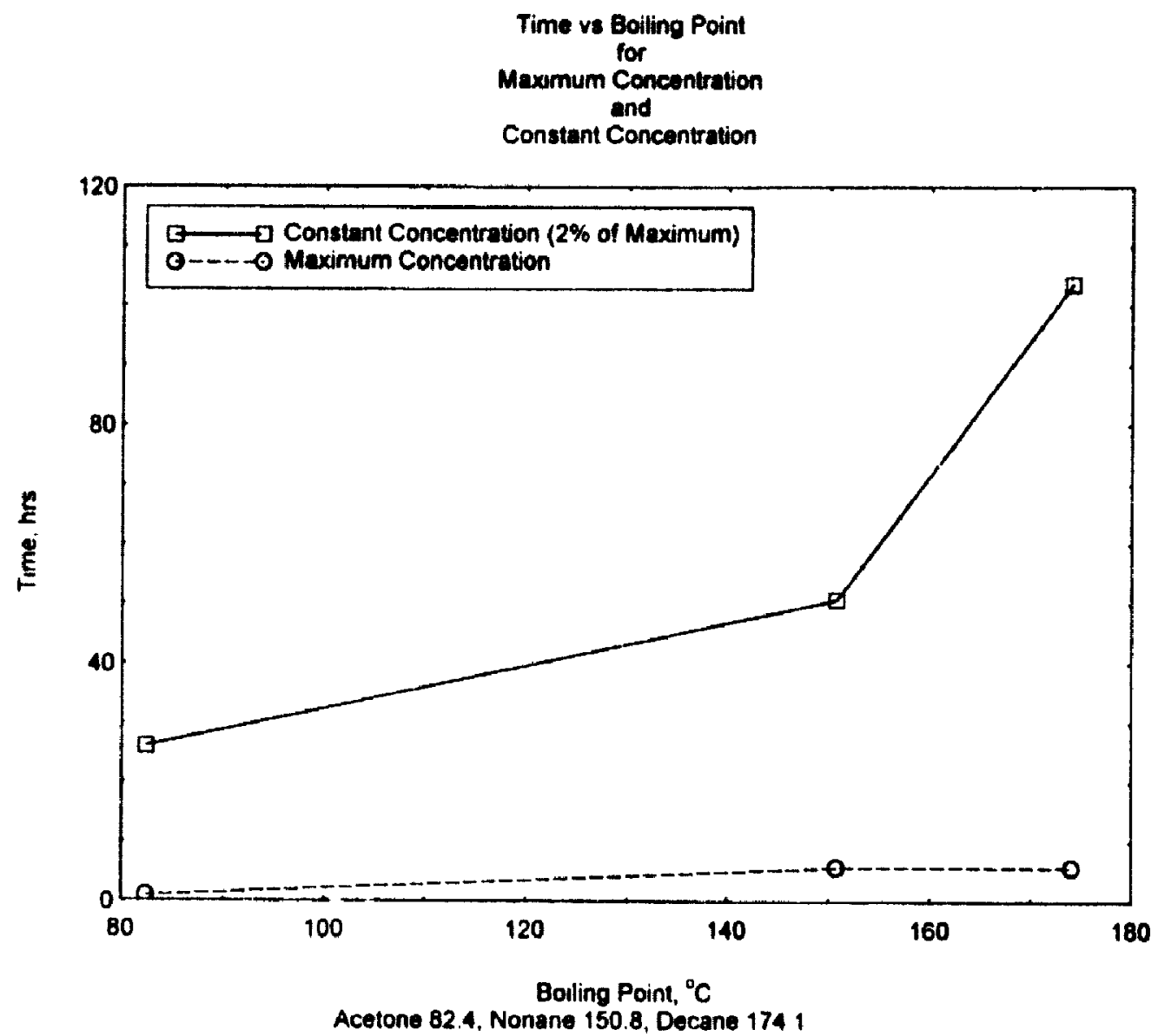

Figure 5.10: Time vs. Boiling Point for Maximum and Constant Concentrations 


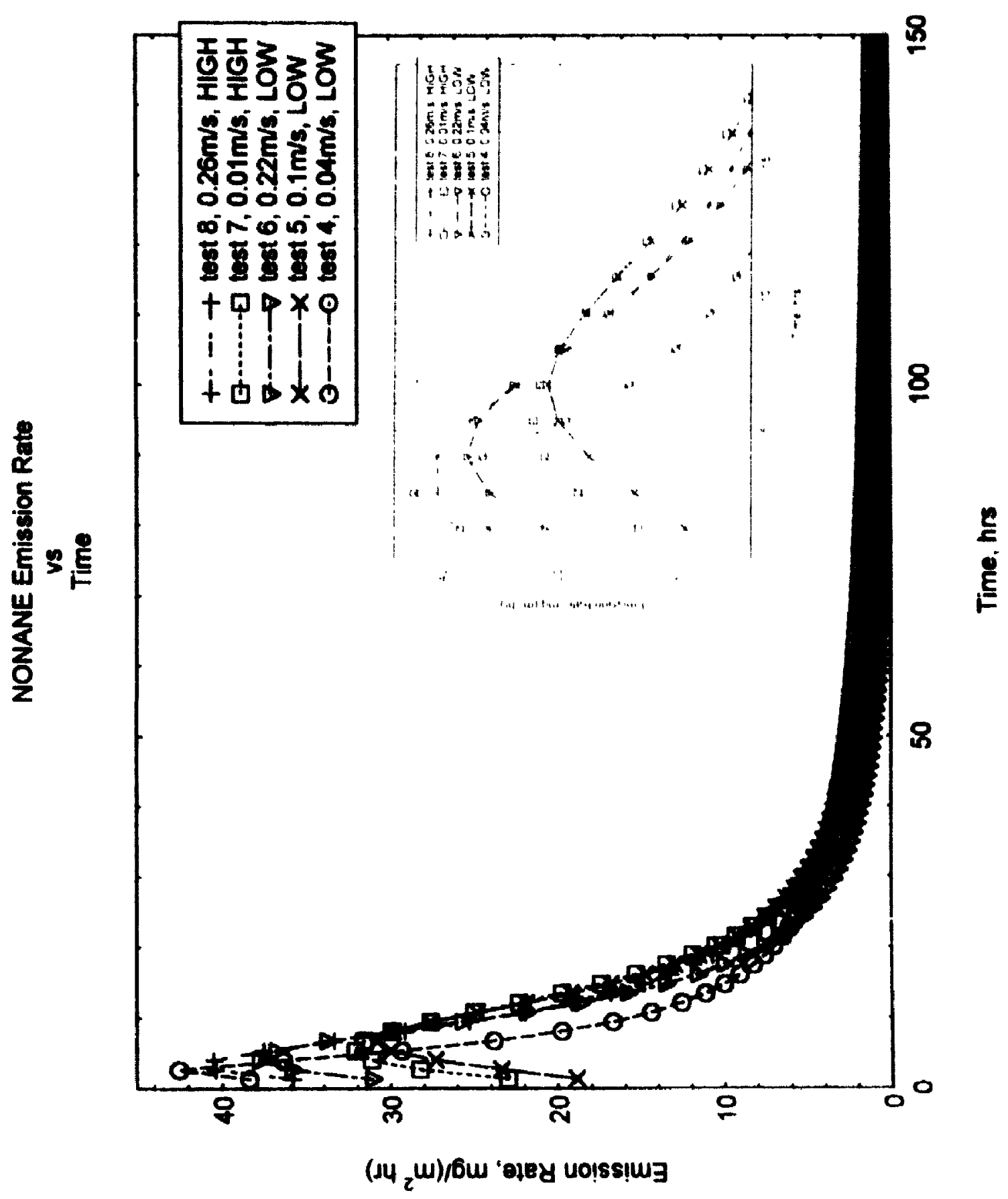

Figure 5.11: Nonane Emission Rate vs Time 


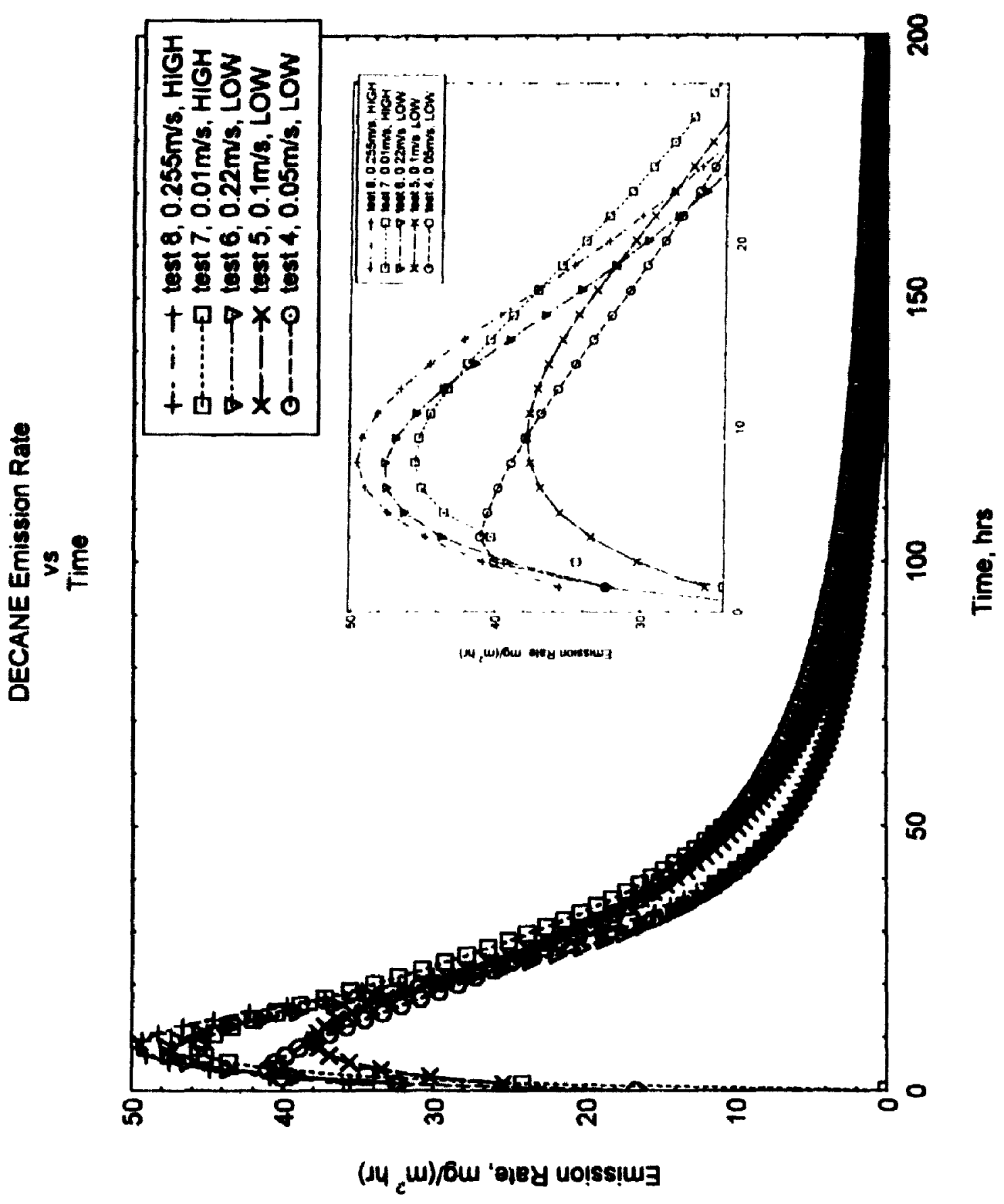

Figure 5.12: Decane Emission Rate vs Time 


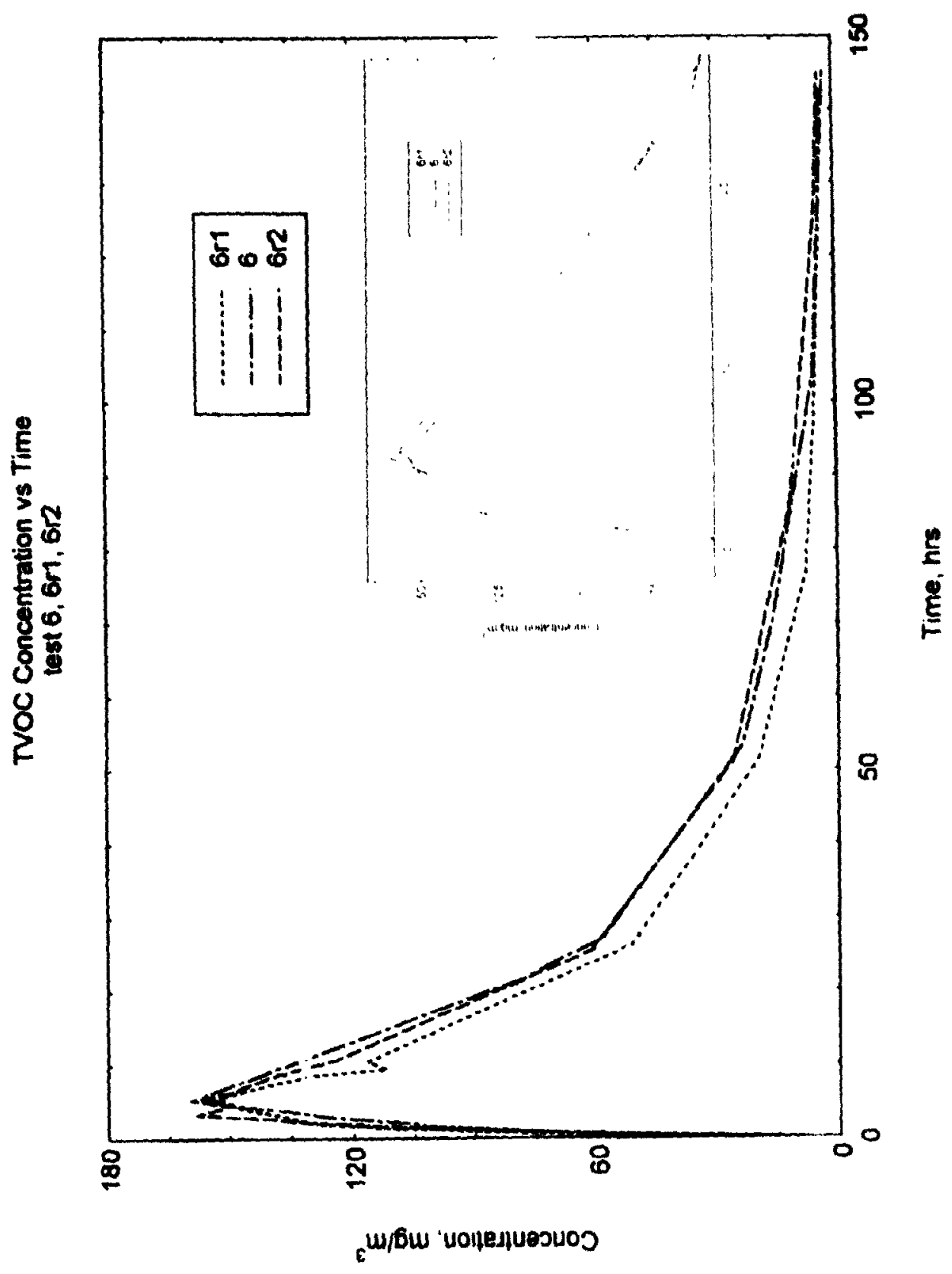

Figure 5.13: TVOC Concentration vs. 'lime - Test 6, Grl, \& 6r2. 


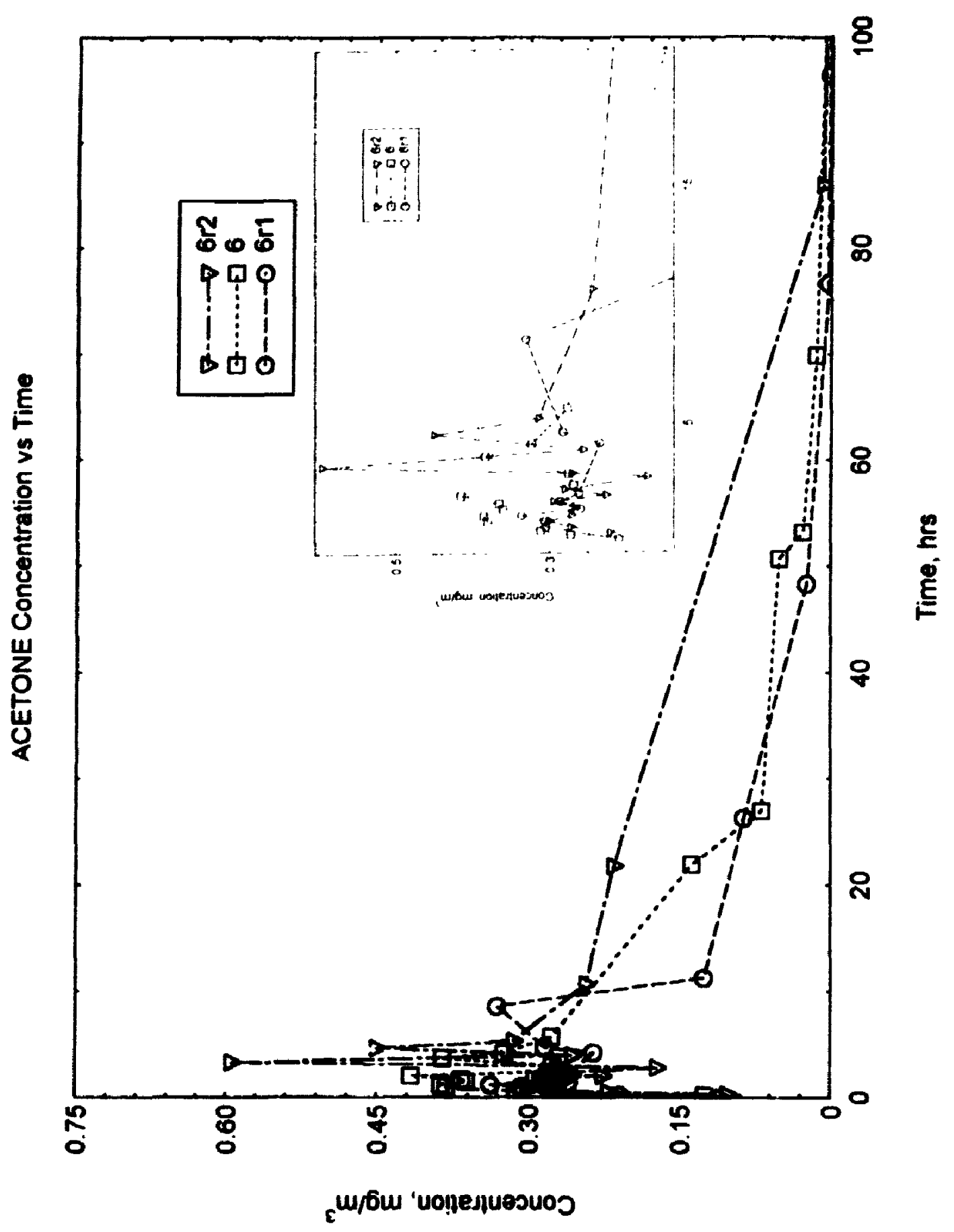

Figure 5.14: Acetone Concentration vs. Time - Test 6, 6r1, 6r2. 


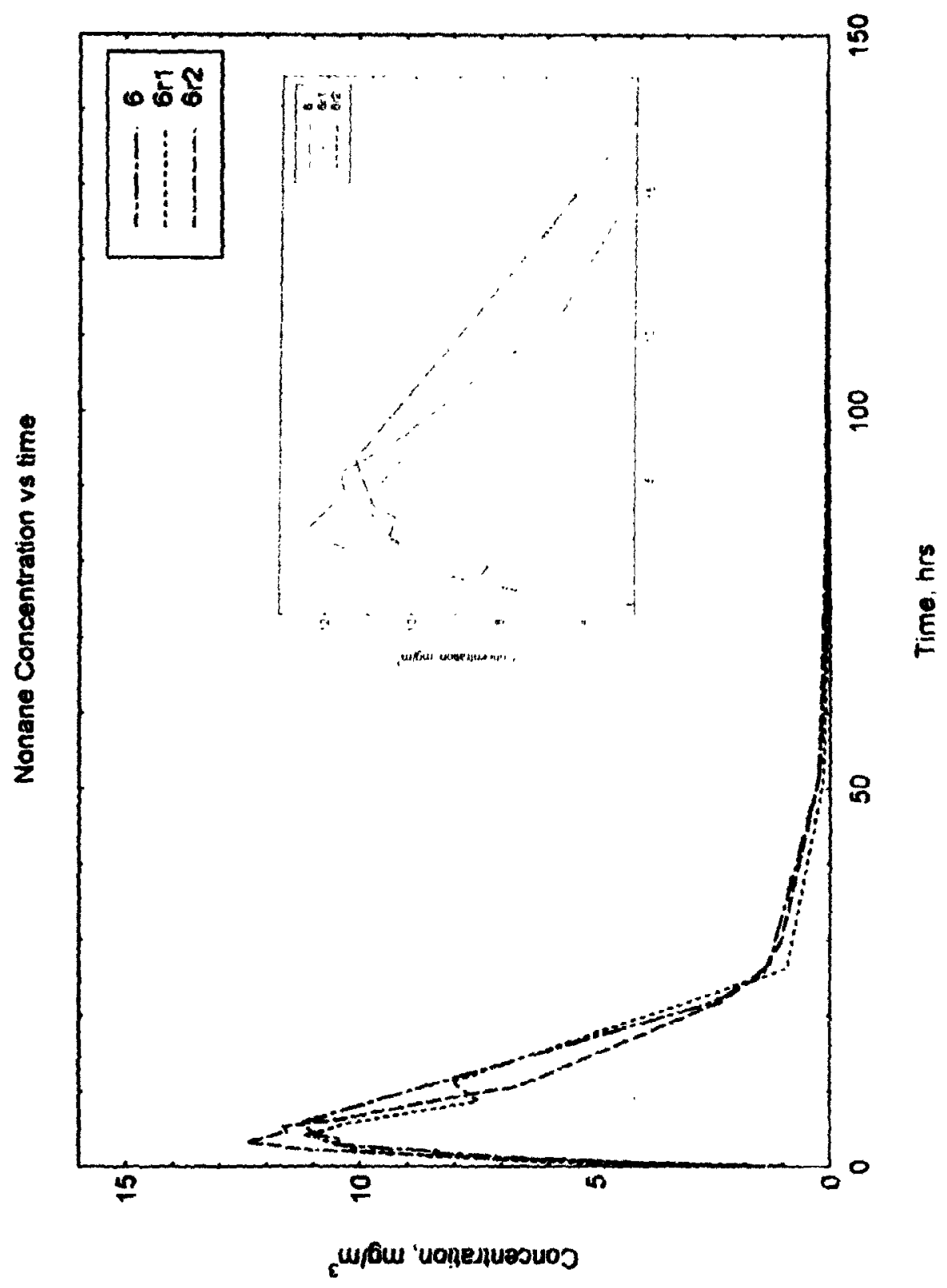

Figure 5.15: Nonane Concentration vs. Time - Test 6, 6r1, 612. 


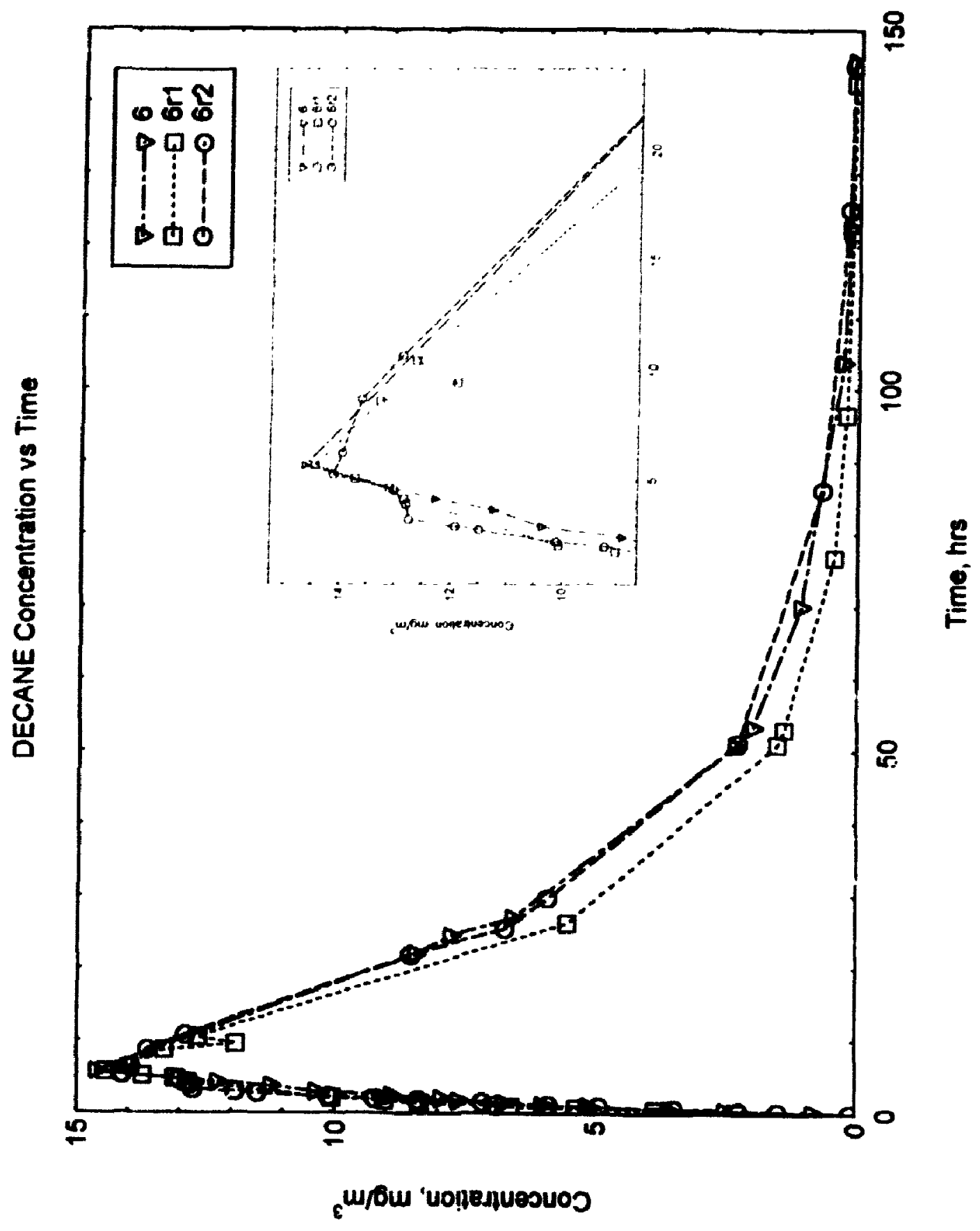

Figure 5.16: Decane Concentration vs. Time - Test 6, 6r1, 6r2. 


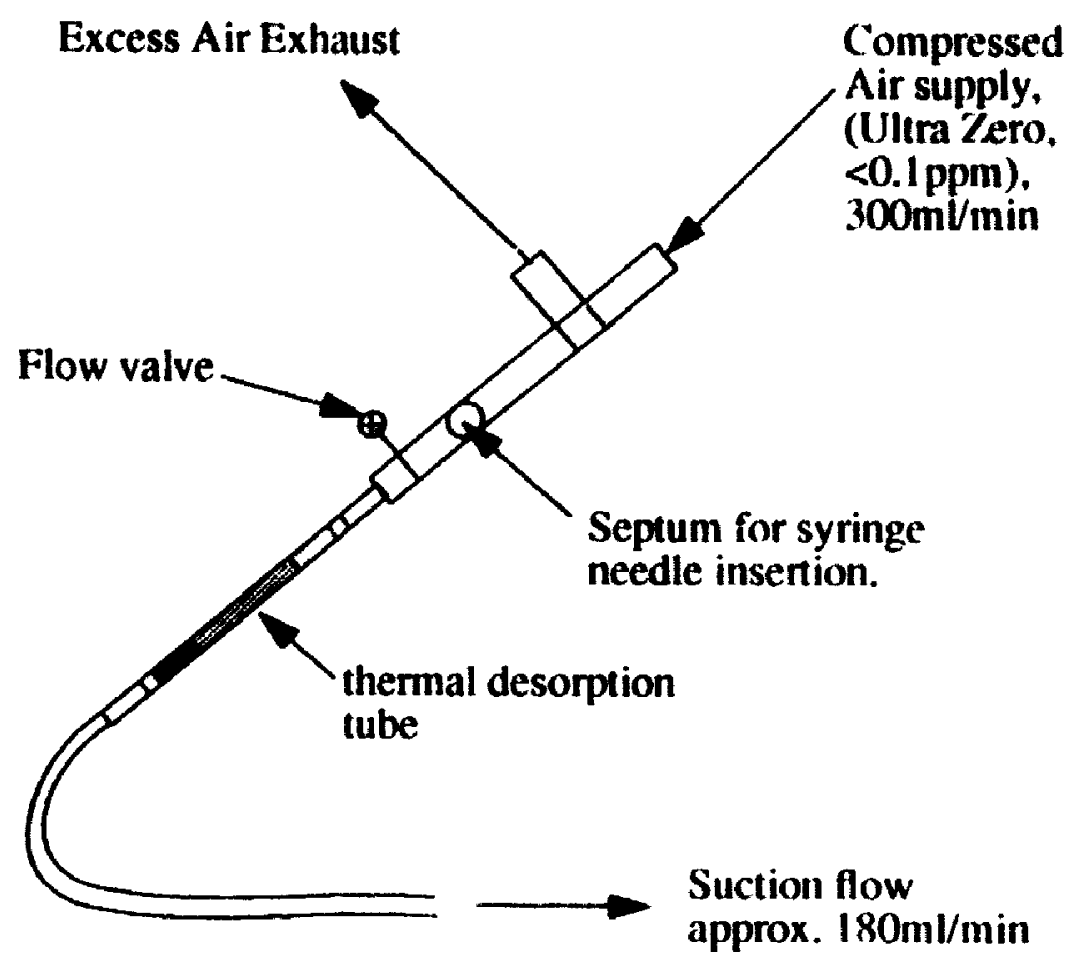

Figure D.1: Syringe Sampling Set-up.

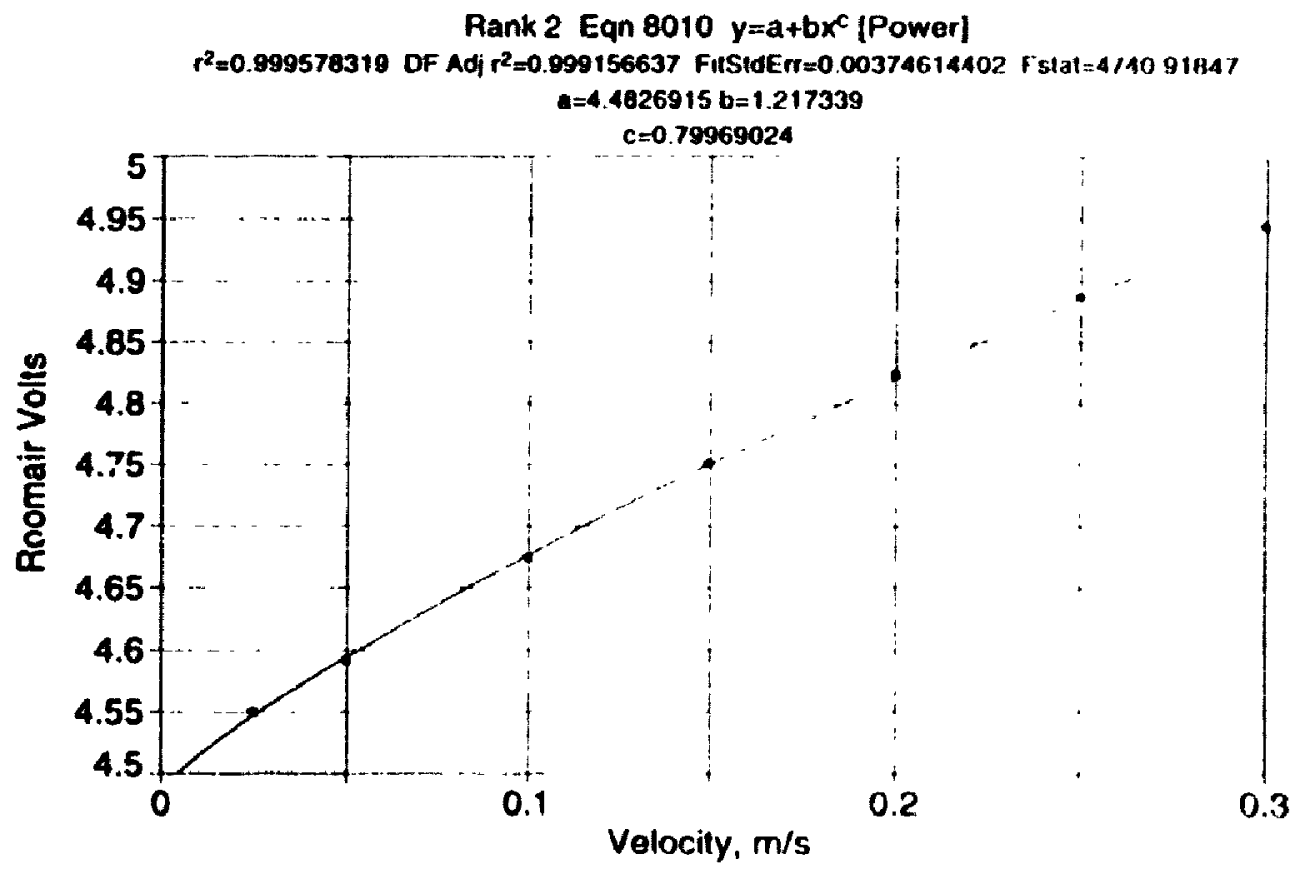

Figure E.1: TSI Calibration Curvc-Fit 


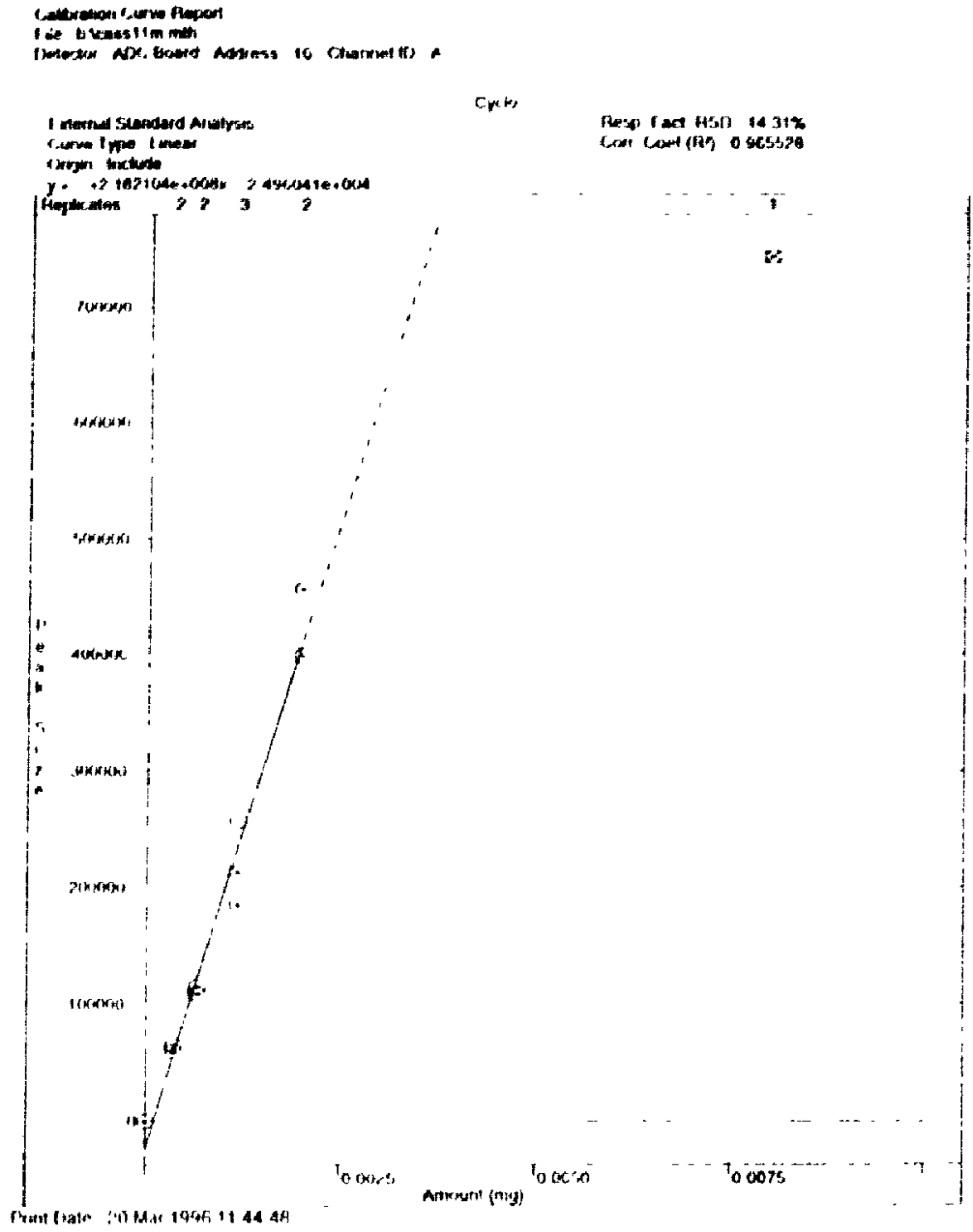

Figure E.2: GC Calibration Curve - Cyclohexane 
Appendix A 
Table A.1: Equipment List

\begin{tabular}{|c|c|c|c|}
\hline Function & Model & $\mathbf{S} / \mathbf{N}$ & misc. \\
\hline $\begin{array}{l}\text { Iinvironmental } \\
\text { ('ontroller }\end{array}$ & $\begin{array}{l}\text { Miller-Nelson } \\
\text { HCS-301 }\end{array}$ & 83110 & \\
\hline $\begin{array}{l}\text { Hydrociarbon } \\
\text { Analyzer }\end{array}$ & $\begin{array}{l}\text { Meloy } \\
\text { HCA500-2C }\end{array}$ & $8 A 165$ & Flow rate: $250 \mathrm{ml} / \mathrm{min}$ \\
\hline $\begin{array}{l}\text { Gas } \\
\text { Chromatograph }\end{array}$ & $\begin{array}{l}\text { Varian } \\
\text { Star 3400CX }\end{array}$ & 18057 & $\begin{array}{l}\text { Carrier Gas: } \\
\text { Helium, } 2.5 \mathrm{ml} / \mathrm{min} @ \\
80 \mathrm{psi} \\
\text { Flame Gases: } \\
\text { Nitrogen, } 27.5 \mathrm{ml} / \mathrm{min} \\
\text { @ } 40 \mathrm{psi} \\
\text { Hydrogen, } 32.5 \mathrm{ml} / \mathrm{min} \\
\text { @ } 45 \mathrm{psi} \\
\text { Air, } 327.5 \mathrm{ml} / \mathrm{min} @ 60 \\
\text { psi }\end{array}$ \\
\hline $\begin{array}{l}\text { Multi-Tuhe } \\
\text { Desorber }\end{array}$ & $\begin{array}{l}\text { Envirochem } \\
8916\end{array}$ & $T-1028$ & \\
\hline Concentrator & $\begin{array}{l}\text { Envirochem Unacon } \\
810 \mathrm{X}\end{array}$ & 268242 & \\
\hline $\begin{array}{l}\text { Multi-Tube } \\
\text { Conditioner }\end{array}$ & Envirochem & NRC 037593 & \\
\hline Flowmeter & $\operatorname{ADM} 3(0) 0$ & $400-(0076$ & $5-750 \mathrm{ml} / \mathrm{min}$ \\
\hline $\begin{array}{l}\text { Measurement and } \\
\text { Control System }\end{array}$ & Keithley $500 \mathrm{~A}$ & NRC 037430 & \\
\hline $\begin{array}{l}\text { lemperature and } \\
\text { Ilumidity Sensor }\end{array}$ & $\begin{array}{l}\text { Vaisala } \\
\text { HMI33 }\end{array}$ & 833863 & \\
\hline Chilled Mirror & Vaisala & $\begin{array}{l}\text { MA 410440 } \\
\text { Probe: } \\
315449\end{array}$ & \\
\hline Flow analyzer & TSI IFA-100 & NRC 104778 & \\
\hline $\begin{array}{l}\text { Hor-Wire } \\
\text { Anemometer }\end{array}$ & TSI $1210-T 15$ & 935095 & \\
\hline
\end{tabular}


Tuble A.1: Equipment Lis!

\begin{tabular}{|c|c|c|c|}
\hline Function & Model & $\mathbf{S} / \mathbf{N}$ & Imist: \\
\hline Windtunnel & TSI & Rel. $121(K) 2$ & \\
\hline Manometer & DP Measurements & NRC 0.37487 & \\
\hline $\begin{array}{l}\text { Catalytic Oxi- } \\
\text { dizer }\end{array}$ & MSA. model B & NRC 196067 & $71 /$ min $\mathbf{M A X}$ \\
\hline $\begin{array}{l}\text { Fan motor Power } \\
\text { Supply }\end{array}$ & Kepco ATE 25-4M & NRC 0.37375 & \\
\hline $\begin{array}{l}\text { Maxon Servo- } \\
\text { Motor }\end{array}$ & $\begin{array}{l}23-32-968-12-216- \\
200\end{array}$ & & \\
\hline Exhaust Pump & GE M19310TC & 8710157 & \\
\hline Air compressor & $\begin{array}{l}\text { Magnatek } \\
\text { HH2H(117 M80218 }\end{array}$ & $52 E$ 79368A & \\
\hline Flowmeter & Humonics & (x)5728 & $0.5-10[. / \mathrm{min}$ \\
\hline
\end{tabular}


Appendix B 


\section{Appendix B - Concrete forming procedures}

Concrete substrates:

Materials for 5 substrates:

$5 \quad 250 \mathrm{~mm} \times \mathbf{5 0 0} \mathrm{mm} \times \mathbf{5 0} \mathrm{mm}$ plexiglass forms

$5.52 \mathrm{~kg} \quad$ Walter

$11.5 \mathrm{~kg}$ Portland Cement

$23 \mathrm{~kg} \quad$ Sand

$34.5 \mathrm{~kg}$ Stone

Procedures:

Wet mixing basin with wet rag. Add Walcr, followed by stonc, portland cement, then sand, in that order. Mix for 3 minutes once all ingredicuts are added to mixing basin. Let sit 3 minutes, then mix again for 3 mimules.

Pour cement mixture into forms. Place forms on a shaker table, onc all at time, and shake to remove any air and to smooth exposed surfice. Place forms in wet room to cure for I week. then remove concretc fiom forms leaving concrete in wet room for another 3 wecks.

Trim area of concretc to a final dimension of approximatcly $238 \mathrm{~mm} \times 488 \mathrm{~mm}$. 


\section{Appendix C}




\section{APPENDIX C - Detailed Test Set-Up Procedures}

\section{Preliminary collection and preparation of test materials:}

a. Obtain carpet samples directly from manuficturer. Caupets must be stalled in mylar bags immediately after manufacturing. Ohtain and record the carpel si date of manulacture.

b. Obtain adhesives which are compatible with the carpet and recoumuended by carpel manufacturer.

c. Remove carpet from sealed bag and cut into individual pieces using a lemplate which is just larger than $0.5 \mathrm{mx} 0.25 \mathrm{~m}$. Immediately return samples not heing tested to the bag and re-seal.

d. Conduct headspace analyses of the carpel, adhesive and concrete lo delermine the VOCs present in each material.

e. When using adhesive, follow the application instructions provided, and ypreal as evenly as possible.

f. When adhesive is not being used, lay carpet directly on stainkes sted platte.

\section{Operating procedures for test}

\section{Prepare chamber and test room for test}

1. Get all measurentent equipment and ambient condituns ready tor test, including cleaning the test chamber with distilled water and performing calibralloms as described in Appendix E.

2. Set ambient air temperature of the test room with the HVAC system in comlinmoms operation. 
3. Set up the data acquisition systems (both the LabMate and the Hot Wire anemometer systems, entering the calibration equations for Q, T, RH, U and THC)

4. (iel the GiC and sampling tubes ready.

5. (iet the hydrociarbon analyzer ready.

6. Synchronize the clocks on all computers with the wall clock.

7. Clean entire small chamber with distilled water.

8. Turn on the air compressor and switch on all valves for both air and water lines.

9. Turn on the power of the air conditioning/llow control unit and set the flow rate, temperature and relative humidity to the required test values.

10. Turn (wn the DC power supply for the fan motor and set the voltage to the desired value for velocity control.

11. Turn on the Catalytic oxidizer, ONLY after thete is air flow.

12. Double the air flow rate to a maximum of 7 L.PM and adjust the exhaust pump to mainlain a pressure delta of $+10 \pm 2$ Pascals wrt to the atmospheric pressure.

13. I.et the system run with the top plate of the chamber in place. but not sealed, for at minimum of thrs, or overnight, before heginning a test.

14. Take an ant sample from the lest room for background veritication.

The ouler chamber is now ready for loading the inner chamber with a test sample

\section{Prepare the test sample:}

15. Pre-set the height of the hot-wire anemometer to the mid-height level in the inner chamber (hefore preparing the sample).

16. lake syringe sample from carpel (in mylau bag). 
17. Weigh the following matterials: at the carpet in the mylat halg. and b) the allhesile. trowel. kimwipes. latex gloves and the applicattion spatulat. all in a phastle hatg

18. Spread adhesive onto substrate using spatula. Spread entenly with trowal. record the time: $t_{a}$. Put all adhesite malterials balck in plaslic bag.

14. Remove the carpet from the mylar bag and record time, t.. Trint the carpet edges using a cardboard template and place carpet remmants back imto melar bagk.

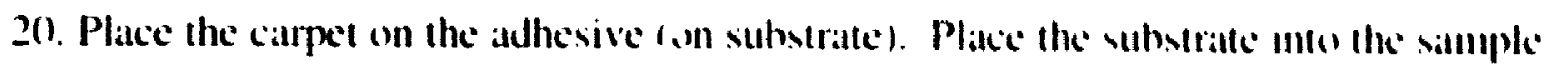
holder of the inner chambet. Adjust catpet. en-armg there is mo gap at the leading edge of the simple.

21. Place stainless steel plate on carpet and roll wer platte fo secure carpel wa alleste

22. Adjust the sample holder legs so the top of the carpet in thush with the satmple holket surface.

\section{Put the inner chamber in place:}

23. Turn off the DC power supply for the tian!!!

24. Turn off the exhatust pump.

25. Remove the top plate.

26. Put the inner chamber in the outer chamber (record time, $1_{10}$ ), assemt ble the thent ams

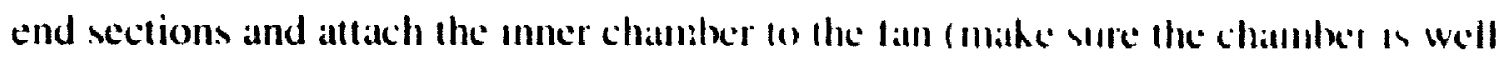
aligned according to Figure ( .1 .

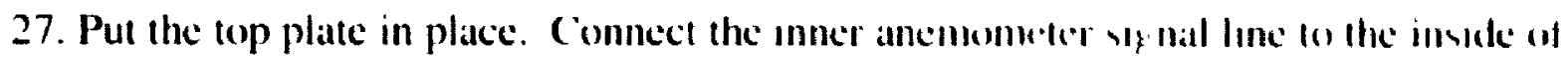

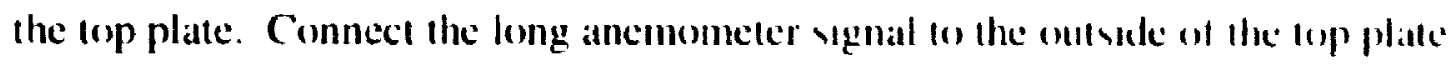

28. Connect the pressure line and the air supply and exhatus hines. 
resull: of the test

The errom assoclated with the llow increase cannest be prevented. hut they are not beleved to be sgmuticant. The errors due wo cleanng the lubes were minimised by usmg the sallice cleanmg procedures alter each wate $u$ as run. 


\section{Appendix E - Calibrations}

\section{f.I Velecity and Turbulence Profiles in Small Chamber}

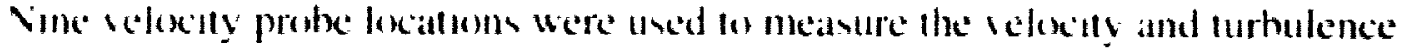
protiles in the small chamber. as shown on Figure 3.6.

The velocity and turbulence mtensity uere measured at $(0.0 .+0$ and $8.0 \mathrm{~cm}$ above the surtace of the carpet for locations A-D. and P-K. Lecation E had measurements taken excry $0.25 \mathrm{~cm}$ from $0.0-2.5 \mathrm{~cm}$, crery $0.5 \mathrm{~cm}$ from $2.5-5.5 \mathrm{~cm}$, and exery $0.25 \mathrm{~cm}$ from $5.5 .8 \mathrm{~cm}$. The anemometer was alwaty located at $4.0 \mathrm{~cm}$ above the carpet surface at foxation E for regulat testing.

The data ohtanned at a lexation $4 \mathrm{~cm}$ above the carpet surface is summartzed in Table F:.

The fan motor voltages used for the Maxon DC motor were 6, 13, \& $23 \mathrm{~V}$ for low furbulence velocities of $0.05,0.15$. \& $0.25 \mathrm{~m} / \mathrm{h}$. respectively. The corresponding voltages uned lor the high lurbulence velocites were $5.14 . \& 23 \mathrm{~V}$. respectively.

\section{F..2 Temperature and Relative Humidity Calibrations}

The cemperature and relative humidity were calibrated in the chamber using the Vitsala Chilled Mirror. The voltage output displayed in Viewdac from the Environmental (ontroller and the Rom Sensor (Vaisala HMI3.3) were recorded along with the Chilled Mirror values. A hest fit power curve $\left(y=a+b x^{c}\right)$ was obtained and this equation was input into Vieudac to provide actual temperature and RH data along with the voltage out- 
Appendix D 


\section{Appendix D - Sampling Procedures}

\section{D.I Syringe sampling procedure (see Figure D.I for orientation)}

1. Attach and Set ero gas fiow to approximately $3(x) \mathrm{ml} / \mathrm{mm}$. (catreer gas)

2. Set sample (suction) llow lo approximalely 180 ) $\mathrm{ml} / \mathrm{min}$.

3. Place thermal desorption tube in "svringe sampler".

4. Take one full syringe sample from specimen (bag of comprewed gav cylluder and expel to room air to remove any other gases which may hase heen presem in llic syringe.

5. Open "syringe sampler" valve to allow flow through thermal desorplion tube,

6. Attach suction line to tube thus vampling Zero gav).

7. Take a syringe sample from specimen.

8. Insert needle into "syringe sampler" septum and expel sample towly tornsture that the suction flow is greater than the syringe expulsion rate.

9. Repeat steps 7 and 8 until required volume is whtained.

10. Remove suction line from tube, then thermal desorption lube can lxe remosed.

11. Tum off Zero gas flow.

\section{D.2 Calculation of sample volume}

$$
\text { Volume }(\mathrm{ml})=\frac{12 \mathrm{ng} * 24450 \mathrm{~m}^{3} / \mathrm{mol} * 1(6) \times(x)(x) \mathrm{ml} / \mathrm{m}^{3}}{840 \times(x) 000 \mathrm{ng} / \mathrm{mol} * \times \mathrm{ppm}} \quad \text { |:y.h }
$$

Using Eq. 6, the sample volume is calculated based on the THC reading Iroun the 
data acquastlun sybtem.

For example, if the THC was $10 \mathrm{ppm}$. the volume would be calculated as follows:

$$
\begin{aligned}
& \text { Volume }(\mathrm{ml})=12 \mathrm{ng} * 24450 \mathrm{~m}^{3} / \mathrm{mol}^{*} \text { 10000(00) ml/m } \\
& \text { x40(6)(0)( } \mathrm{ng} / \mathrm{mol} * 10 \mathrm{ppm}
\end{aligned}
$$

Volume $=.449 .3 \mathrm{ml}$. for $10 \mathrm{ppm}$ THC concentration.

To determune the sampling fow rate $(40)<1$ ou rate $<250 \mathrm{ml} / \mathrm{min}$ ) the volume is lirst divided by 5 minutes lo get a flow rate of $1.349 .3 \mathrm{ml} / 5 \mathrm{~min})=69.8 \mathrm{ml} / \mathrm{min}$.

If the flow rate calculated for a given THC had heen less than $40 \mathrm{ml} / \mathrm{min}$. the flow ratc would have heen increased to $\$(1) \mathrm{ml} / \mathrm{min}$ and the sampling time calculated by dividing the volume by the llow rate. If the sampling flow rate had been greater than $250 \mathrm{ml} / \mathrm{min}$. the sampling flow rate would have been set $10250 \mathrm{ml} / \mathrm{min}$ and the time calculated in the same manner.

\section{D.3 Regular Sampling Procedures}

1. Turn on the sampling flow controller and let warm up for 5 minutes. Set suction flow ratc as calculated in Appendix D.2.

2. Adjust the exhaust pump to maintain a positive pressure difference of $15 \pm 2$ Pascals w.r.t. atmospheric pressure while collecting samples.

3. Insert a thermal desorption tube into the sampling apparatus (see Figure 3.8), with the cartuon end (black end) out - last part to have air fiow through it. 
4. Record the suction flow rate.

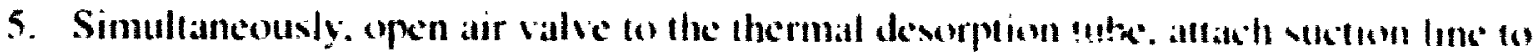
the carbon end of the whe and record the lume.

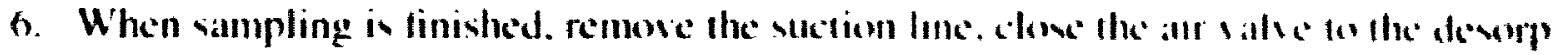
lion tube and record the slop time.

7. Re-adjust the exhaus pump to maintain $+10 \pm 2$ paseals witt almonpleste presure

8. Re-measure the suction flow ratc and record.

9. Calculate the actual sample sice using the average flow rate and the fotal vampling time.

\section{D.4 Sampling Error}

The sampling error was not measured, although the potentaal for corror is dencriked in this section.

As the suction line is placed on the tube after the destred flow ralle wabamed, the flow through the desorption tube does not instantaneously go from /ero to the de vired flow rate. This effect will cause a higher error in small samples that are taken quickly and at low flow rates. Larger sample volumes which are sampled over a longet period of imme, minimize the effect of this flow change.

Another error introduced in the sampling procedure is the variallom of the desorption tubes. All the tubes used were of one type, they were bought at the simle time, and they were only used for these carpet-adhesive test. However. as they are used and cleaned. their adsoprtion and desorption characteristics may change slightiy, alfectung the 
results of the test.

The errors assoclated with the fow increase cannot be prevented. but they are not helieved to be stgniticant. The errors dee wo cleaning the tubes were minimifed by using the sance cleaning procedures after each tube was run. 
Appendix E 


\section{Appendix E-Calibrations}

\section{F.I Velocity and Turbulence Profiles in Small Chamber}

Sinc velocity probe licatums were uned to measure the velocity and turbulence protikes in the whall chamber. as shown in tigure 3.6 .

The velocily and turbulence mtensity were measured at $0.0,40$ and $8.0 \mathrm{~cm}$ ahove the surtace af the carpet for locations A-D. and F-K. Locitlon E had measurements taken cuery $0.25 \mathrm{~cm}$ from $(1.0)-2.5 \mathrm{~cm}$, every $0.5 \mathrm{~cm}$ from $2.5-5.5 \mathrm{~cm}$, and every $0.25 \mathrm{~cm}$ from $5.5 .8 \mathrm{~cm}$. The anemometer was alway localcel al $4.0 \mathrm{~cm}$ airove the carpet vurtace all Lxatuon I: for regular 心゙ ting.

The data ohtamed all a locallon $4 \mathrm{~cm}$ above the carpet surface ss summanced in Tible 1:. I.

The fim motor voltages used for the Maxon DC motor were 6, $13,823 \mathrm{~V}$ for low turhuknce velucities of $0.05 .0 .15 . \& 0.25 \mathrm{~m} / \mathrm{s}$. respectively. The corresponding voltages uned for the high turbulence velocition were $5.14 .82 .3 \mathrm{~V}$. respectively.

\section{E.2 Temperature and Relative Humidity Calibrations}

The temperature and relative humidity were calibrated in the chamber using the Vaisala Chilled Mirror. The voltage output displayed in Viewdac from the Environmental (ontroller and the Rom Sensor (Vaisala HMI3.3) were recorded along with the Chilled Mirror values. A best lit power curve $\left(y=a+b x^{c}\right)$ was obtained and this equation was input into Viewdic to provide atctual temperature and RH data along with the voltage out- 


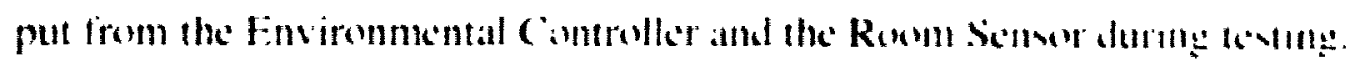

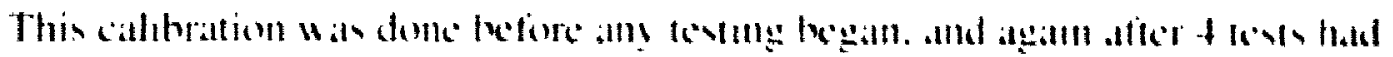

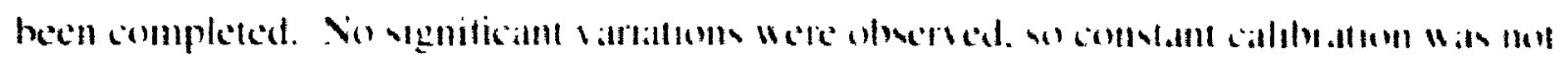
reyuired.

\section{F..3 TSI Anemometer Calibration}

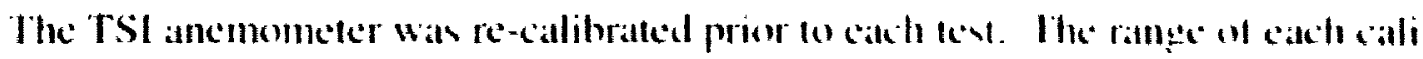

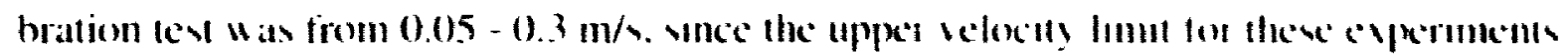
uals $0.25 \mathrm{~m} / \mathrm{s}$.

The TSI Wind Tunnel was used for callibration using TSI platc \#2. The TSI manUal fFOOTNOTE) Was followed for calibration procedures.

A Roomair program. developed at NRC to recond the veltage outpun from tsis, IFA- I(K). was used during calibration and testing. The voltage was recorded for cateh velocity and a bev-fit power curve was obtained before cach lest. Thu cathhatlon was also dependent on the room temperature and atmospheric pressure. Therefore, lle atmo spheric pressure was recorded daily and the room temperature was coconded communumly.

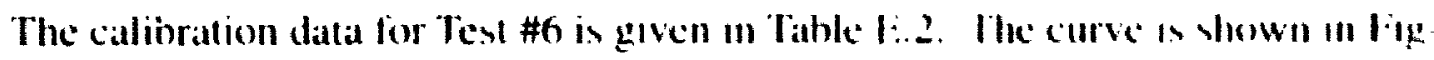
urs E.1.

The velocity calibration curve, the daily atmospherte pressure and lempreatlure were then used with the Roomvent program. also developed at NR6: Wo analy a the dala and provide the velocity data for each test. 


\section{L.A Flow (alibration}

The llow required for tasting was 6.67 LPM. This corresponded to an air change rate of I ACH anr change per hour) in the small lest chamber.

A Bubble meter was intially used to calibrate the flow into the small chamber. The calibraten volume was 2.01 .. The time il look for a bubble 10 till the $2.0 \mathrm{~L}$ volume was recorded and averaged, along with the voltage output from the Environmental Controller an Viewdac), for various flow rates to obtain a flow calibration curve. The calibralion curve was then inpul into Viewdac. This calibration was done all the same time as the temperature and RH calibrations. A Humonics Flowmeter with a range of 0.5 - 10 LPM was received after testing had begun and was used to uccessfully verify previous calibraIIeIIs, thus continuous flow calibrations ware not required.

\section{L.5 Meloy HCA Calibration}

The HCA was re-adjusted prior to each test and was also adjusted during each test when the concentration levels changed from onc range to another. The upper range setIIng on the HCA were: $10 \mathrm{ppm} .50 \mathrm{ppm}$. $100 \mathrm{ppm}$ and $10(00) \mathrm{ppm}$. The calibration gases used were cyclohexane and lltra Kero compresied air. They were mixed at 24 psi each to get the required concentrations for each range.

A warm-up precedure was used for the HCA before calibrations or "zero and Ypan" as follows: it was turned on for $30 \mathrm{~min}$., after which the hanke was ignited and the HCA was left for another 30min.

The tirst step before calibration. in each range, was to "zero and span" the HCA. 


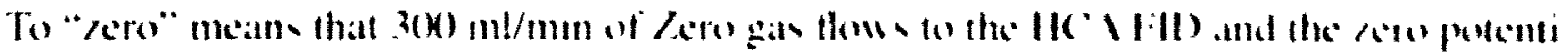

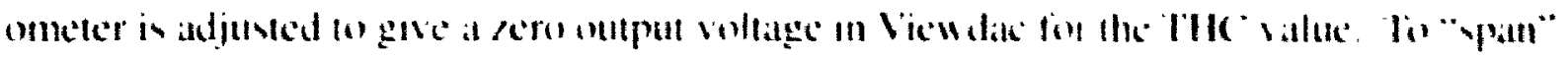

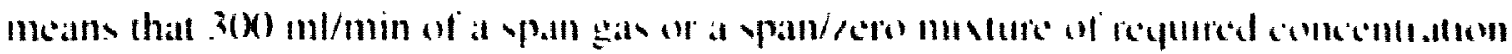

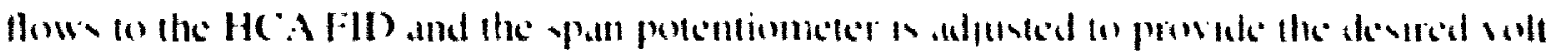

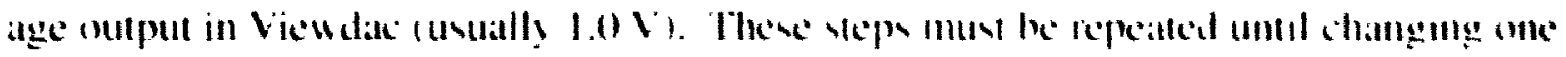
no longer changes the other.

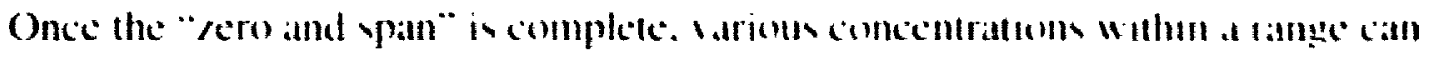

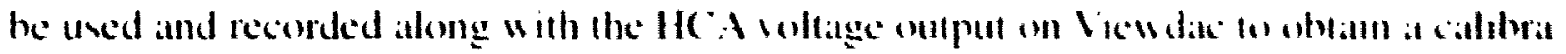

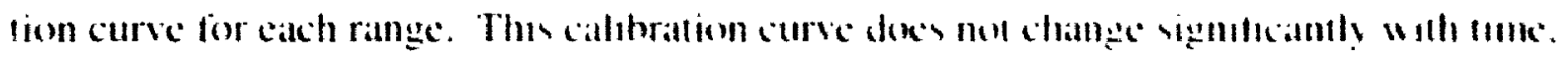

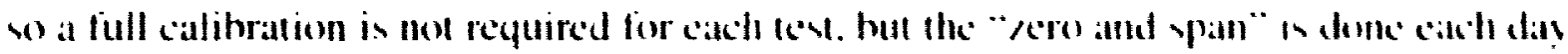
and each time the range changes.

\section{E.6 (.C. Calibration}

The GC is calibrated using varous concentratums of eyclohexame, Symge same ples of eyclohexane are adsothed onto a thermal desorpton tube. The sample in llen des.

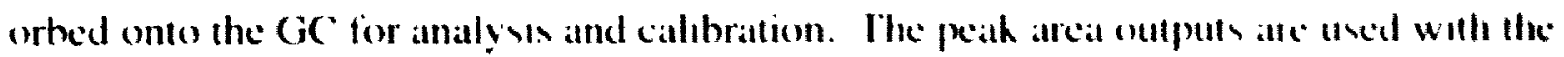
concentrations (Table E.3) to obtain a calibration curve based on cyclohexalle, shown in

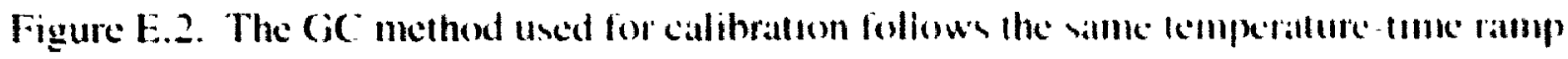
ing procedure as for regular sample analyss. The (ic method lemperiture rampung proxe dure is shown in Figure 3.9.

The prediction error associated with this calibralton is shown in liable 1:.3. The maximum prediction error was $28.2 \%$ for a peak area of $\mid 8.5(\% 6 \mid$. However. since the 
Sance cahlorallon curse was uned for all tests, any error introduced with the calibration equation would he consistent from test for tes and would not affect the comparison of the lenl Is:sults. 


\section{Appendix $\mathbf{F}$}




\section{Appendix F - GC Method for analyzing samples}

\section{F.1 Semi-autemated procedure for the GC:}

1. From the computer in the Star Software Window, click on $<$ System Control/Automation>. while waiting for number 17 and 16 to appear, respectively. below the GC and ADCB icons, go to Step 2.

2. Turn on the Air, and $\mathrm{H}_{2}$ gases to $60 \mathrm{psi}, 40 \mathrm{psi}$, respectively. Turn the Helium pressure up 1080 psi. Ensure $\mathbf{N}_{2}$ pressure is $80 \mathrm{psi}$.

3. Turn the Air, $N_{2}$ and $H_{2}$ gases on at the GC (front plastic door on left of GC opens to access knobs).

4. Light the flame (press the Ignite button on front of GC and leave depressed until "pop" is heard).

5. On the GC re-set the Detector temperature as follows:

press $<$ Build/Modify $>$, $<$ Method $1>$, $<$ Detector $>, 300^{\text {"C }}$ (using numeric pad on GC), press <ENTER>.

6. Back to the Computer, the number 17 and 16 should be below the GC and ADCB icons, respectively. Double-click on the White (empty) space of the Varian Star\#1 window.

7. From FILE choose METHOD, then ACTIVATE, then select CASS IIM.MTH, click OK.

8. Check Multi-tube desorter, change LAST SAMPLE number (top left corner of Desorber) to allow slightly more than I hour for each tube, i.e., if the desorber is currently 
at Tube location 9 and there are 4 hours available, then set the :AST SAMPLI: number to 12 (>1 hour for each run of tubes 10. 11, and 12). This will allow time to shut down the GC before leaving.

9. Connect BLACK and RED wires (hetween computer and GC). This tells the (iC that the concentrator is READY, and allows the GC wo send a START signal to the MultiTube Desorber.

10. When samples are done, disconnect the BLACK and RED wires: modify the Detector temperature to $150^{\circ} \mathrm{C}$ following the same procedure as in Step 5: Turn off the Air. $\mathrm{N}_{2}$ and $\mathrm{H}_{2}$ gases at the $\mathrm{GC}$ and the $\mathrm{Air}$ and $\mathrm{H}_{2}$ at the tanks: Turn the Helium pressure down to 60 psi (to save Helium).

\section{NOTES:}

Steps 9. \& 10. were developed to overcome the missing signal connection from the Concentrator to the GC to tell the GC that the Concentrator was READY.

\section{F.2 GC Flow calibration}

1. Turn on gases following steps 2 . \& 3. from the semi-automated procedures above.

2. On the GC, set the column temperature to $100^{\prime \prime} \mathrm{C}$ by selecting <Build/Midify>, $<$ Method 1>, <Column>, 100 (using numeric pad on GC), press <ENTER>.

3. When the column temperature has reached $100^{\circ} \mathrm{C}$ and it is stable, go to sicp 4 .

4. Attach the flow tube of the ADM300 to the FID adapter tube. Plug the FID adapter into the FID opening. 
5. Measure the flow of Helium (SET point $=2.5 \mathrm{ml} / \mathrm{min}$ ), adjust as required.

6. Turn on the Nitrogen (TOTAL FLOW SET point $=30 \mathrm{ml} / \mathrm{min}$ ), adjust as required.

7. Turn on the Hydrogen (TOTAL FLOW SET point $=60 \mathrm{ml} / \mathrm{min}$ ), adjust as required.

8. Turn on the Air (TOTAL FLOW SET point $=360 \mathrm{ml} / \mathrm{min}$ ), adjust as required. 
Appendix G 


\section{Appendix G - Emission Rate Sample Calculation}

TEST 4 - TVOC calculation

$$
\begin{aligned}
& C(t)_{\text {Troc }}=\left(a+b x^{2}+c e^{-x}\right)^{-1} \\
& \text { where, } \quad a=0.007404 \\
& \mathrm{~b}=1.2408 \times 10^{-5} \\
& c=0.01634 \\
& \frac{d C_{\text {Troc }}}{d t}=\frac{-\left(2 b x-c e^{-x}\right)}{\left(a+b * x^{2}+c e^{-x}\right)^{2}} \\
& \begin{array}{ll}
R(t)_{\text {TVOC }}=\mathrm{VdC} / \mathrm{dt}+\mathrm{Q} C(\mathrm{t}) & \mathrm{V}=0.4 \mathrm{~m}^{3} \\
A & \mathrm{Q}=0.4 \mathrm{~m}^{3} / \mathrm{hr}
\end{array} \\
& R(t)_{\text {TVOC }}=\frac{0.024-8.034 \times 10^{-5} x+4.02 \times 10^{-5} x^{2}+0.1058 \mathrm{e}^{-x}}{\left(0.0074+1.241 \times 10^{-5}+0.0163 \mathrm{e}^{-x}\right)^{2}}
\end{aligned}
$$

Similarly, the emission rate equations were obtained for all other tests and compounds.

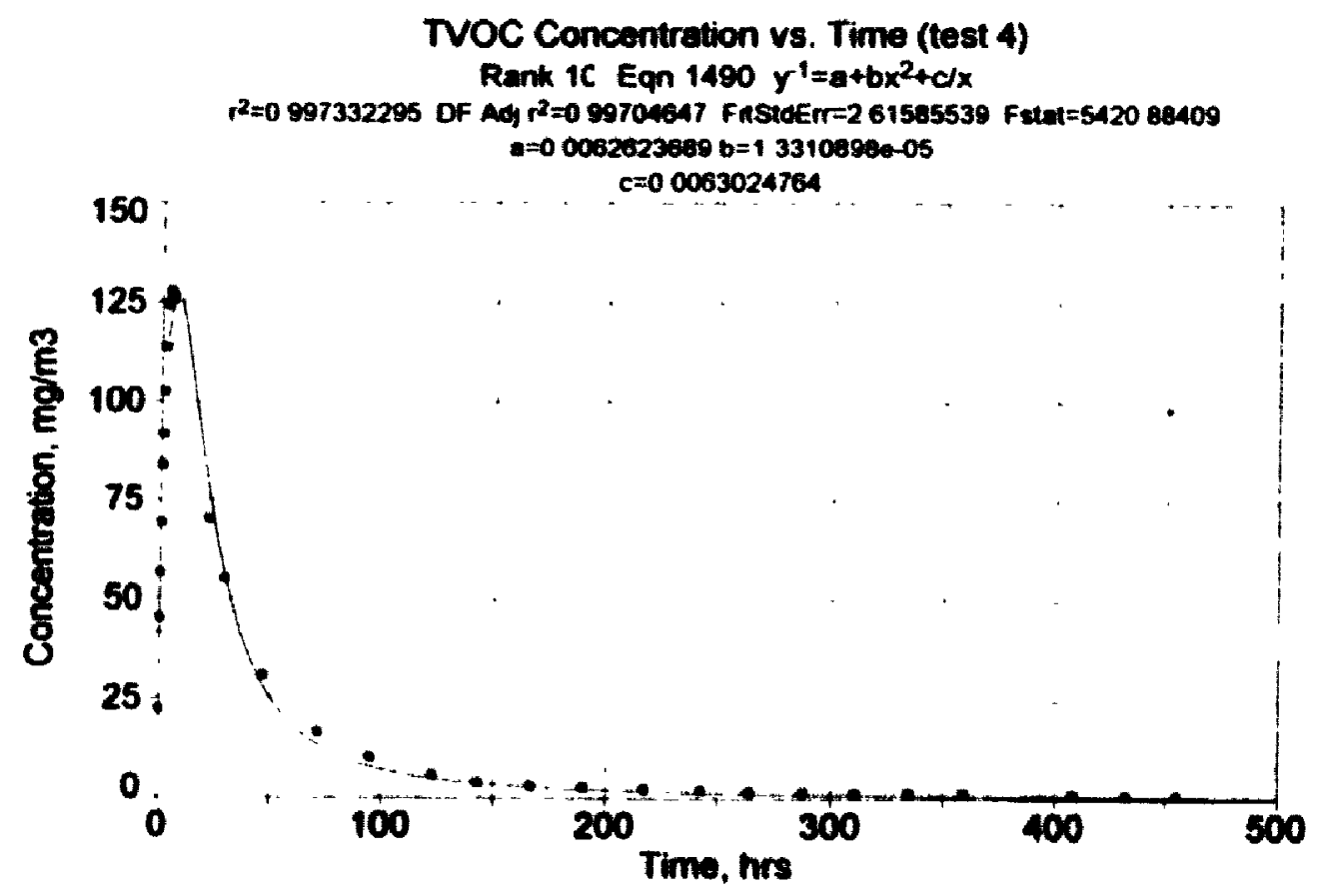

Figure G.1: TVOC Concentration vs. Time (test 4) 


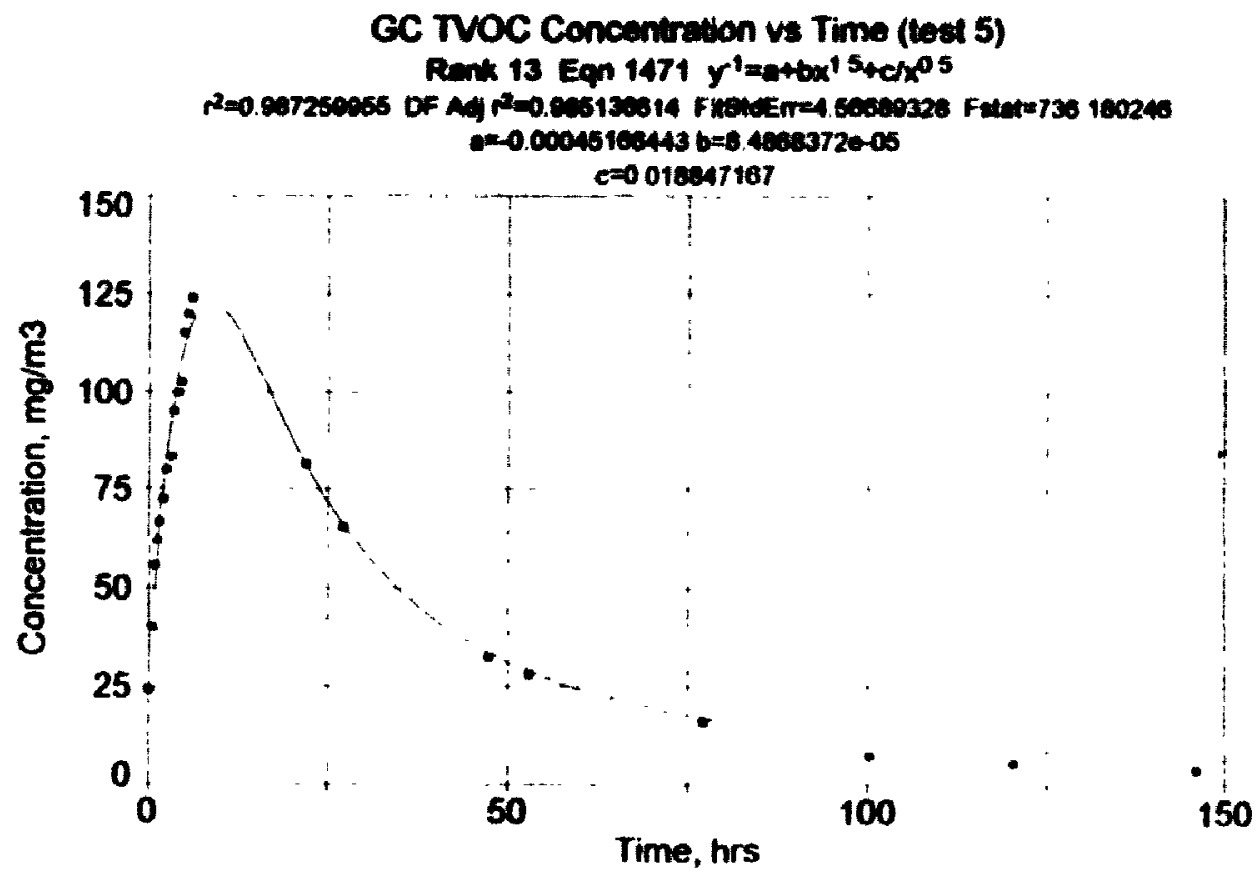

Figure G.2: TVOC Concentration vs. Time (test 5)

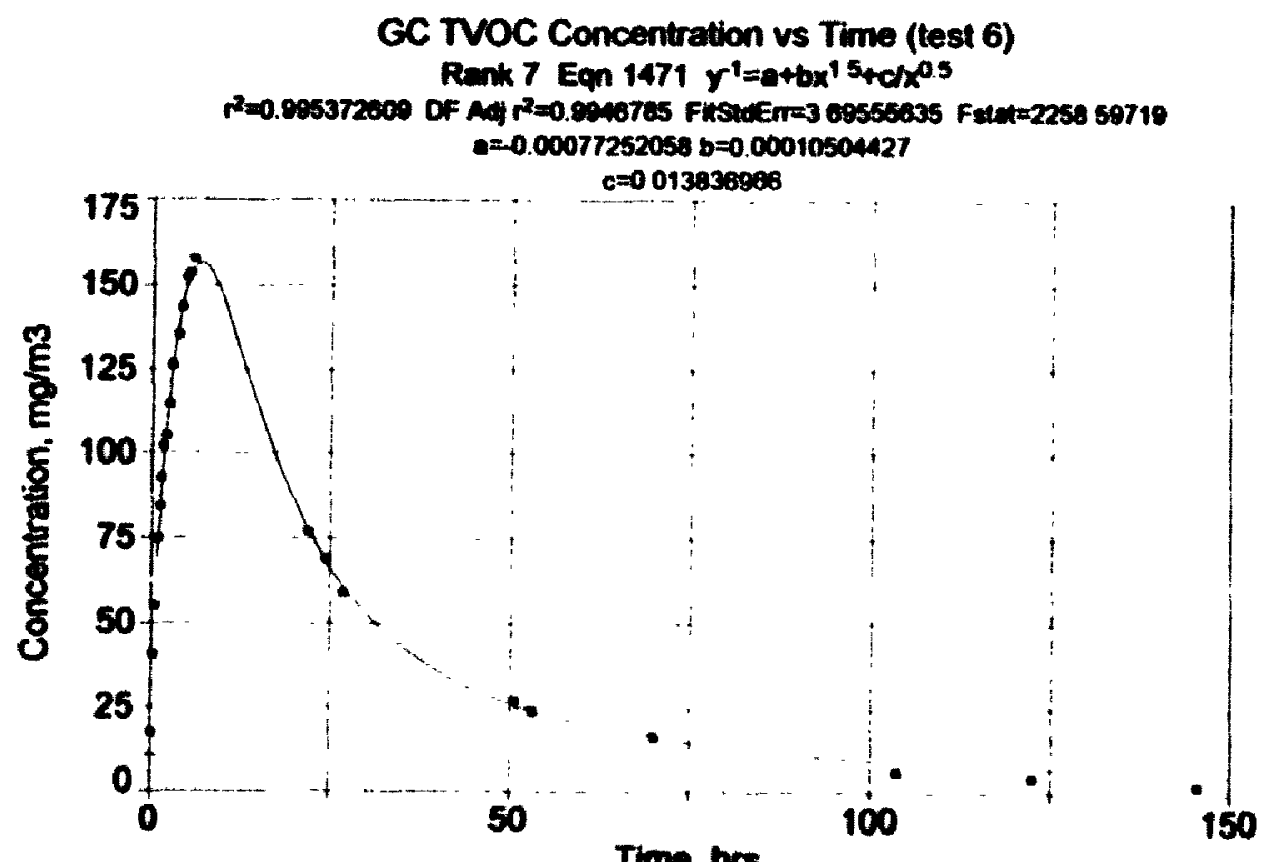

Figure G.3: TVOC Concentration vs. Time (test 6) 


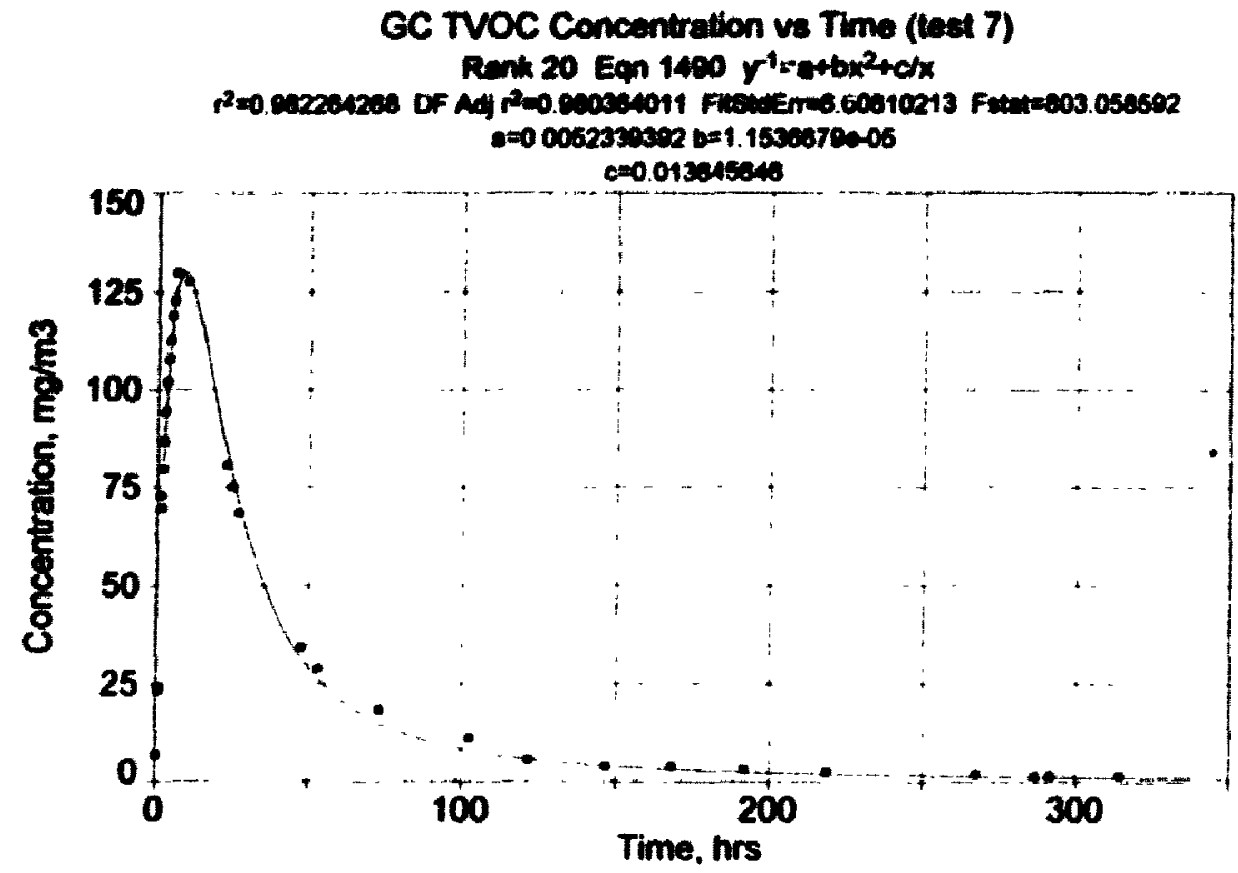

Figure G.4: TVOC Concentration vs. Time (test 7)

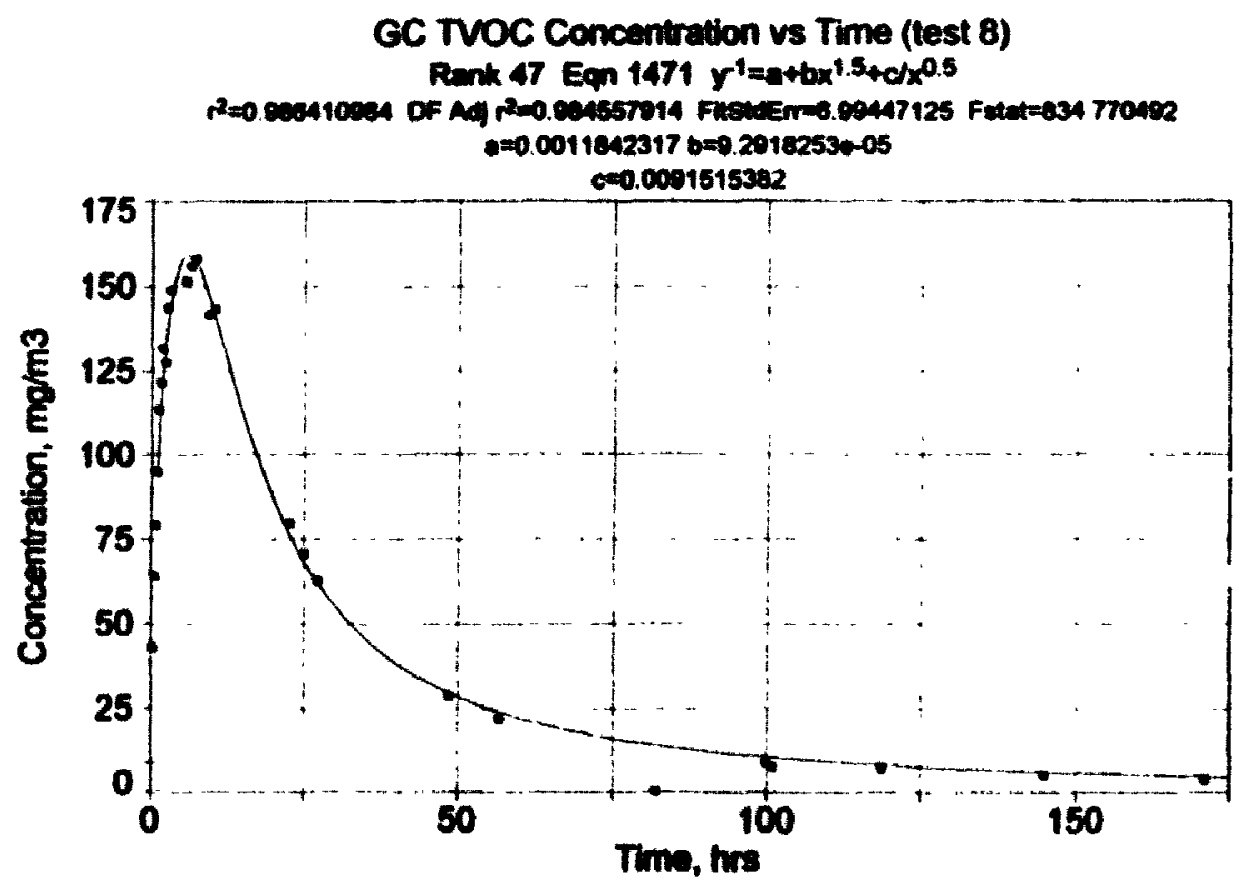

Figure O.S: TVOC Concentration vs. Time (test 8) 


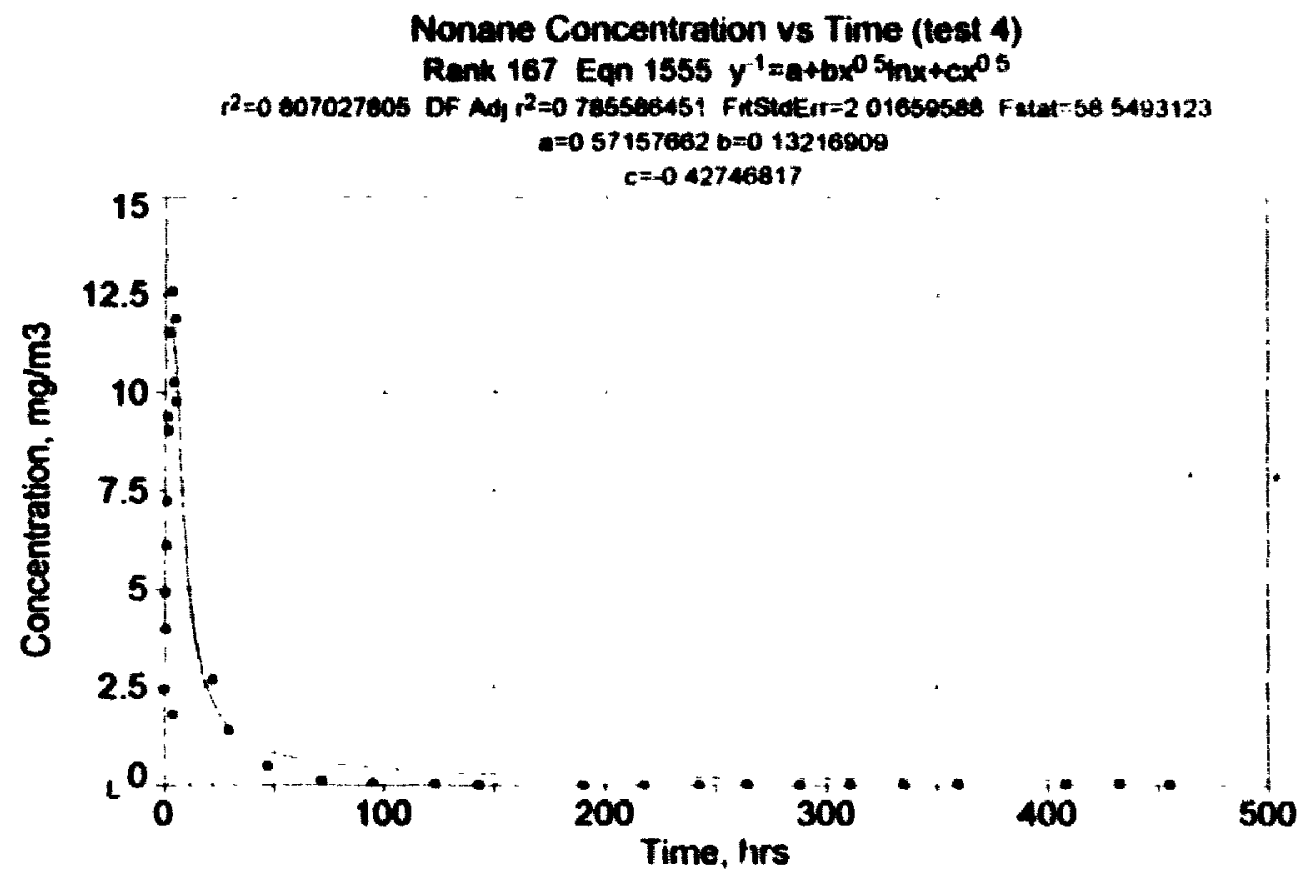

Figure G.6: Nonane Concentration vs. Time (test 4)

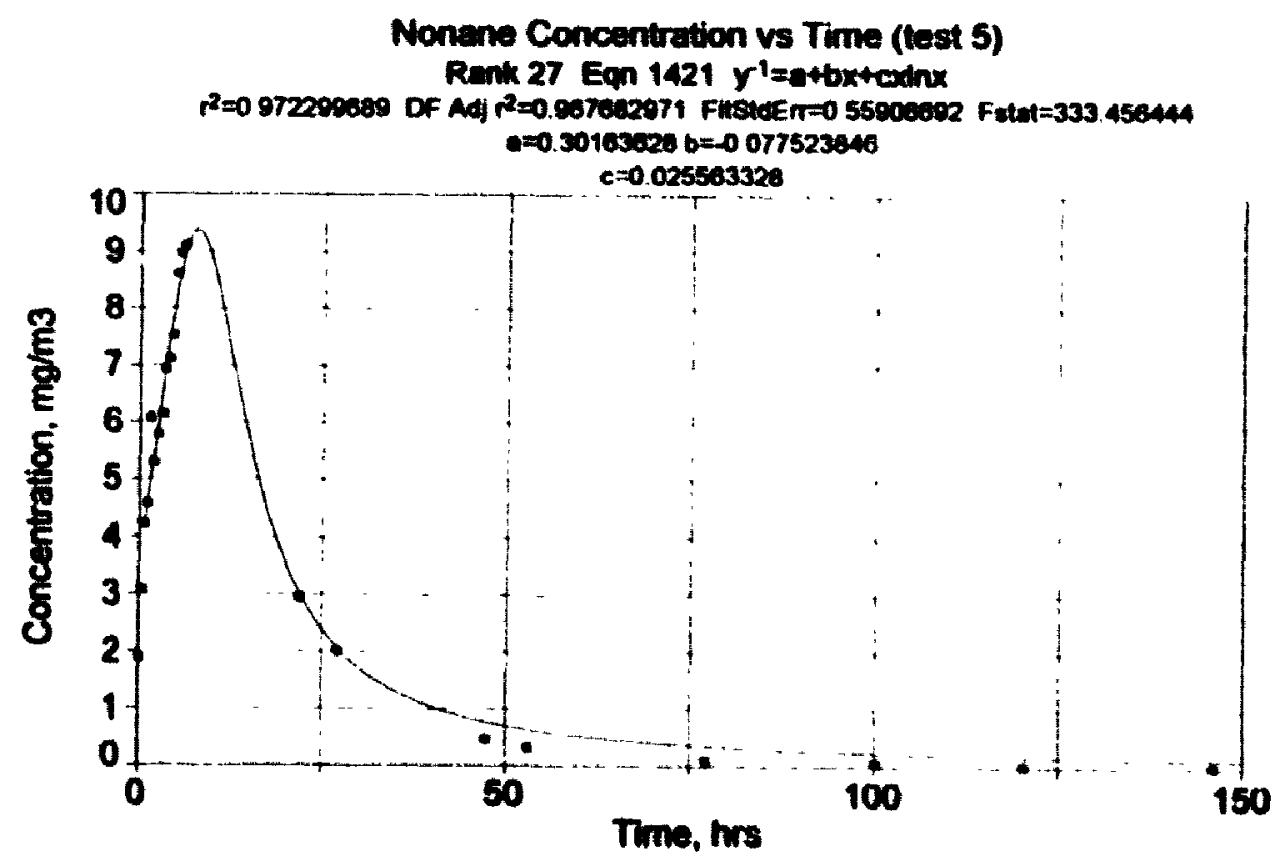

Figure G.7: Nonane Concentration vs. Time (test 5) 


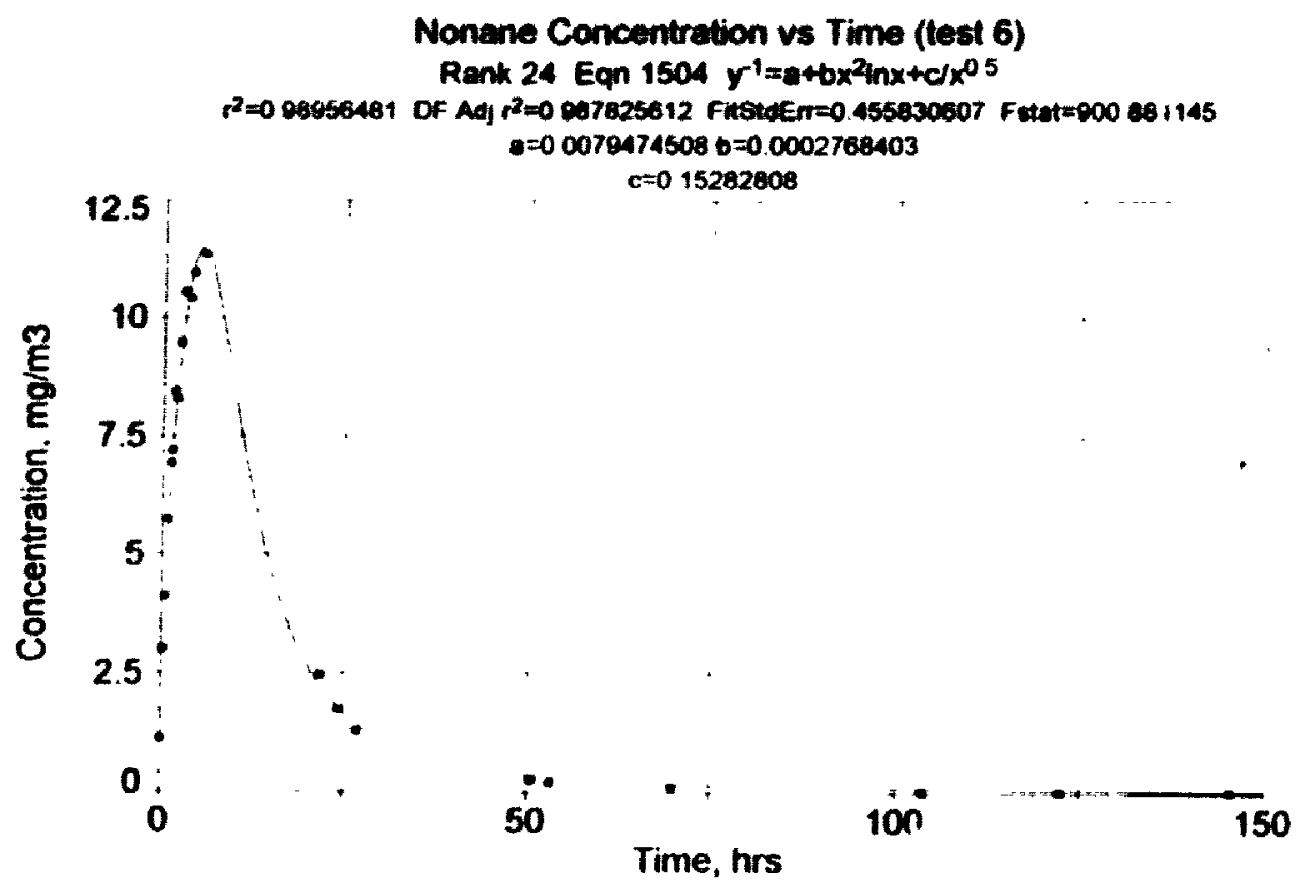

Figure G.8: Nonane Concentration vs. Time (test 6)

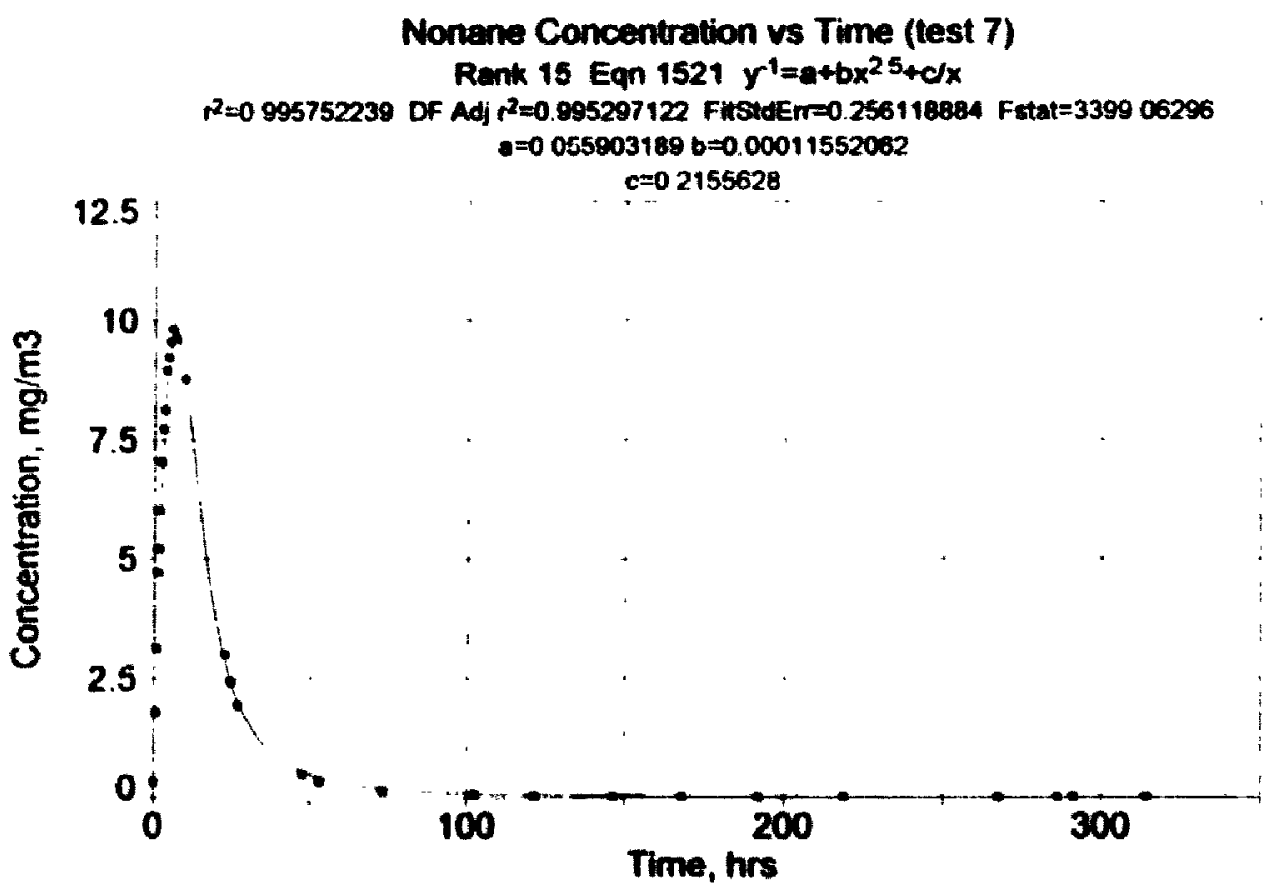

Figure 6.9: Nonane Concentration vs. Time (test 7) 
Nonane Concentration vs Time (test 8 )

Rank 51 Eqn $1469 y^{\prime}=a+b x^{13}+c$ Inx

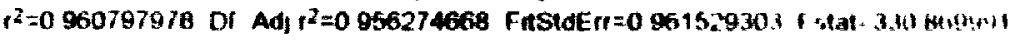
$a=012793891 b=00038540545$

15 $c=-0054740104$

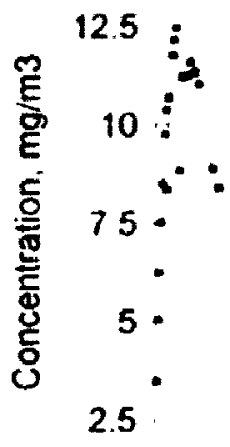

0 .

0

50

100 150

Time. hrs

Figure G.10: Nonane Concentration vs. Time (test 8 )

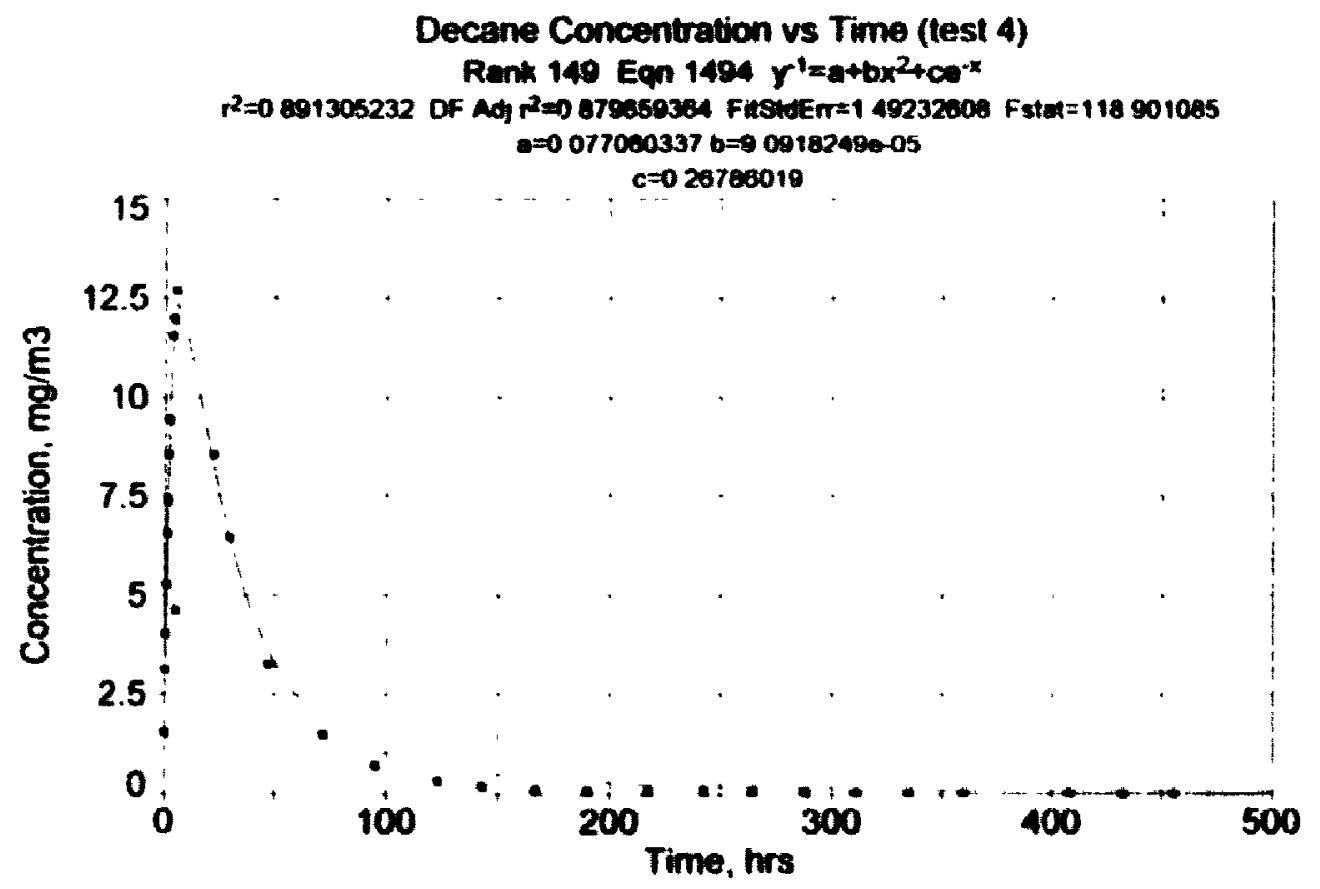

Figure G.11: Decane Concentration vs. Time (test 4) 
DECANE Concentretion ve Time (lest 5)

Rank 33 Eqn $1506 y^{1}=4+b x^{2} \ln x+c / x$

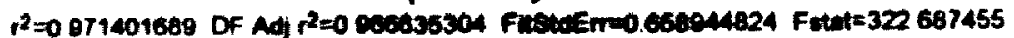

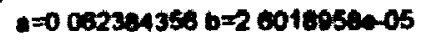

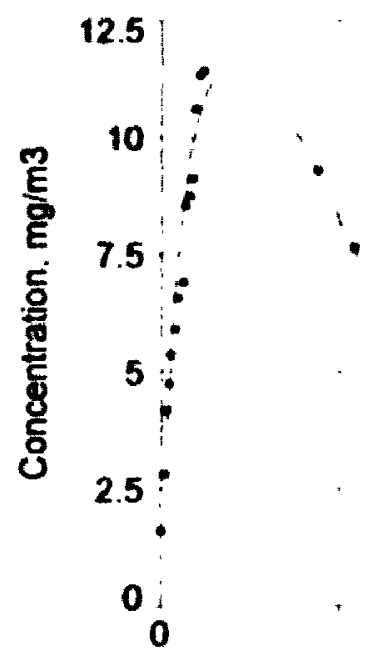
$c=017260540$

Figure G.12: Decane Concentration vs. Time (test 5)

Decane Concentration vs Time (lest 6)

Renk 9 Eqn $1506 y^{1}=04 b x^{2} 4 x+c / x$

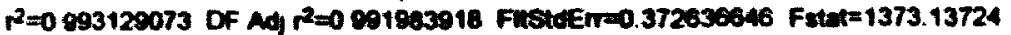
$0=0.0444419916=4.22628010-05$

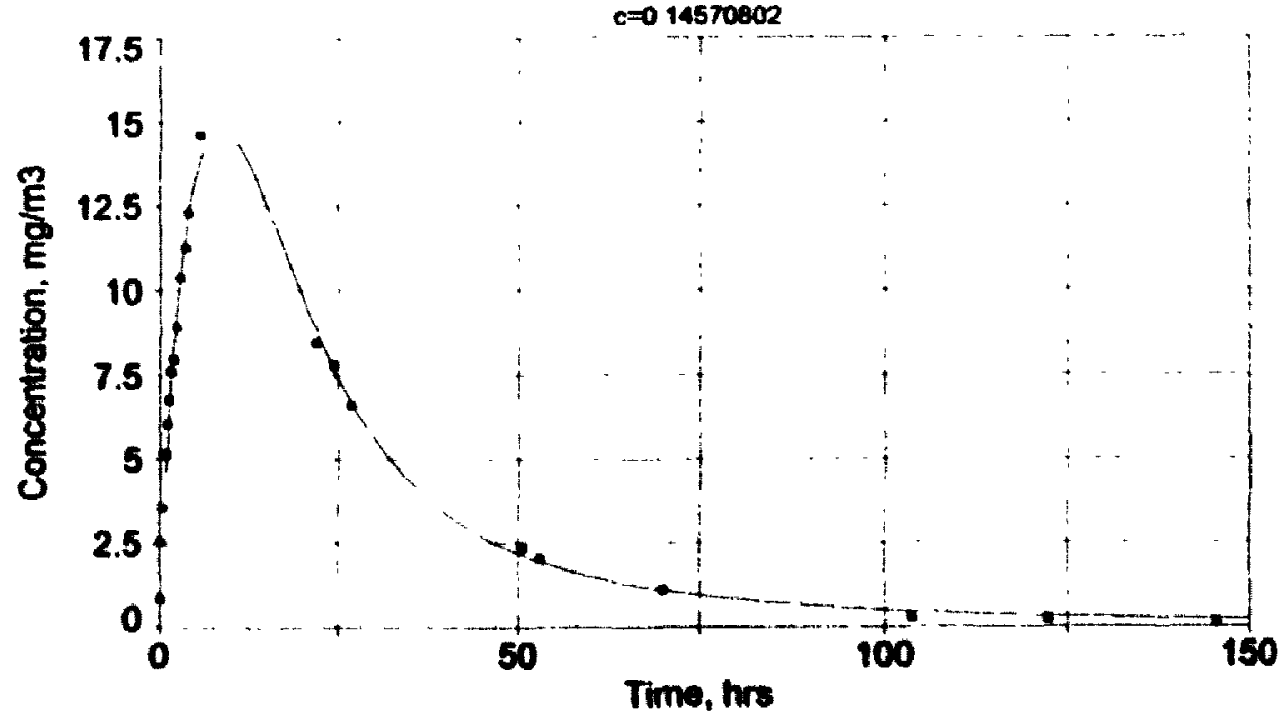

Figure G.13: Decane Concentration vs. Time (test 6) 


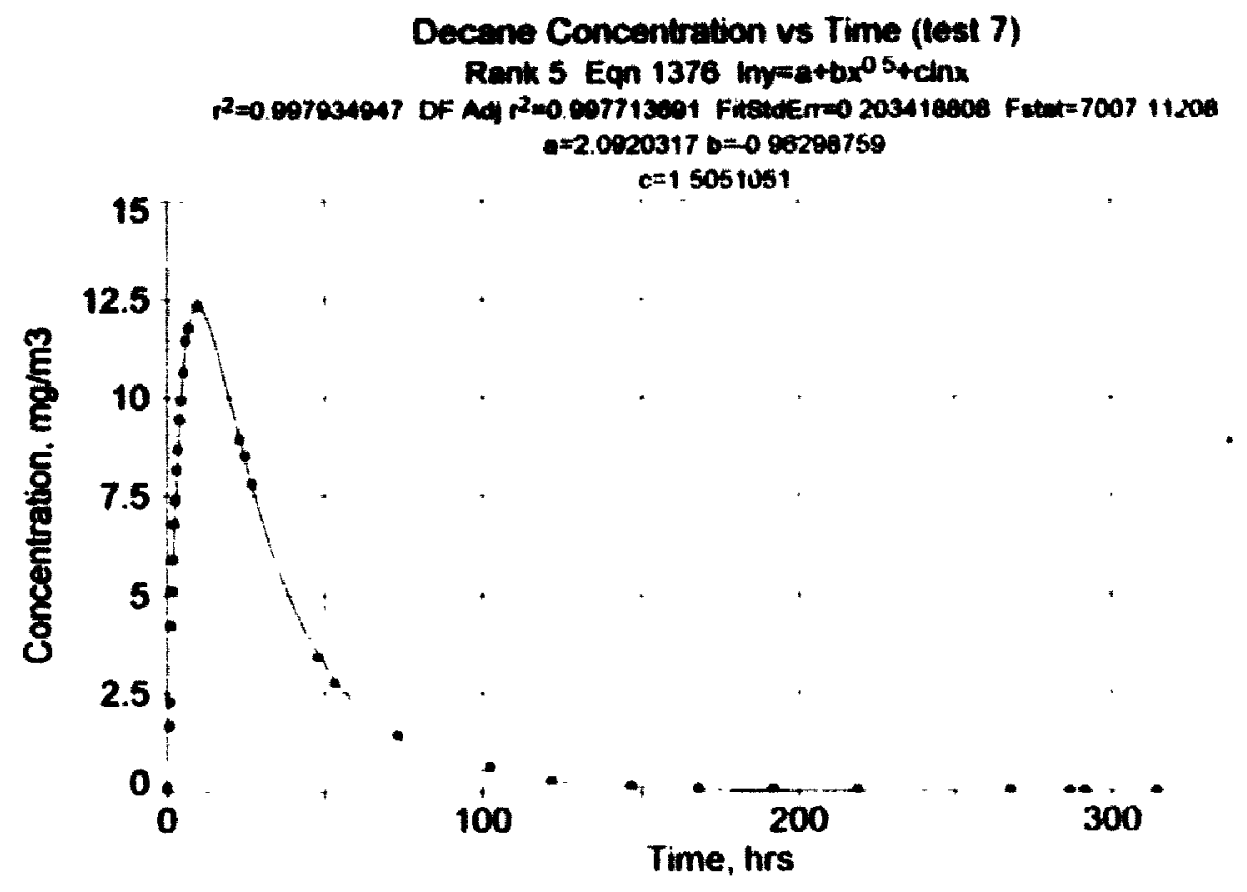

Figure G.14: Decane Concentration vs. Time (test 7)

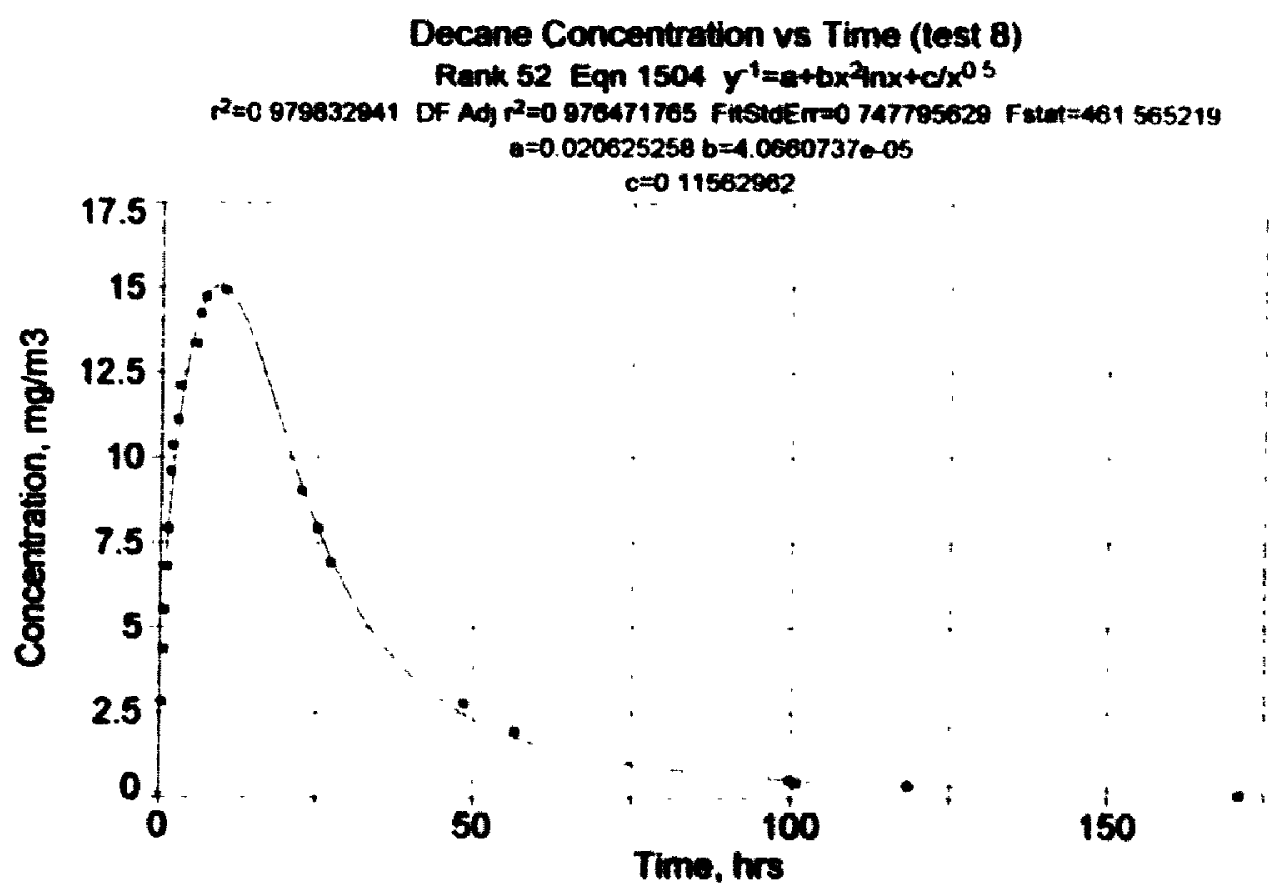

Figure G.15: Decane Concentration vs. Time (test 8) 


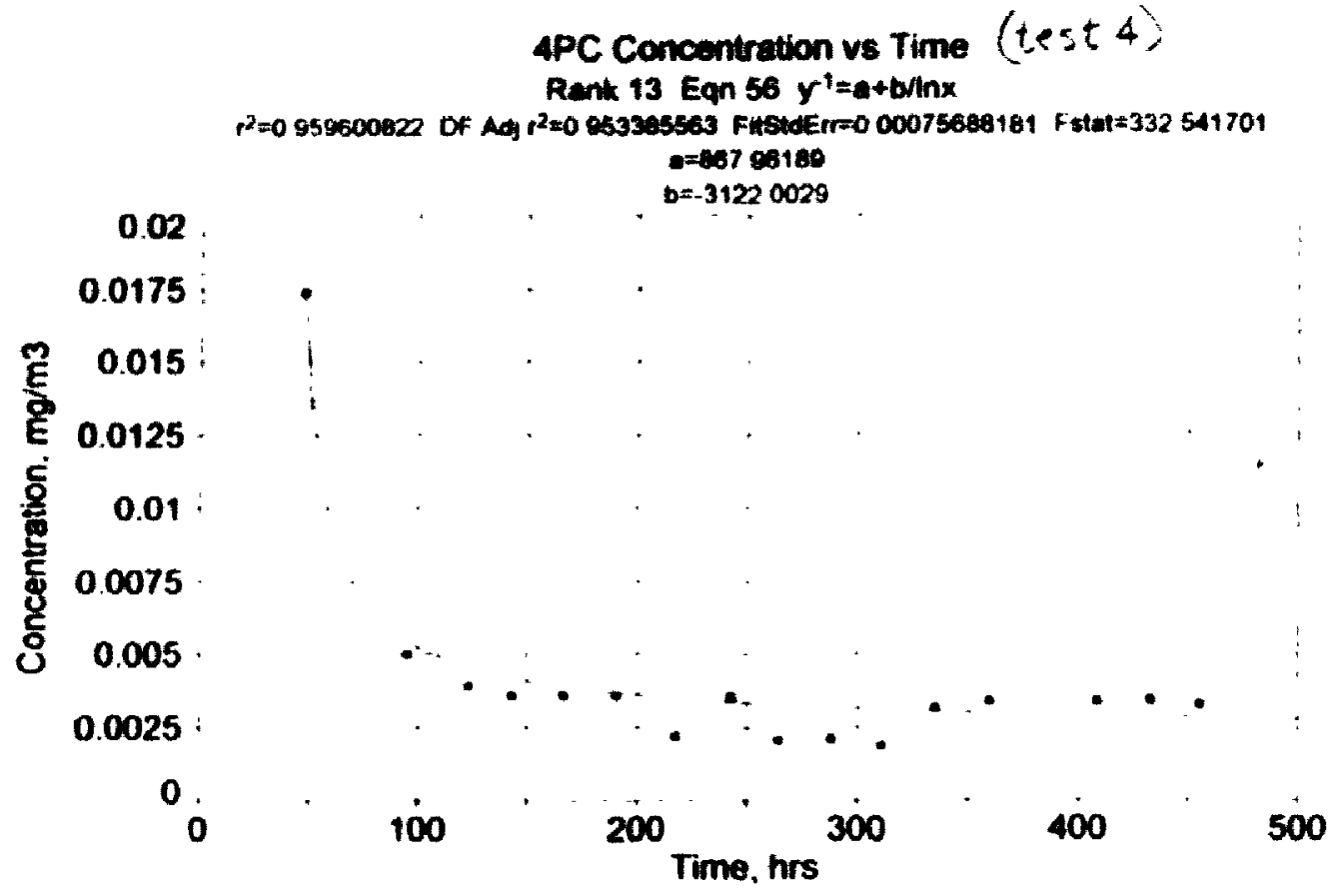

Figure G.16: 4PC Concentration vs. Time (test 4) 

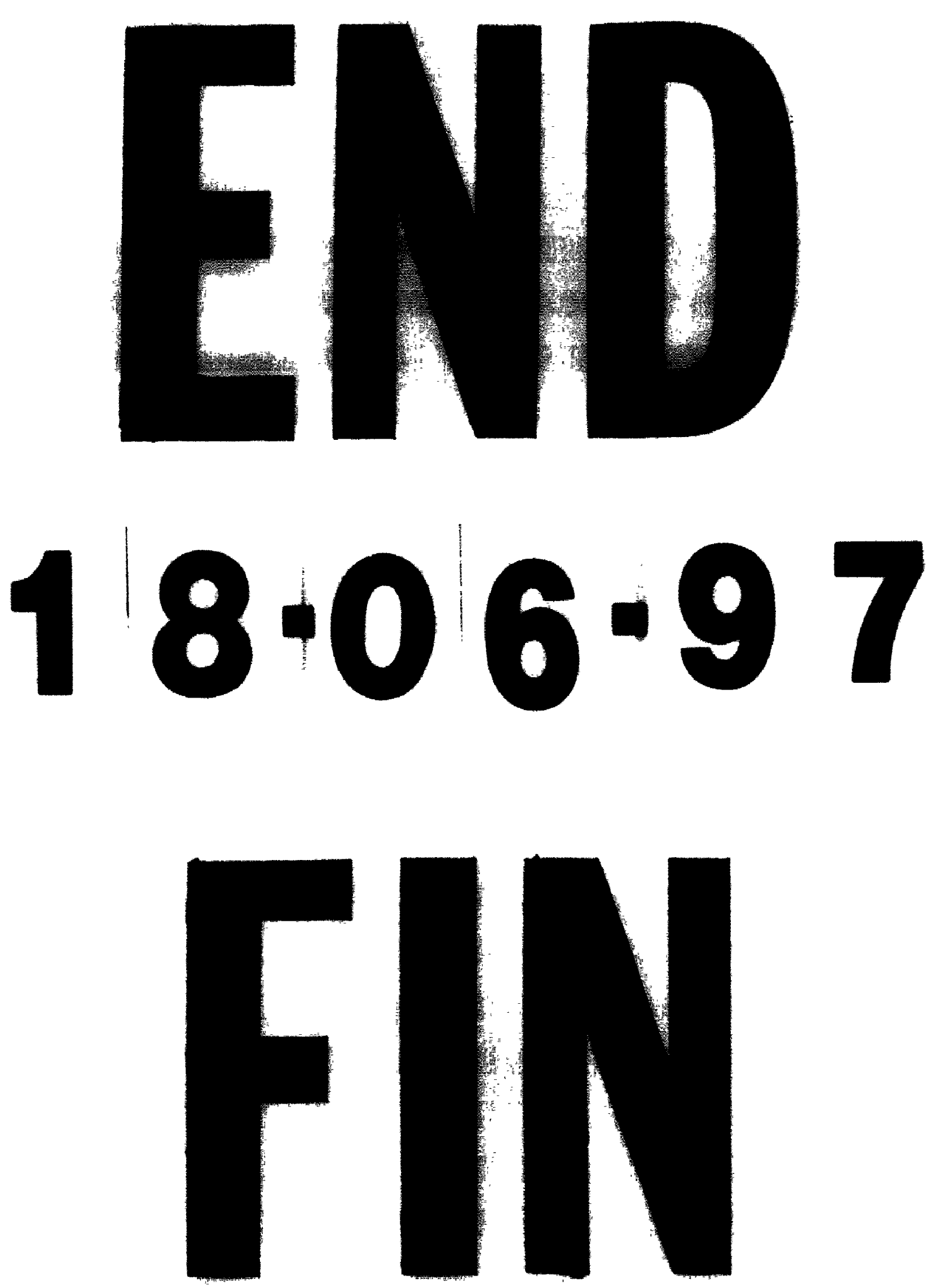

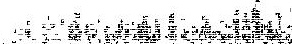

